MARIANA TORRENTE GONÇALVES

\title{
AÇÃO DO IMUNOMODULADOR P-MAPA SOBRE O SISTEMA COMPLEMENTO E RECEPTORES DO TIPO TOLL EM MODELO DE INFLAMAÇÃO INDUZIDA POR LIPOPOLISSACARÍDEO
}

Dissertação apresentada ao Programa de PósGraduação em Imunologia do Instituto de Ciências Biomédicas da Universidade de São Paulo, para obtenção do Título de Mestre em Ciências. 


\title{
AÇÃO DO IMUNOMODULADOR P-MAPA SOBRE O SISTEMA COMPLEMENTO E RECEPTORES DO TIPO TOLL EM MODELO DE INFLAMAÇÃO INDUZIDA POR LIPOPOLISSACARÍDEO
}

\author{
Dissertação apresentada ao Programa de Pós- \\ Graduação em Imunologia do Instituto de Ciências \\ Biomédicas da Universidade de São Paulo, para \\ obtenção do Título de Mestre em Ciências. \\ Área de Concentração: Imunologia \\ Orientador: Prof. Dra. Denise Vilarinho Tambourgi \\ Versão original
}


DADOS DE CATALOGAÇÃO NA PUBLICAÇÃO (CIP)

Serviço de Biblioteca e Informação Biomédica do

Instituto de Ciências Biomédicas da Universidade de São Paulo

reprodução não autorizada pelo autor

Gonçalves, Mariana Torrente.

Ação do imunomodulador P-MAPA sobre o sistema complemento e receptores do tipo Toll em modelo de inflamação induzida por lipopolissacarídeo / Mariana Torrente Gonçalves. -- São Paulo, 2014.

Orientador: Prof. Dra. Denise Vilarinho Tambourgi.

Dissertação (Mestrado) - Universidade de São Paulo. Instituto de Ciências Biomédicas. Departamento de Imunologia. Área de concentração: Imunologia. Linha de pesquisa: Interações de toxinas animais e de microorganismo com sistema complemento, células imunes e inflamatórias.

Versão do título para o inglês: Action of the immunomodulator PMAPA on the complement system and Toll like receptors in a model of inflammation induced by lipopolysaccharide.

1. Inflamação 2. Imunomodulares 3. P-MAPA 4. Receptores do tipo Toll 5. Sistema Complemento 6. Sangue total humano I.

Tambourgi, Prof. Dra. Denise Vilarinho II. Universidade de São Paulo. Instituto de Ciências Biomédicas. Programa de Pós-Graduação em Imunologia III. Título. 
Candidato(a):

Título da Dissertação:

Orientador(a):
Mariana Torrente Gonçalves.

Ação do imunomodulador P-MAPA sobre o sistema complemento e receptores do tipo Toll em modelo de inflamação induzida por lipopolissacarídeo.

Profa. Dra. Denise Vilarinho Tambourgi.

A Comissão Julgadora dos trabalhos de Defesa da Dissertação de Mestrado, em sessão pública realizada a considerou
( ) Aprovado(a)
( ) Reprovado(a)

Examinador(a): Assinatura:

Nome:

Instituição:

Examinador(a): Assinatura:

Nome:

Instituição:

Presidente: Assinatura:

Nome:

Instituição: 
Decl. CEPSH. 017/2013.

Em adendo ao PARECER 1084/CEP, de 10.10.2012, declaro que o Projeto intitulado: "Ação do imunomodulador P-MAPA sobre o sistema complemento e receptores do tipo Toll em modelo de inflamação induzida por LPS", sob responsabilidade dos autores Denise V. TAmbourgi e aluna Mariana Torrente Gonçalves, contempla a aprovação desta Instituição.

São Paulo, 05 de março de 2013.

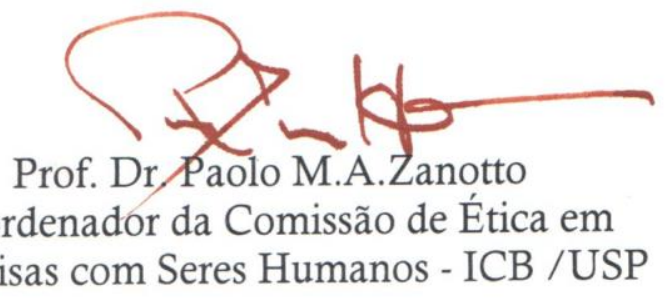


Av. Dr. Vital Brazil, 1500, CEP 05503-900, São Paulo, SP, Brazil

Telefone: (55) (011) 2627-9585 - Fax: (55) (011) 2627-9505

ceuaib@butantan.gov.br

\section{CERTIFICADO}

Certificamos que o projeto intitulado "Ação de imunomodulador P-MAPA sobre o sistema complemento e receptores do tipo Toll em modelo de inflamação induzida por lipopolissacarídeo", protocolo $\mathrm{n}^{0}$ 1145/13, sob a responsabilidade de Denise Vilarinho Tambourgi e Mariana Torrente Gonçalves - que envolve a criação e/ou utilização de animais pertencentes ao filo Chordata, subfilo Vertebrata (exceto o homem), para fins de pesquisa científica - está de acordo com os preceitos da Lei $\mathrm{n}^{\circ} 11.794$, de 8 de outubro de 2008, do Decreto 6.899, de 15 de julho de 2009 e de normas complementares, bem como está de acordo com os Princípios Éticos na Experimentação Animal adotado pelo Colégio Brasileiro de Experimentação Animal (COB̉EA), e foi aprovado pela COMISSÃO DE ÉTICA NO USO DE ANIMAIS DO INSTITUTO BUTANTAN (CEUAIB) em reunião de 9/10/2013.

\begin{tabular}{|c|c|}
\hline $\begin{array}{c}\text { Vigência do Projeto: } \\
10 / 2013-01 / 2014\end{array}$ & $\mathbf{N}^{\circ}$ de animais/espécie \\
\hline Laboratório de Imunoquímica & 54 camundongos Balb/c $8 \mathrm{~s}-18 \mathrm{a} 22 \mathrm{~g} \mathrm{(M);}$ \\
& l coelho NZW 3kg (M); \\
Sangue de carneiro*
\end{tabular}

São Paulo, 9 de outubro de 2013

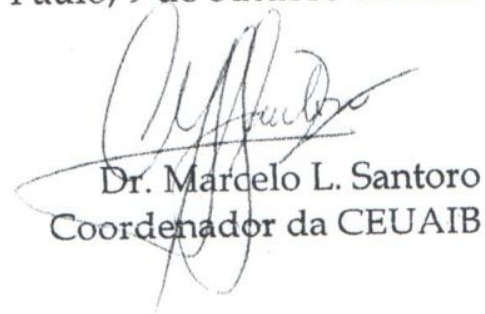

*A coleta de sangue e os procedimentos de manutenção de carneiros se referem ao protocolo $\mathrm{n}^{\circ}$ 1103/13, intitulado "Manutenção e obtenção de sangue de carneiros para fornecimento aos laboratórios do Instituto", sob a responsabilidade do Dr. Ronaldo de Azevedo Ferreira, aprovado em $19 / 06 / 2013$ 


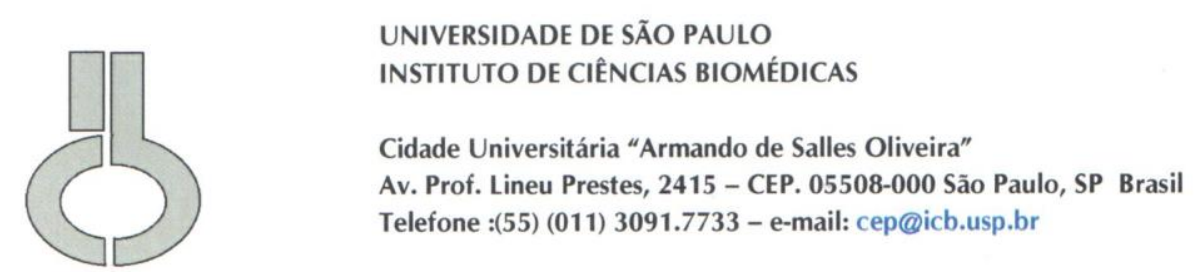

\section{Certificado}

Certificamos que o protocolo registrado sob n 129 nas fls. 13 do livro 03 para uso de animais em experimentação, sob a responsabilidade do $\operatorname{Prof(a)} \operatorname{Dr}(\mathrm{a})$ ) Denise Vilarinho Tambourgi, Coordenador (a) da "Ação do imunomodulador P-MAPA sobre o sistema complemento e receptores do tipo Toll em modelo de iluminação induzida por LPS" do qual participam o(s) aluno(s) Mariana Torrente Gonçalves, está de acordo com os Princípios Éticos de Experimentação Animal adotado pela Sociedade Brasileira de Ciência de Animais de Laboratório (SBCAL) e foi aprovado pela COMISSÃO DE ÉTICA NO USO DE ANIMAIS (CEUA) em $\mathbf{1 6 . 0 1 . 2 0 1 4}$, com validade de 4 anos.

São Paulo, 20 de janeiro de 2013.
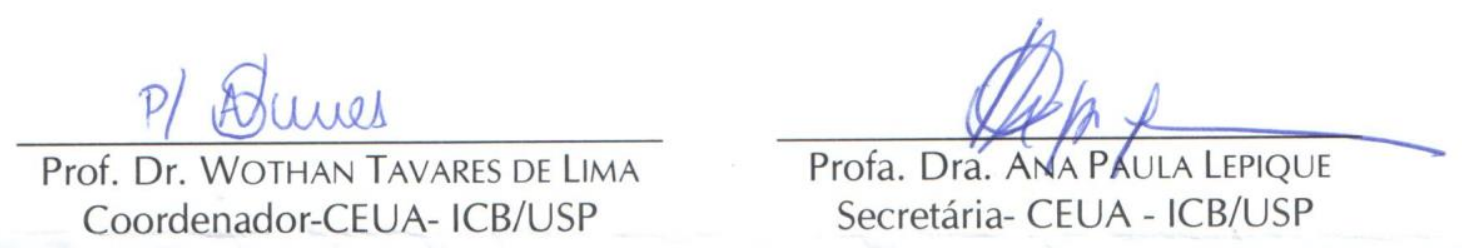
Aos meus pais:

meu norte, sempre. 


\section{AGRADECIMENTOS}

\section{Meus sinceros agradecimentos...}

À minha orientadora Dra. Denise Vilarinho Tambourgi, pela confiança depositada em mim. Por toda a paciência, dedicação, alegrias, pelos conselhos, por todo meu aprendizado e por todo o apoio ao longo destes anos.

Ao professor Osvaldo Sant'Anna, por ter me concedido, juntamente com minha orientadora, a oportunidade de trabalhar com o P-MAPA, e também pelas sugestões, apoio e incentivo.

Ao Carlos Henrique Fioravanti, Iseu Nunes, Dr. Wagner Fávaro e Dr. Nélson Durán, pela disponibilidade e pela oportunidade de poder colaborar com um pequeno parágrafo na história do P-MAPA.

Ao Prof. Dr. Wilmar Dias da Silva, pela convivência no laboratório e pelas discussões sobre ciência e experiências de vida.

Aos Drs. Fernanda Portaro, Fábio Magnoli e Jorge Ferreira, por todas as sugestões dedicadas ao meu trabalho.

À Dra. Carla Squaiella, pelo auxílio durante meus experimentos de citometria de fluxo, pelas sugestões e ajuda na realização do meu trabalho, e pelo apoio e incentivo no desenvolvimento da minha carreira.

Às amigas Dra. Isadora Villas Boas e Dra. Priscila Hess, por toda ajuda durante o desenvolvimento desse trabalho, pelas discussões intelectuais, pelos momentos de alegrias, companhia e aprendizado. E também à Lygia "Niça", pela amizade, e por ter depositado sua confiança em mim, no tempo em que acompanhou meus experimentos. Levarei vocês para sempre no meu coração!

Aos meus amigos (Dr.) Estevam e Felipe Guidolin, pela amizade, momentos de descontração, críticas, sugestões, broncas e ajuda nos momentos particularmente difíceis. Duas palavras pra vocês: Super Shark!-Dark Souls!

Aos colegas de laboratório Felipe França (especialmente pelas doações de sangue!), Daniela Myamoto, Marie, Vivian, Verônica, Angela, Joel, Karina, Cinthya, Giselle, Aurélio, Daniel e Danielle Paixão, pelos momentos de descontração, auxílios, e por tornarem o trabalho no laboratório muito mais divertido.

Aos funcionários: Ricardo, Ramos, Ana Cláudia, Ana Freire, Márcia, Alécio, Guilherme e Osmair, fundamentais para o funcionamento do laboratório, pela ajuda e boa convivência. 
Às secretárias do laboratório de Imunoquímica, Elaine e Lia, e também à Denise Santiago, sempre prestativas e divertidas!

Às enfermeiras do Hospital Vital Brazil e do Ambulatório do Instituto Butantan, especialmente à Antônia, pelo auxílio na coleta de sangue.

À Bibliotecária Monica, pela atenção, eficiência e ajuda com as normas na minha tese.

À secretária da Pós Graduação em Imunologia, Maria Eni, pela atenção e disponibilidade com que sempre me atendeu.

À banca de qualificação e à Comissão julgadora, por auxiliarem nesta etapa do meu desenvolvimento profissional.

Aos meus pais, Cristina e José Henrique, por todo apoio, orientação, inspiração, amor, e por sempre acreditarem em mim.

Ao meu irmão Gustavo e aos meus avós, João e Maria, Neiva e Osvaldo (in memoriam), que apesar da distância, sempre contribuíram com seu carinho.

Ao meu querido amigo Senna, por todos esses anos de amizade e contribuição em todos os momentos, nos mais diversos assuntos: da vida acadêmica ao novo single do Bastille.

Por fim, a todos aqueles que contribuíram para a realização deste trabalho e contribuíram para o meu desenvolvimento profissional e pessoal. 
Este trabalho foi realizado com o apoio financeiro:
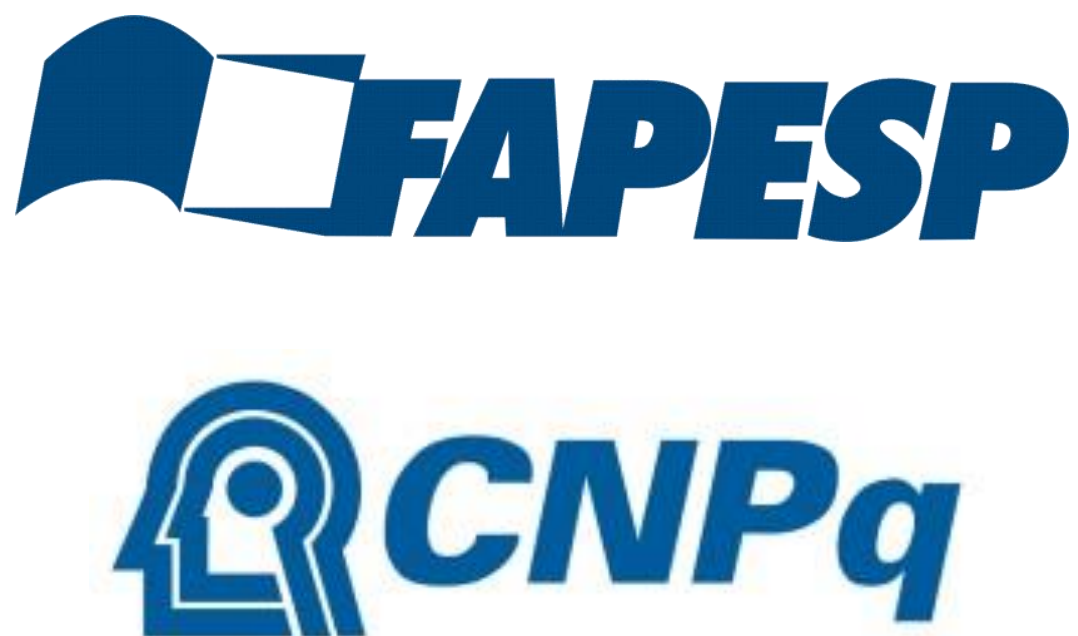

Conselho Nacional de Desenvolvimento

Científico e Tecnológico
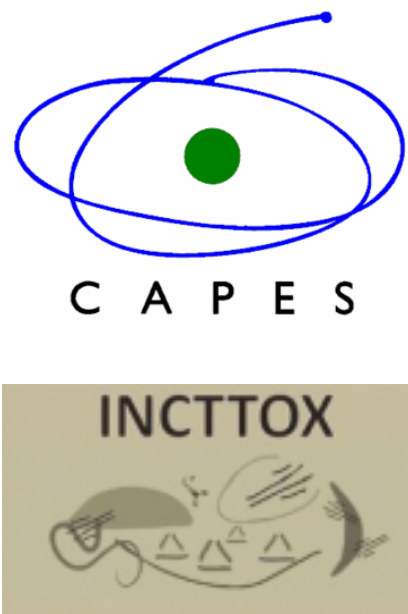
"There are many hypotheses in science that are wrong. That's perfectly alright; it's the aperture to finding out what's right. Science is a self-correcting process."

- Carl Sagan

"Science and everyday life cannot and should not be separated"

- Rosalind Franklin

"Le vent se lève!. . .

"l faut tenter de vivre!"

- Paul Valéry 


\section{RESUMO}

GONÇALVES, M. T. Ação do imunomodulador P-MAPA sobre o sistema complemento e receptores do tipo Toll em modelo de inflamação induzida por lipopolissacarídeo. 2014. 107 f. Dissertação (Mestrado em Imunologia) - Instituto de Ciências Biomédicas, Universidade de São Paulo, São Paulo, 2014.

Concebido inicialmente como um composto antitumoral, o P-MAPA (agregado polimérico de fosfolinoleato-palmitoleato de magnésio e amônio proteico) apresentou potencial imunomodulatório, em diversos estudos, sobre a secreção de citocinas, produção de óxido nítrico por macrófagos, eliminação de patógenos intracelulares e redução da progressão de tumores. No entanto, a sua ação sobre elementos da imunidade inata, como o sistema complemento e receptores do tipo Toll (TLRs), ainda não é conhecida, embora já existam evidências de que o P-MAPA possa agir sobre TLRs. Neste estudo foi avaliado o papel modulador do P-MAPA sobre o sistema complemento, os receptores TLR2 e TLR4, as moléculas acessórias CD14 e CD11b, e os receptores de anafilatoxinas C3aR e C5aR, na inflamação induzida por LPS de E.coli, usando o modelo ex vivo de sangue total humano. Nossos resultados mostraram que o P-MAPA promove ativação das vias clássica e alternativa do sistema complemento e produção das anafilatoxinas C3a e C5a. Sobre leucócitos de sangue periférico, o composto promoveu aumento da expressão de CD11b e CD14, diminuição da expressão de C5aR, TLR2 e TLR4, quando combinado com LPS, mas não promoveu alterações na expressão de C3aR. O P-MAPA promoveu redução dos níveis de IFN$\gamma$ no plasma, aumento da produção de TNF- $\alpha, \mathrm{IL}-8, \mathrm{IL}-12(\mathrm{p} 70)$ e peróxinitrito, mas não induziu produção de superóxido, IL-6, IL-1 $\beta$, TGF- $\beta$ ou IL-10. Ensaios, nos quais a inibição do sistema complemento foi induzida, sugerem que o P-MAPA pode interagir direta ou indiretamente (via ativação do complemento) com TLR2 e TLR4. Por meio de testes in vivo foi possível determinar a dose letal do P-MAPA e, em conjunto, os dados obtidos no presente estudo mostram que o P-MAPA apresenta ação pró-inflamatória em modelo ex vivo de sangue total humano e que o tratamento combinado com LPS leva a uma amplificação dos seus efeitos.

Palavras-chave: P-MAPA. Inflamação. Imunomoduladores. Receptores do tipo Toll. Sistema Complemento. Sangue total humano. 


\begin{abstract}
GONÇALVES, M. T. Action of the immunomodulator P-MAPA on the complement system and Toll like receptors in a model of inflammation induced by lipopolysaccharide. 2014. 107 p. Masters Thesis (Immunology) - Instituto de Ciências Biomédicas, Universidade de São Paulo, São Paulo, 2014.

Originally designed as an anti-tumor compound, P-MAPA (proteinaceous aggregate of ammonium and magnesium phospholinoleate-palmitoleate anhydride) has been described as a promising immunomodulatory compound in several studies, having promoted cytokine secretion, nitric oxide production by macrophages, killing of intracellular pathogens and reduction of tumor progression. However, its role on elements of innate immunity, such as the complement system and Toll-like receptors (TLRs) is unknown, although there is evidence that P-MAPA can activate TLRs. In this study, we have evaluated the modulating effects of P-MAPA on the complement system, TLR2 and TLR4, the accessory molecules CD14 and CD11b, and anaphylatoxins receptors C3aR and C5aR, in E. coli's LPS-induced inflammation, using an ex vivo model of human whole blood. Our results demonstrated that the compound promotes activation of the complement's classical and alternative pathways and the production of anaphylatoxins C3a and C5a. On peripheral blood leukocytes, the compound promoted increase of CD11b and CD14 expression, decrease of C5aR, TLR2 and TLR4, when combined with LPS, but did not change C3aR expression. P-MAPA promoted reduction of IFN- $\gamma$ in plasma, increased production of TNF- $\alpha$, IL-8, IL-12(p70) and peroxynitrite, but did not induce the production of superoxide, IL-6, IL-1 $\beta$, TGF- $\beta$ or IL-10. In assays where the complement system was inhibited suggest that P-MAPA can interact directly or indirectly (through complement activation) with TLR2 and TLR4. Through in vivo tests, we were able to determine a lethal dose for P-MAPA. Altogether, our data indicates that P-MAPA has proinflammatory action in ex vivo model of human whole blood and that treatment combined with LPS leads to amplification of its effects.
\end{abstract}

Keywords: P-MAPA. Inflammation. Immunomodulators, Toll like Receptors. Complement System. Human whole blood. 


\section{LISTA DE ILUSTRAÇÕES}

Figura 1 - Imagens dos cristais de P-MAPA 20

Figura 2 - Esquema das vias de ativação do sistema complemento 24

Figura 3 - Ação do P-MAPA sobre a Via Clássica do Sistema Complemento 40

Figura 4 - Ação do P-MAPA sobre a Via Alternativa do Sistema Complemento 41

Figura 5 - Ação do P-MAPA não solubilizado sobre a Via Alternativa do Sistema Complemento

Figura 6 - Ação do P-MAPA sobre a Via das Lectinas do Sistema Complemento 43

Figura 7 - Ativação da Via Alternativa após os tratamentos experimentais em sangue total

Figura 8 - Níveis plasmáticos de C3a/ C3a-desArg após os tratamentos experimentais

Figura 9 - Níveis plasmáticos de C5a/ C5a-desArg após os tratamentos experimentais 48

Figura 10 - Níveis plasmáticos de SC5b-9 após os tratamentos experimentais

Figura 11 - Ação do P-MAPA e do LPS sobre a expressão de CD11b em leucócitos 52

Figura 12 - Ação do P-MAPA e do LPS sobre a expressão de CD11b em populações celulares distintas 53

Figura 13 - Ação do P-MAPA e do LPS sobre a expressão de CD14 em leucócitos 55

Figura 14 - Ação do P-MAPA e do LPS sobre a expressão de CD14 em populações celulares distintas 56

Figura 15 - Ação do P-MAPA e do LPS sobre a expressão de TLR2 na superfície de leucócito 58

Figura 16 - Ação do P-MAPA e do LPS sobre a expressão de TLR2 em populações celulares distintas 59

Figura 17 - Ação do P-MAPA e do LPS sobre a expressão de TLR4 na superfície de leucócitos

Figura 18 - Ação do P-MAPA e do LPS sobre a expressão de TLR4 em populações celulares distintas

Figura 19 - Ação do P-MAPA e do LPS sobre a expressão de C3aR em leucócitos 64

Figura 20 - Ação do P-MAPA e do LPS sobre a expressão de C3aR em populações celulares distintas

Figura 21 - Ação do P-MAPA e do LPS sobre a expressão de C5aR em leucócitos 
Figura 22 - Ação do P-MAPA e do LPS sobre a expressão de C5aR em populações celulares distintas

Figura 23 - Ação do P-MAPA não solubilizado sobre a expressão marcadores de superfície, em leucócitos

Figura 24 - Níveis plasmáticos de TNF- $\alpha$ após os tratamentos experimentais 72

Figura 25 - Níveis plasmáticos de IL-8 após os tratamentos experimentais. 73

Figura 26 - Níveis plasmáticos de IL-12p70 após os tratamentos experimentais 74

Figura 27 - Níveis plasmáticos de IFN- $\gamma$ após os tratamentos experimentais. 75

Figura 28 - Níveis plasmáticos de TGF- $\beta$ após os tratamentos experimentais 76

Figura 29 - Produção de ROS por leucócitos tratados com P-MAPA .... 77

Figura 30 - Ação da compstatina sobre a Via Alternativa do Sistema Complemento 79 Figura 31 - Ação do P-MAPA e do LPS sobre a expressão de receptores celulares na presença de compstatina..... 80

Figura 32 - Ação do ácido linoleico sobre a expressão de receptores celulares em leucócitos totais 


\section{SUMÁRIO}

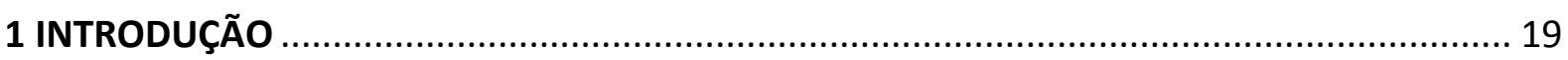

1.1 P-MAPA

1.2 Crosstalk entre sistema complemento e receptores do tipo Toll ................................ 23

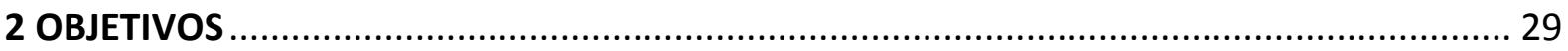

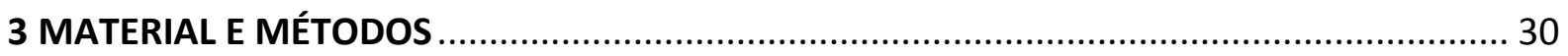

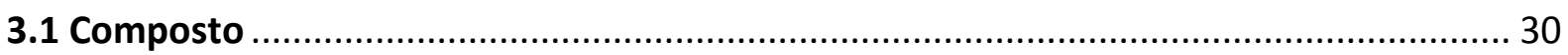

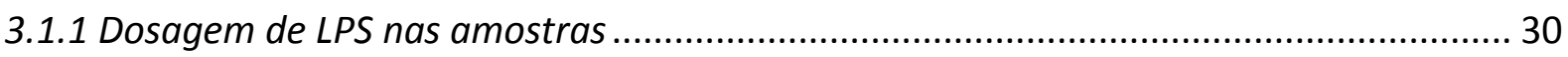

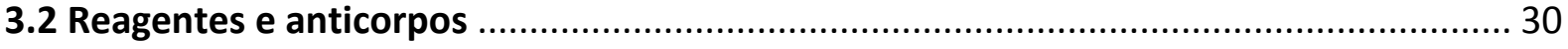

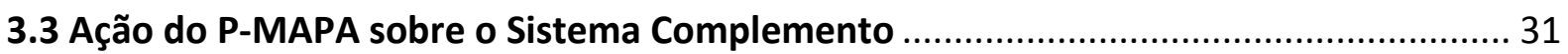

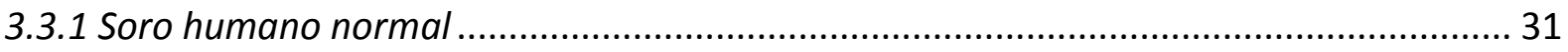

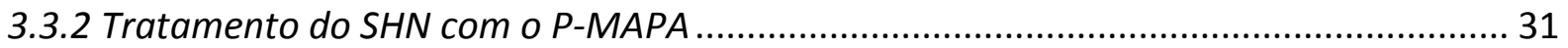

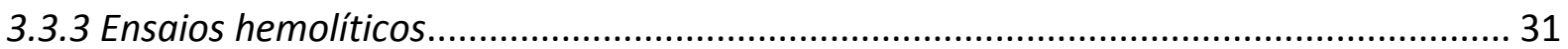

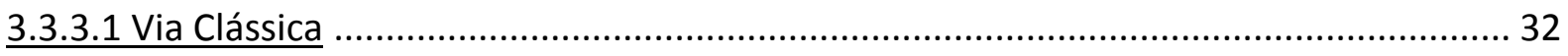

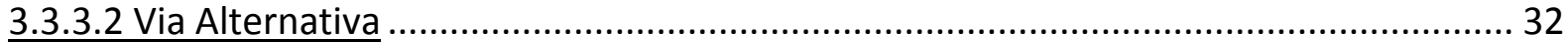

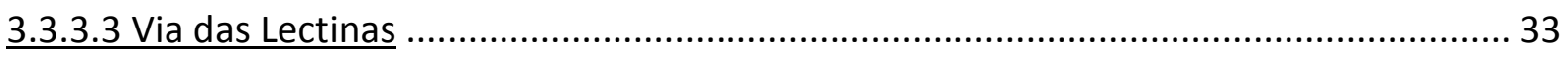

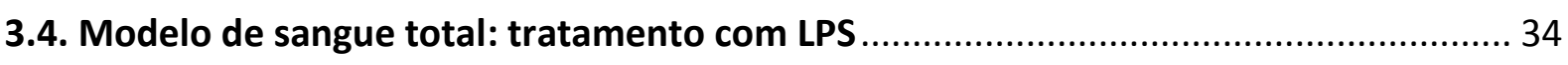

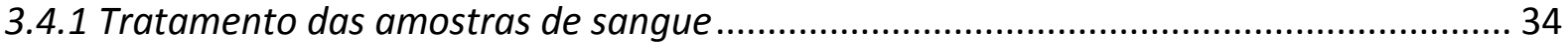

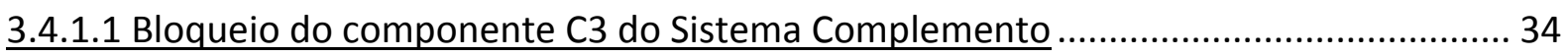

3.4.2 Ensaio hemolítico da Via Alternativa por ELISA ......................................................... 35

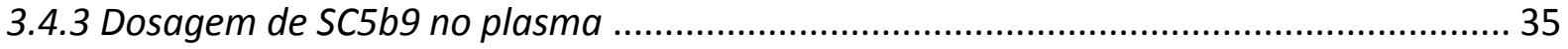

3.4.4 Análise da expressão de marcadores de superfície em leucócitos ................................. 36

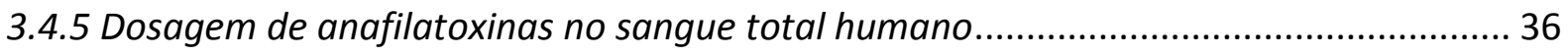

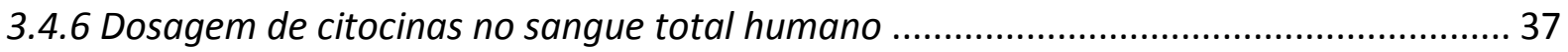

3.4.7 Detecção de espécies reativas de oxigênio e nitrogênio ............................................... 38

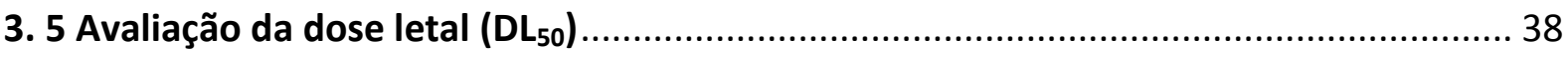

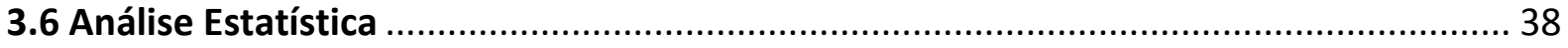

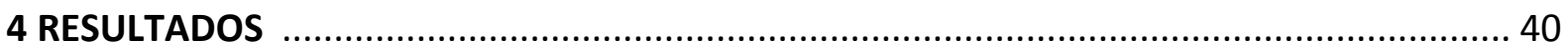

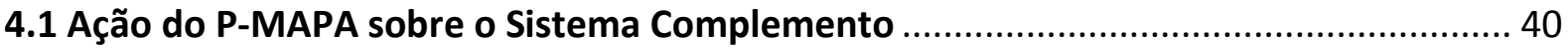

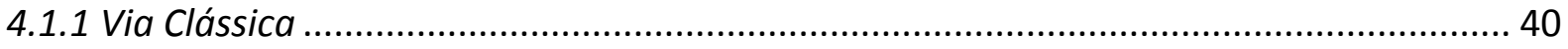

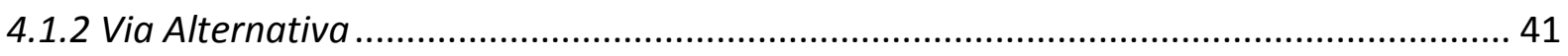

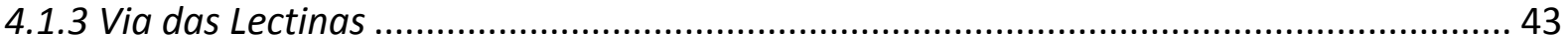


4.2 Determinação da atividade residual da Via Alternativa do Sistema Complemento após os tratamentos experimentais em sangue total humano ............................................... 44

4.3 Dosagem de anafilatoxinas no sangue total humano .............................................. 46

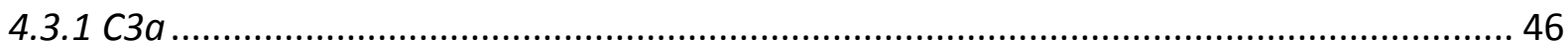

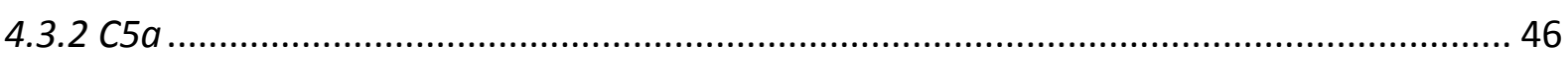

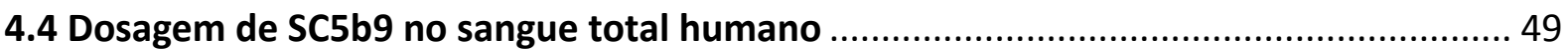

4.5 Análise da expressão de marcadores de superfície em leucócitos tratados com P-MAPA

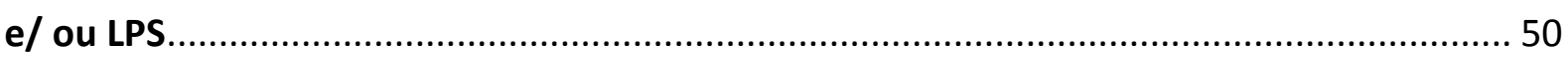

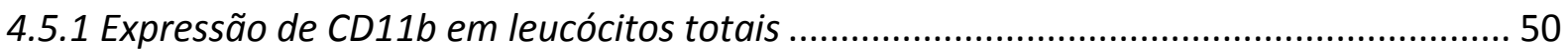

4.5.1.1 Expressão de CD11b em diferentes populações celulares.......................................... 50

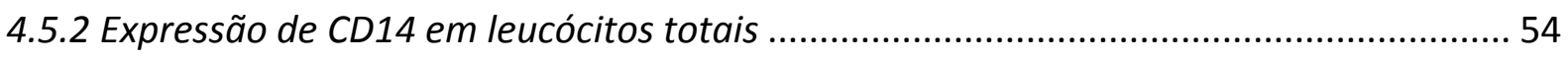

4.5.2.1 Expressão de CD14 em diferentes populações celulares........................................... 54

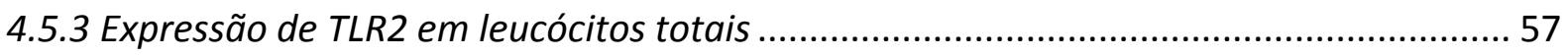

4.5.3.1 Expressão de TLR2 em diferentes populações celulares........................................... 57

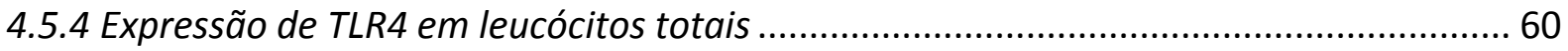

4.5.4 1 Expressão de TLR4 em diferentes populações celulares............................................ 60

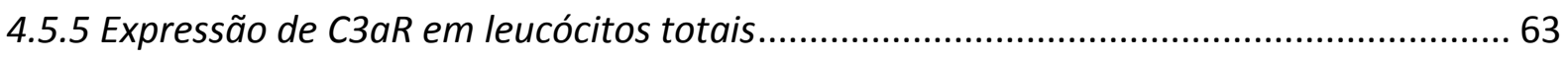

4.5.5.1 Expressão de C3aR em diferentes populações celulares …........................................ 63

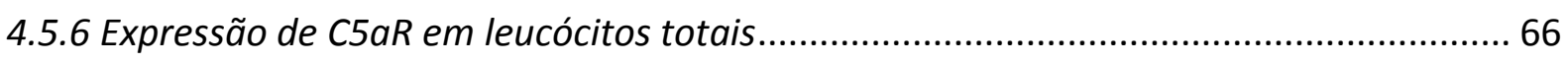

4.5.6.1 Expressão de C5aR em diferentes populações celulares .......................................... 66

4.6 Análise da expressão de marcadores de superfície em leucócitos tratados com P-MAPA

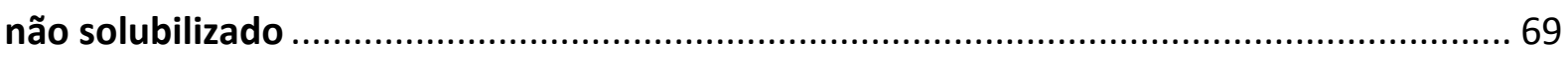

4.7 Dosagem de citocinas em sangue total humano após os tratamentos experimentais .

4.8 Análise da produção de espécies reativas de oxigênio e nitrogênio (superóxido e peróxinitrito)

4.9 Análise da expressão de marcadores de superfície em leucócitos após o bloqueio do componente $\mathrm{C} 3$ do complemento no sangue.

4.10 Análise da expressão de marcadores de superfície em leucócitos após o tratamento de sangue total com ácido linoléico

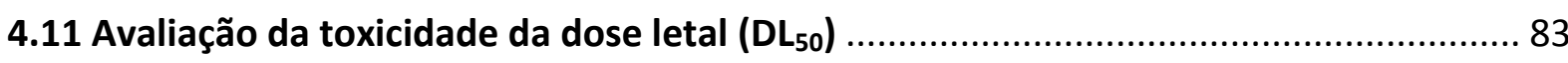

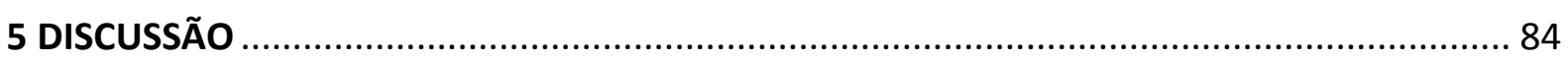


APÊNDICE A - Gates utilizados para análise da expressão de moléculas expressas por leucócitos coletados de sangue periférico 103 APÊNDICE B - Ação do P-MAPA e do LPS na expressão de marcadores celulares em leucócitos: cinética de tempo. 104 APÊNDICE C - Ação de tratamentos com PBS ou LPS na expressão de marcadores celulares em leucócitos totais 105 APÊNDICE D - Ação de duas diferentes partidas de P-MAPA sobre a expressão de receptores celulares em leucócitos totais 106 


\section{INTRODUÇÃO}

\subsection{P-MAPA}

O agregado polimérico de fosfolinoleato-palmitoleato de magnésio e amônio protéico, conhecido como P-MAPA, é um produto obtido a partir da fermentação de culturas selecionadas de Aspergillus oryzae (FARMABRASILIS, 2008). Ele foi concebido, inicialmente, como um tratamento anti-tumoral (FARMABRASILIS, 2008), mas estudos em modelos animais $\mathrm{e}$ in vitro têm sugerido que o composto pode possuir propriedades imunomodulatórias.

O P-MAPA possui uma história de desenvolvimento distinta. Durante mais de 20 anos, o Dr. Odilon da Silva Nunes, médico residente de Birigui, SP, desenvolveu sozinho o composto, em um pequeno laboratório que mantinha em sua própria casa. Em meados dos anos 1980, seu filho, Iseu Nunes, levou a descoberta do pai ao laboratório do Dr. Nelson Durán, um químico que lecionava na Universidade Estadual de Campinas (UNICAMP). Foi com a ajuda do Dr. Durán que se iniciaram os estudos de caracterização do P-MAPA e surgiram as primeiras oportunidades para estudá-lo em um ambiente acadêmico (FIORAVANTI, 2010). Hoje, o P-MAPA foi patenteado, sob regime de patente aberta, e é fornecido pela Farmabrasilis, uma Organização Não Governamental, sediada na cidade de Campinas, SP.

O processo de produção do composto consiste na fermentação do fungo Aspergillus oryzae em biorreatores esterilizados, em meio de cultura aquoso de aveia e gelatina, na proporção de 10/1. A mistura é fermentada por 120 horas, sob temperatura de 20 a $35^{\circ} \mathrm{C}$, $\mathrm{pH}$ entre 2 a 4, aeração e agitação. Após este período, o meio é filtrado e o composto é extraído com acetado de etila, seguido de precipitação por solução aquosa de carbonato de sódio (20\%, pH 11). Como resultado, são formados microcristais (Figura 1) que, em seguida, são lavados com acetato de etila e éter e secados (DURÁN et al., 1990 apud FIORAVANTI, 2010; MELO et al., 2014)'.

Descrito por Durán e Nunes (1991), este agregado polimérico possui em sua estrutura magnésio $(20,1 \pm 0,9 \%)$, amônio $(10 \pm 3,3 \%)$, fosfato $(45,2 \pm 2,7 \%)$, ácido linoleico $(11,6 \pm 4,3 \%)$ e proteína $(0,49 \pm 0,07 \%)$, com peso molecular totalizando $316 \mathrm{kDa}$, e a fração 
protéica, 16 kDa. Estudos relativos à fração protéica do P-MAPA não foram ainda realizados, não se conhecendo sua função biológica.

Figura 1 - Imagens dos cristais de P-MAPA

A)

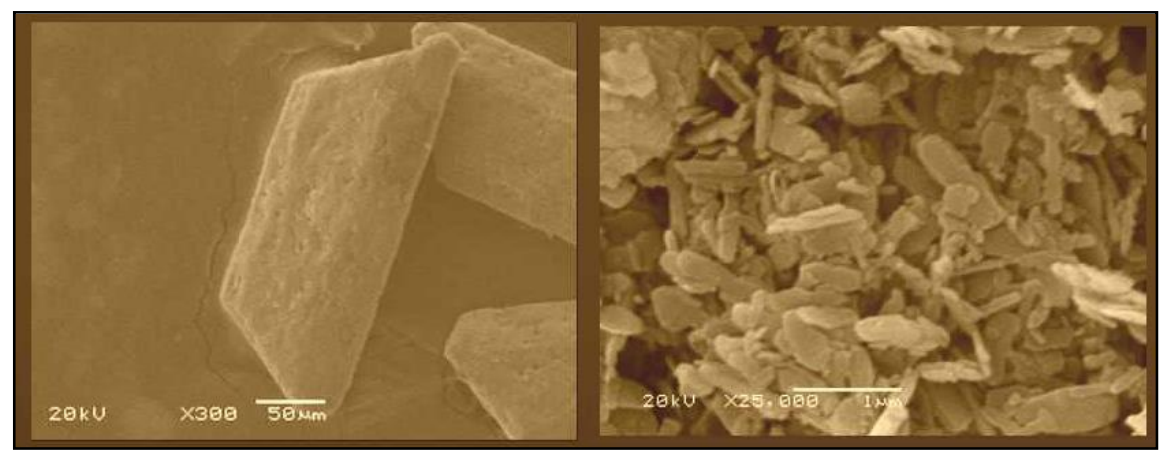

B)

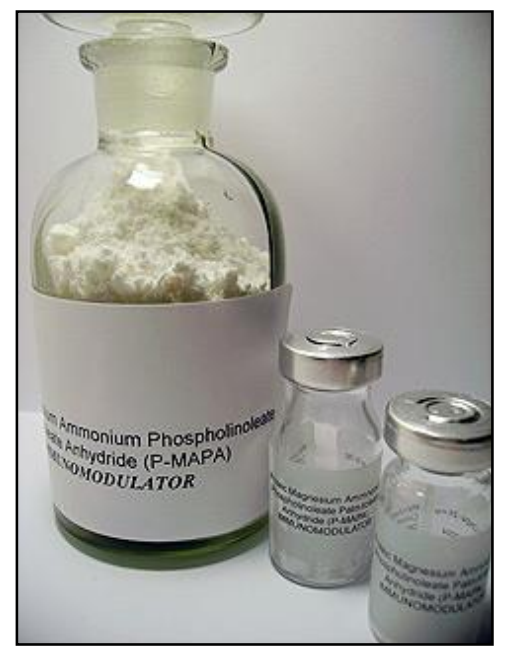

A) Cristais fotografados por microscópio eletrônico de varredura. À esquerda, em aumento de 300x, e à direita, em aumento de 25000x. (Fotos: FARMABRAILIS, 2008). B) Cristais de P-MAPA em embalagens fornecidas pela Farmabrasilis. (Foto: FARMABRAILIS, 2010).

Devido à sua estrutura complexa, o P-MAPA não é facilmente solubilizado, o que fez com que grupos de estudo optassem por administrar o composto ressuspendido em solução salina $(\mathrm{NaCl}$ 0,9\%). Apesar desta condição, ensaios in vitro e in vivo realizados pela Farmabrasilis (2010) não mostraram toxicidade para o composto.

O P-MAPA demonstrou ser eficaz no controle de diferentes tipos de tumores, prolongando o tempo de vida de camundongos BALB/c com tumor ascítico de Ehrlich (EAT), com doses entre 0,5 a 10 mg/kg (JUSTO; DURÁN; QUEIROZ, 2000), de ratos Wistar com tumor de Walker 256, com dose de $0,5 \mathrm{mg} / \mathrm{kg}$ e camundongos BALB/c fêmeas 
transplantados com plasmocitoma ou carcinoma mamário, com doses de $80 \mu \mathrm{g} / \mathrm{kg}$ (FARMABRASILIS, 2010), e de ratas com câncer de bexiga, com doses de $5 \mathrm{mg} / \mathrm{kg}$, ao longo de 8 semanas (FÁVARO et al., 2012).

Estudos mostraram também a eficácia do P-MAPA na eliminação de patógenos intracelulares, ao evitar a morte e diminuir a carga viral de camundongos infectados com 0 vírus Punta Toro (DURAN et al., 2009), inibir a infecção por Plasmodium yoelii e Plasmodium chabaudi em camundongos (DURAN et al., 2008), prolongar a sobrevida de camundongos infectados com dose letal de Listeria monocytogenes (de MELO; JUSTO; de SOUZA QUEIROZ, 2001), reduzir a carga parasitária do protozoário Leishmania infantum na pele de cães infectados (SANTIAGO et al., 2013) e reduzir a quantidade de unidades formadoras de colônia (CFU) do bacilo Mycobacterium tuberculosis no pulmão de animais tratados (FÁVARO et al., 2012).

Segundo alguns autores, a eficácia do P-MAPA, em prolongar a sobrevida de animais com câncer ou infectados com patógenos intracelulares, está associada à sua capacidade de induzir a produção e diferenciação de células progenitoras de granulócitos e monócitos pela medula óssea, uma vez que foi detectado aumento do número de CFU-GM (unidades formadores de colônia de granulócitos e monócitos) em animais com tumores (JUSTO; DURÁN; QUEIROZ, 2000) e infecções por patógenos intracelulares (de MELO; JUSTO; de SOUZA QUEIROZ, 2001), e de células uroteliais progenitoras (urothelial stem cells, USCs) em animais com câncer superficial de bexiga (REIS et al., 2011), tratados com $5 \mathrm{mg} / \mathrm{kg}$ do composto. Foi também demonstrado que o tratamento com P-MAPA promoveu aumento no número de linfócitos T CD8 ${ }^{+}$em cães com leishmaniose visceral (SANTIAGO et al., 2013).

As características imunoestimulatórias do P-MAPA foram também detectadas em culturas de celulares, tendo estimulado macrófagos a produzirem óxido nítrico (NO) (BROMBERG et al., 2006; MELO et al., 2014) e espécies reativas de oxigênio (ROS) (MELO et al., 2014), o que também poderia ter contribuído para a contenção de infecções e crescimento tumoral.

Tratamentos com o polímero promoveram ainda aumento dos níveis de IFN- $\gamma$ e IL-2 e diminuição de IL-10 em camundongos pré-tratados por 72 horas antes de serem infectados com Listeria monocytogenes (de MELO; JUSTO; de SOUZA QUEIROZ, 2001), em macrófagos de cães infectados com Leishmania infantum (SANTIAGO et al., 2013), e em camundongos com tumor ascítico de Ehrlich (EAT), além de ter sido observada restauração da atividade das 
células NK e ausência de IL-4 (JUSTO; DURÁN; QUEIROZ, 2003). A produção desse conjunto de citocinas sugere que o P-MAPA promove direcionamento da resposta imune para um perfil do tipo $T_{h} 1$ (FARMABRASILIS, 2010).

A especialização da resposta imune contra um patógeno é moldada por diferentes citocinas, inicialmente pela ativação de receptores de reconhecimento de patógenos (PRRs), nas células da imunidade inata. Em resposta a microorganismos intracelulares ou antígenos protéicos, macrófagos e células NK desencadeiam a liberação de IL-12, IL-18 e interferon tipo I, a partir da ativação direta de receptores do tipo Toll (TLRs), ou indiretamente, pela secreção de IFN- $\gamma$ por células NK, que ativam macrófagos e os induzem a produzir IL-12. Ativados, os macrófagos passam a expressar CD40 ligante (CD4OL), que ao efetuar ligação com CD40 de um linfócito T CD4 ${ }^{+}$naive, secretam IFN- $\psi$, citocina crucial para a diferenciação do linfócito naive no subconjunto $T_{h} 1$.

Imunomoduladores são capazes de induzir a produção de citocinas, direta ou indiretamente, incluindo IL-12, IFN- $\gamma$, TNF- $\alpha$ e IFN- $\alpha$ (WU et al., 2005), sendo a secreção destes mediadores detectadas em tratamentos com P-MAPA.

Os mecanismos de ação do polímero, no entanto, ainda não estão devidamente esclarecidos. Estudos têm indicado que o P-MAPA atua sobre as células a partir da ativação de receptores do tipo Toll (TLRs) 2 e/ou 4, tendo sido detectada reatividade com estes receptores in vitro (FÁVARO et al., 2012). Estudos in vivo mostraram que o composto promoveu aumento da expressão de TLR2 e TLR4 por células uroteliais, após o tratamento intravesical de ratas com câncer de bexiga (FÁVARO et al., 2012; REIS et al., 2011), e aumento da expressão de TLR2 em macrófagos de cães infectados com Leishmania chagasi (MELO et al., 2014). O composto também induziu fosforilação de IKK e p38 MAPK (p38 mitogen-activated protein kinase), indicando duas possíveis vias de sinalização induzidas pela ativação dos TLRs e consequente produção de ROS e NO (MELO et al., 2014). O composto parece também estar envolvido na regulação do gene p53 (REIS et al., 2011).

As propriedades imunoestimulantes, antivirais e antineoplásicas apresentadas pelo PMAPA o tornam um composto com potencial terapêutico promissor, porém, são necessários estudos mais detalhados da molécula, a fim de se conhecer melhor seus mecanismos de ação sobre o sistema imune. Junto a isso, nada se sabe sobre os efeitos do P-MAPA sobre elementos do compartimento humoral do sistema imune, como o Sistema Complemento, um dos elementos centrais da imunidade inata. 


\subsection{Crosstalk entre sistema complemento e receptores do tipo Toll}

O sistema complemento consiste em um conjunto de mais de 30 proteínas, encontradas no plasma e na superfície de células, cujas principais funções envolvem a destruição e opsonização de microorganismos patogênicos, quimiotaxia de neutrófilos e monócitos, participação na regeneração tecidual (revisado por SARMA; WARD, 2011). Considerado inicialmente apenas como um mecanismo de apoio da imunidade inata, atualmente entende-se o complemento como um dos componentes mais importantes desta, capaz de atuar sobre diversos aspectos da imunidade, e como sendo um mecanismo crucial para a manutenção da homeostase e vigilância do sistema imune.

Embora a ativação deste sistema possa ocorrer por três vias distintas, a via clássica, alternativa ou das lectinas (Figura 2), todas convergem para a formação de uma C3 convertase, que promove a clivagem da proteína C3 e, a partir desta, a produção de fragmentos com propriedades distintas, como a anafilatoxina C3a e a opsonina C3b. A partir da formação de C3 convertases, independente de qual a via de ativação, ocorre amplificação da clivagem de C3 e formação de uma nova convertase, a C5 convertase, responsável por clivar o componente C5 em novos fragmentos de tamanhos e funções distintas: C5a, uma anafilatoxina, e a molécula C5b. Esta última associa-se com os componentes seguintes da cascata do complemento, $\mathrm{C} 6$ e C7, e insere-se na membrana celular. Em seguida, os últimos componentes da cascata, C8 e C9, ligam-se ao complexo C5bC6C7, onde ocorre polimerização de várias moléculas de C9 para a formação de um poro lítico na membrana, o complexo de ataque a membrana (MAC) (revisado por RICKLIN et al., 2010; SARMA; WARD, 2011).

As principais anafilatoxinas do complemento, C3a e C5a exercem diversos efeitos sobre neutrófilos, monócitos e macrófagos (MARTIN et al., 1997), como quimiotaxia, aumento da expressão de moléculas de adesão, explosão respiratória e até mesmo ação sobre o endotélio vascular (FERNANDEZ et al., 1978; KLOS et al., 2009; WEBSTER; ZANOLARI; HENSON, 1980). Elas ligam-se a seus receptores específicos, C3aR e C5aR, receptores extracelulares acoplados à proteína G (LANGKABEL; ZWIRNER; OPPERMANN, 1999). 
Figura 2 - Esquema das vias de ativação do sistema complemento

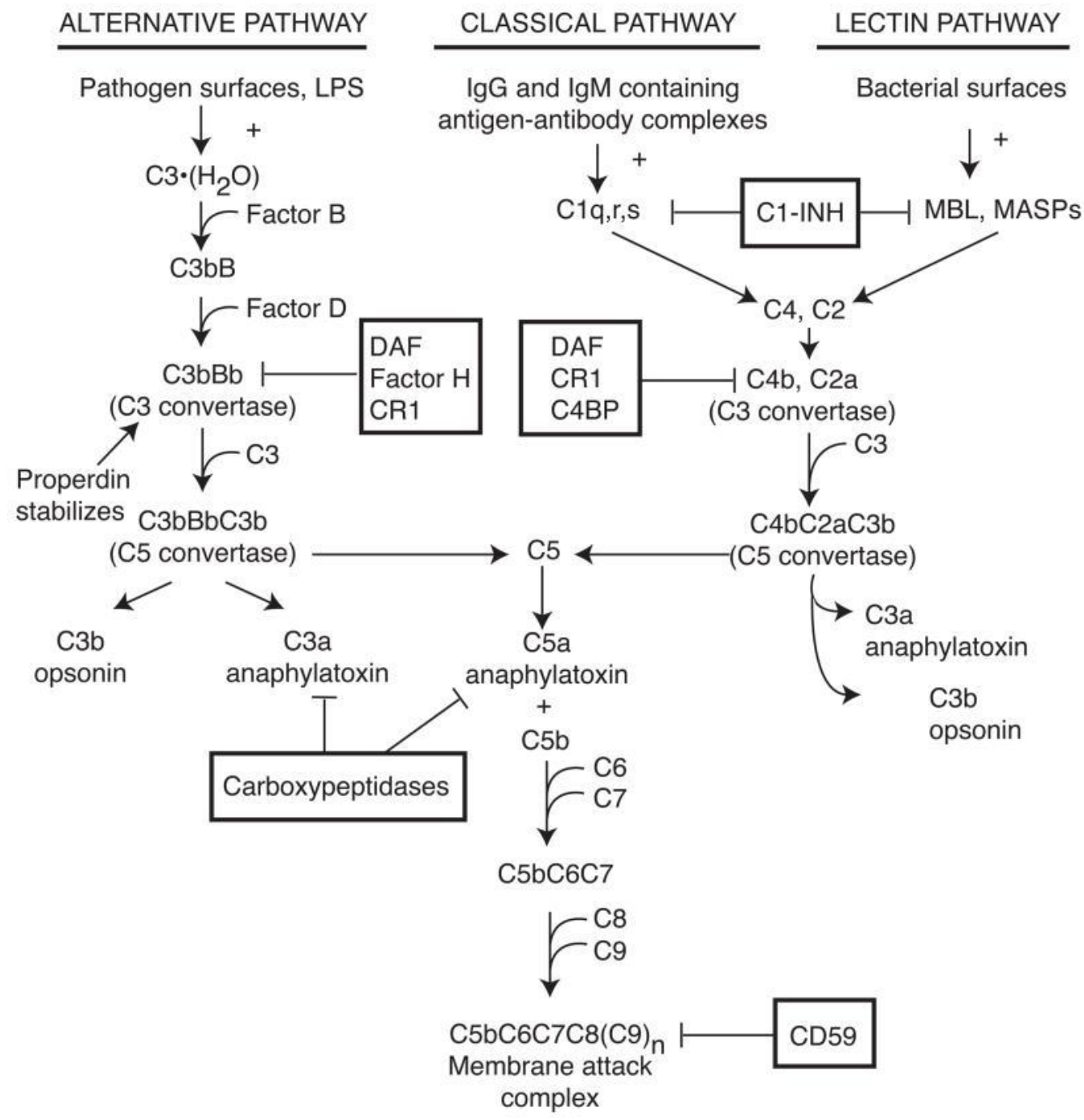

Esquema das três vias de ativação do sistema complemento: via alternativa, clássica e das lectinas. Reguladores do complemento estão indicados por caixas de texto (SARMA; WARD, 2011).

Assim como o sistema complemento, os receptores do tipo Toll (TLRs) são peças fundamentais da imunidade inata contra agentes nocivos e, também, no desenvolvimento da imunidade adaptativa. Os TLRs fazem parte da grande família de receptores de reconhecimento de padrões (PRRs) e são encontrados na superfície e em vesículas intracelulares de células da imunidade inata. Sua função é reconhecer uma variedade de padrões moleculares compartilhados por patógenos, tendo grande importância na discriminação do self do não-self (revisado por KAWAI; AKIRA, 2011; MORESCO; LAVINE; BEUTLER, 2011). 
Tais padrões moleculares compartilhados por patógenos incluem constituintes da parede celular de bactérias, como o lipopolissacarídeo (LPS), lipoproteínas, lipopeptídeos, lipoarabinomanana (LAM), proteínas como a flagelina, RNA viral, e sequências de CpG não metilado em DNA de vírus ou bactérias (UEMATSU; AKIRA, 2008).

O LPS, conhecido também por endotoxina, é um componente da parede externa de bactérias Gram-negativas e pode ser dividido bioquimicamente em regiões lipídica e polissacarídica. O glicolipídio central, lipídio A, e o polissacarídeo central são componentes obrigatórios da parede bacteriana e, enquanto os açúcares da cadeia polissacarídea apresentam grande variação e diferem de uma linhagem para outra, o lipídio A está altamente conservado ao longo da evolução e é a porção tóxica da endotoxina (BERCZI; QUINTANAR-STEPHANO; KOVACS, 2006).

O reconhecimento do LPS começa no plasma, pela ligação da endotoxina com a LBP (lipopolysaccharide binding protein), uma glicoproteína encontrada no soro em concentrações que variam de 0,5 a $10 \mu \mathrm{g} / \mathrm{mL}$ em humanos (TOBIAS et al., 1992). Ao uniremse, formam o complexo LPS-LBP que é identificado pelo CD14, uma glicoproteína expressa na superfície de monócitos macrófagos, neutrófilos e células dendríticas. A LPB eleva a interação do CD14 com LPS e facilita a detecção da endotoxina; desse modo, a célula é capaz de detectar níveis extremamente baixos de LPS (MATHISON et al., 1993). O CD14 não possui cauda transmembrana, então age como co-receptor para os receptores TLR4 e TLR2, que reconhecem o LPS diretamente e transmitem os sinais intracelulares para a produção de citocinas (CHOW et al., 1999; YANG et al., 1998). Ainda, o CD14 pode atuar não somente como co-receptor para TLRs na membrana extracelular, mas também para TLRs intracelulares, como TLR7 e TLR9 (BAUMANN et al., 2010). Outra molécula também envolvida no processo de interação com o LPS é o MD-2, um co-receptor presente na superfície de monócitos e macrófagos. MD-2, uma proteína secretada, liga-se ao LPS sem necessidade de LBP, e este, por sua vez, liga-se ao TLR4 na presença de CD14 (CHRISTIANSEN et al., 2012; VIRIYAKOSOL et al., 2001).

A ativação dos TLR2 e TLR4 por LPS promove a associação intracelular dos domínios TIR dos TLRs com MyD88 (myeloid differentiation primary-response protein 88), que em seguida recruta IRAK4 (IL-1R-associated kinase 4). A cascata de sinalização prossegue até a fosforilação das proteínas IKK e consequente ativação do fator de transcrição NFKB e sua translocação para o núcleo; porém, a sinalização por TLR4 pode ocorrer também de maneira 
MyD88 independente, pela ativação de IRF3 (interferon-regulatory fator), levando a produção de IFN- $\beta$ e à ativação tardia de NFKB (revisado por AKIRA; TAKEDA, 2004). A transcrição de NFKB, por sua vez, promove a síntese de citocinas inflamatórias TNF- $\alpha, \mathrm{IL}-6$, IL-8 e IL-1ß (AKIRA; TAKEDA, 2004; HEUMANN; ROGER, 2002).

Muitos patógenos podem ativar o sistema complemento e os TLRs, mas a literatura sugere que além de atuarem independentemente, estes elementos interagem entre si, com a finalidade de potencializar a resposta do hospedeiro contra o agente agressor. De acordo com Hajishengallis e Lambris (2010), tais interações, ou crosstalk, tem grande valor biológico, na medida em que reforçam a imunidade inata ou regulam a inflamação excessiva, através de interações sinérgicas ou antagônicas, respectivamente. Estudos mostraram que o crosstalk promove, em termos gerais, a regulação da expressão de receptores e a regulação da produção de citocinas, induzidas a partir da ativação dos receptores envolvidos.

Através da anafilatoxina $\mathrm{C} 5 \mathrm{a}$ e sua ligação com $\mathrm{C} 5 \mathrm{aR}$, o sistema complemento pode regular a produção de citocinas secretadas pela ativação de TLR4 em macrófagos, aumentando a produção de IL-10 (OKAZAKI et al., 2011) ou diminuindo a secreção de IL-12 (HAWLISCH et al., 2005; OKAZAKI et al., 2011), possivelmente pela via de sinalização Erk1/2 (extracellular signal-regulated kinases), utilizada pelos TLRs (OKAZAKI et al., 2011). A sinalização do TLR9 pode também ser mediada por produtos do complemento, principalmente por C3a, por meio de C3aR e, em menor extensão, por C5aR. Relação similar ocorre com TLR4, porém é C5aR, e não C3aR, quem mais afeta a sinalização deste receptor (ZHANG et al., 2007). Segundo este último estudo, os sinais gerados por C5a/C3a poderiam regular positivamente a expressão do fator de transcrição NFkB e amplificar a transdução de sinal feita normalmente por TLR4.

A cooperação entre TLRs e proteínas do complemento, como C3, parece contribuir para a ativação dos mecanismos de destruição de microorganismos e endotoxinas por moléculas microbicidas em fagolisossomos de fagócitos. Além de C3, a presença de C5 contribui para a indução da explosão respiratória e destruição de microorganismos, como $E$. coli, em granulócitos (LAPPEGÅRD et al., 2009). No entanto, tais eventos mediados pelo complemento cessam com a inibição do CD14, sugerindo uma interação entre o complemento e este co-receptor (LAPPEGÅRD et al., 2009).

A associação entre CD14 e TLR4 ou TLR2 é fundamental, por exemplo, para indução da síntese de TNF- $\alpha$ (PAPADOPOULOS et al., 2012; PERERA et al., 2001; RABY et al., 2013). 
Mas CD14 também opera em associação com proteínas do complemento, como C3 e C5, na promoção da síntese das citocinas TNF- $\alpha$, IL-6, IL-8 e IL-1 $\beta$ (BREKKE et al., 2008) e na regulação positiva da expressão de CD11b (BREKKE et al., 2007; MOLLNES et al., 2002), molécula presente na superfície de macrófagos e encontrada em associação com CD18. Juntas, as moléculas formam o complexo CD11b/CD18, denominado CR3 (complement receptor 3), uma integrina capaz de mediar a adesão célula-célula e de funcionar como receptor para a opsonina iC3b, um subproduto da clivagem de C3 (ROSS; VĔTVICKA, 1993). Em associação com CD14 e TLR4, CR3 promove a expressão ótima dos genes para IL-12 p35, IL-12 p40 e COX-2 (PERERA et al., 2001).

Os efeitos pró-inflamatórios promovidos por C5a também estão sujeitos à regulação, inclusive pelo próprio sistema: C3aR pode reduzir o recrutamento de neutrófilos, mediado por C5a e C5aR (WU et al., 2013), contribuindo, em parte, para a regulação do processo inflamatório. Porém, C5a é capaz de impedir a internalização de C3aR em monócitos e granulócitos (SETTMACHER et al., 1999). TLR4 também pode modular as respostas a C5a, aumentando-a a partir de sua ativação, ou diminuindo-a, ao modular negativamente C5L2, outro receptor de C5a, reduzindo sua expressão (RABY et al., 2011).

No entanto, o crosstalk entre TLRs e elementos do sistema complemento pode ser manipulado por patógenos (HAJISHENGALLIS; LAMBRIS, 2011), e assim, os efeitos sinérgicos das interações, como aumentar a secreção de TNF- $\alpha$, IL-1 $\beta$ e IL-6, podem se tornar prejudiciais sob ativação excessiva do complemento (HAJISHENGALLIS; LAMBRIS, 2010). Tais efeitos são observados na sepse, que se caracteriza como um intenso processo inflamatório, resultante de infecção generalizada. Durante a sepse, grandes concentrações de endotoxina induzem ativação excessiva do sistema imune e, em resposta, citocinas inflamatórias podem induzir choque e até mesmo levar à morte (NDUKA; PARRILLO, 2011).

Atualmente, as estratégias terapêuticas para o tratamento de sepse consistem do uso de medicamentos anti-inflamatórios e fatores pró-resolução da inflamação (revisado por BANNENBERG et al., 2005). Mas, como TLR4, TLR2 e o sistema complemento possuem grande importância no estabelecimento e desenvolvimento desta patologia, estudos têm abordado estes receptores e proteínas como alvo de novas estratégias terapêuticas para o tratamento da sepse, testando in vitro, o bloqueio de receptores celulares, principalmente CD14 (BREKKE et al., 2007, 2008; CHRISTIANSEN et al., 2012) e receptores de proteínas do 
sistema complemento, como CR3 (EGGE, et al., 2013) e C5aR BREKKE et al., 2007, 2008; MOLLNES et al., 2002).

Apesar das relações entre TLRs e complemento serem alvos potenciais para terapias, o conhecimento das interações entre ambos é relativamente recente, e muitas delas ainda devem ser descobertas (HAJISHENGALLIS; LAMBRIS, 2010).

Experimentalmente, o modelo que vem sendo usado para a avaliação do crosstalk entre receptores do tipo Toll e sistema complemento é o de sangue total humano (BREKKE et al., 2007, 2008; MOLLNES et al., 2002). Ele permite investigar as interações do sistema complemento com outras vias inflamatórias utilizando sangue periférico (HAJISHENGALLIS; LAMBRIS, 2010). Estabelecido in vitro, o modelo consiste no uso de LPS, principal fator de virulência de bactérias Gram-negativas, para ativar ambos complemento e TLRs, permitindo a análise da resposta inflamatória pela quantificação de citocinas, fatores de crescimento e populações celulares presentes no sangue. Além destes produtos resultantes da ativação celular, este modelo permite analisar a expressão de moléculas relacionadas aos receptores TLR2 e TLR4 e complemento, como o CD14, os receptores de anafilatoxinas, C3aR e C5aR, e o CD11b, todos presente em monócitos, macrófagos e granulócitos.

Baseado nos estudos do crosstalk entre TLRs e complemento, o modelo de sangue total oferece a possibilidade de estudar o comportamento imunomodulatório do P-MAPA sob estas interações em ambiente inflamatório, usando material de fácil acesso - sangue periférico humano. 


\section{OBJETIVOS}

O presente projeto tem como objetivo analisar a possível ação modulatória do PMAPA sobre as vias de ativação do sistema complemento, receptores tipo Toll 4 e 2, moléculas acessórias, CD11b, CD14, C3aR e C5aR, e sobre as interações destes elementos da imunidade inata. O uso de LPS, como estimulador de receptores tipo Toll, complemento e outras moléculas acessórias ao seu reconhecimento, permitirá analisar a imunomodulação promovida pelo P-MAPA usando o modelo ex vivo de sangue total humano. 


\section{MATERIAL E MÉTODOS}

\subsection{Composto}

P-MAPA, gentilmente fornecido pela Farmabrasilis (Campinas-SP), se apresenta na forma de cristais. A solubilização do P-MAPA foi feita com uma solução de ácido fórmico 0,25\% em água deionizada e, em seguida, secada a vácuo e ressuspendida em PBS estéril (8,1 mM Na $\left.2 \mathrm{HPO}_{4} ; 1,5 \mathrm{mM} \mathrm{KH}_{2} \mathrm{PO}_{4} ; 137 \mathrm{mM} \mathrm{NaCl} ; 2,7 \mathrm{mM} \mathrm{KCl}, \mathrm{pH} 7,4\right)$. As partidas de PMAPA utilizadas foram a P-17, para os testes in vitro, e a NL-12 para os testes in vivo.

\subsubsection{Dosagem de LPS nas amostras}

A concentração de lipopolissacarídeo (LPS) nas amostras de P-MAPA solubilizado, e sob a forma de cristais, ressuspendidos em PBS estéril, foi analisada pelo método de LAL (Limulus amebocyte lisate), pela Seção de Controle Microbiológico (Serviço de controle de qualidade, Divisão Bioindustrial) do Instituto Butantan, com a utilização do Kit PYROGENT ${ }^{T M}$ Plus Gel Clot LAL Assays (Lonza, Walkersville, MD, EUA). A concentração de endotoxina presente nas amostras, calculada de acordo com uma curva padrão de endotoxina de $E$. coli, com concentrações de 2,5 a 0,125 UE/mL, apresentou valores abaixo do limite de sensibilidade, 0,125 UE/mL, o que sugere que todos os efeitos detectados neste estudo são decorrentes da ação do P-MAPA.

\subsection{Reagentes e anticorpos}

Para o ensaio da via das lectinas, foi utilizada manose (Sigma-Aldrich, Missouri, EUA), anticorpo de cabra anti-C3 humano (Quidel Corporation, San Diego, CA, EUA), anticorpos anti-IgG de cabra conjugados com peroxidase (Pierce, Washington, EUA) e ortodihidrocloreto de fenilediamina (OPD, Sigma, Missouri, EUA). Nos ensaios de citometria de fluxo foram utilizados anticorpos monoclonais da Invitrogen (Califórnia, EUA), eBioscience (Califórnia, EUA) e Santa Cruz Biotechnology, (Texas, EUA), diluídos na proporção de 1:5: anti-C5aR FITC (clone 8D6), anti-C3aR FITC (clone 17), anti-CD14 FITC (clones 61D3 e TüK4), anti-CD11b PE (clone VIM12), anti-TLR4 PE (clone HTA125) e anti-TLR2 PE (clone TL2.1) 
Foram também utilizados como controle isotipico anticorpos monoclonais mouse $\operatorname{lgG} 1_{\mathrm{K}} \mathrm{PE}$ e mouse IgG2 $\mathrm{a}_{\mathrm{k}}$ FITC (Dako, Califórnia, EUA). A compstatina (Ac-ICVVQDWGHHRCT-NH2) e seu peptídeo controle (IAVVQDWGHHRAT-NH2) foram sintetizados no Instituto Butantan (São Paulo, Brasil), de acordo com as sequências descritas por Morikis et al. (1998), e utilizadas na concentração de $1 \mathrm{mM}$. Como anticoagulante foi utilizado a lepirudina (Refludan ${ }^{\circledR}$, Celgene, Munique, Alemanha) e, como indutor de inflamação, LPS de Escherichia coli (0111:B4, Sigma-Aldrich Co., Missouri, EUA). A dosagem de anafilatoxinas foi feita com os kits OptEIA Human C3a Elisa Kit e OptEIA Human C5a Elisa Kit (BD Biosciences, Califórnia, EUA), a dosagem de citocinas TNF- $\alpha$, IL-6, IL-8, IL-1 $\beta$, IL-10, IL-12(p70), IFN- $\gamma$ e TGF- $\beta$, feita com os kits BD OptEIA Human Set (BD Biosciences, Califórnia, EUA) e a dosagem do complexo terminal do complemento, TCC, feita com o MicroVue SC5b-9 Plus EIA Kit (Quidel Corporation, Califórnia, EUA).

\subsection{Ação do P-MAPA sobre o Sistema Complemento}

\subsubsection{Soro humano normal}

O soro humano normal (SHN) foi obtido de indivíduos adultos saudáveis. O sangue foi coletado por punção venosa, mantido à temperatura ambiente por 10 minutos e refrigerado a $4{ }^{\circ} \mathrm{C}$ por 4 horas, para retração do coágulo. Em seguida, o sangue foi centrifugado a $404 \mathrm{~g}$ por 15 minutos a $4{ }^{\circ} \mathrm{C}$ e o soro coletado, aliquotado e armazenado a $-80^{\circ} \mathrm{C}$ até o momento de uso.

\subsubsection{Tratamento do SHN com o P-MAPA}

Alíquotas de SHN (50 $\mu \mathrm{L})$ foram tratadas com concentrações crescentes de P-MAPA e incubadas a $37^{\circ} \mathrm{C}$ por 30 minutos. Amostras controles foram tratadas com PBS.

\subsubsection{Ensaios hemolíticos}


Para os ensaios hemolíticos da Via Clássica do complemento (C) foram utilizados eritrócitos de carneiro $\left(E^{S}\right)$, sensibilizados com anticorpos de coelho anti- $E^{S}$ (hemolisina) e para os ensaios da via alternativa do $C$, eritrócitos de coelho $\left(E^{R}\right)$.

\subsubsection{Via Clássica}

Amostras de SHN, previamente incubadas com P-MAPA, foram diluídas 1:80 em tampão $\mathrm{VBS}^{2+}(145,5 \mathrm{mM}$ de cloreto de sódio; 0,9 mM de 5,5 dietilbarbiturato de sódio; 2,8 $\mathrm{mM}$ de ácido barbitúrico; 0,8 mM de cloreto de magnésio e 0,3 mM de cloreto de cálcio - pH 7,2). Alíquotas dessas diluições, variando de 10 a $100 \mu \mathrm{L}$, foram incubadas em placas de poliestireno de 96 poços (Costar ${ }^{\oplus}$, Corning Inc., Massachusetts, EUA), com $50 \mu \mathrm{L}$ da suspensão a $2 \%$ dos $E^{S}$ sensibilizados e volumes de $\mathrm{VBS}^{++}$suficientes para completar 0 volume final de $100 \mu \mathrm{L}$ por poço. Como controles negativo (branco) ou positivo (100\% de

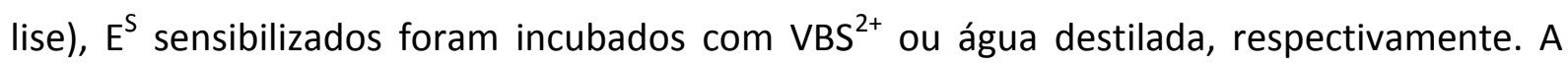
placa foi incubada a $37{ }^{\circ} \mathrm{C}$ por 30 minutos e, em seguida, centrifugada a $238 \mathrm{~g}$ por 5 minutos e a $4{ }^{\circ} \mathrm{C}$. Os sobrenadantes foram transferidos para placas de fundo chato e a hemólise determinada pela medida da absorbância da hemoglobina liberada, em $\lambda 414 \mathrm{~nm}$, utilizando espectrofotômetro (Biotek ELx800, Biotek Instruments, Vermont, EUA). Os valores de $\mathrm{CH}_{50}$, para as amostras de soro incubadas com P-MAPA, foram calculados a partir da curva construída com as porcentagens de hemólise.

Cálculo da atividade hemolítica - A partir dos valores da leitura de absorbância (Abs), as porcentagens de hemólise (y) foram calculadas utilizando a seguinte fórmula:

$$
y=\left[\left(\mathrm{Abs}^{\text {SORO }}-\mathrm{Abs}^{\text {BRANCO }}\right) /\left(\mathrm{Abs}^{100 \% \text { LISE }}-\mathrm{Abs}^{\text {BRANCO }}\right)\right] \times 100 \%
$$

Os valores de $\mathrm{CH}_{50}$ foram calculados a partir da curva construída com a porcentagem de hemólise, induzida após o tratamento do soro com P-MAPA.

\subsubsection{Via Alternativa}

Amostras do SHN, previamente incubadas com P-MAPA, foram diluídas 1:4 em tampão APB (5mM de 5,5-dietilbarbiturato de sódio; 7 mM de cloreto de magnésio; 10 mM de EGTA e 150 mM de cloreto de sódio - pH 7,4). Alíquotas dessas diluições, variando de $10 \mathrm{a}$ $100 \mu \mathrm{L}$, foram incubadas em placas de 96 poços, com $50 \mu \mathrm{L}$ da suspensão a $2 \%$ de $E^{R}$ e 
volumes do tampão suficientes para completar volume final de $100 \mu \mathrm{L}$ por poço. Como controles negativo (branco) ou positivo ( $100 \%$ de lise), amostras de $E^{R}$ foram incubadas com tampão ou água destilada, respectivamente. A placa foi incubada a $37{ }^{\circ} \mathrm{C}$ por 30 minutos e, em seguida, centrifugada a $238 \mathrm{~g}$ por 5 minutos e a $4{ }^{\circ} \mathrm{C}$. Os sobrenadantes foram transferidos para placas de fundo chato e a hemólise determinada pela medida da absorbância da hemoglobina liberada, em $\lambda 414 \mathrm{~nm}$, utilizando espectrofotômetro (Biotek ELx800, Biotek Instruments, Vermont, EUA).

Cálculo da atividade hemolítica - A partir dos valores da leitura de absorbância (Abs), as porcentagens de hemólise ( $\mathrm{y}$ ) foram calculadas utilizando a seguinte fórmula:

$$
y=\left[\left(\text { Abs }^{\text {SORO }}-\text { Abs }^{\text {BRANCO }}\right) /\left(\text { Abs }^{100 \% \text { LISE }}-\text { Abs }^{\text {BRANCO }}\right)\right] \times 100 \%
$$

Assim como o cálculo para o $\mathrm{CH}_{50}$, os valores de $\mathrm{AP}_{50}$ foram calculados a partir da curva construída com a porcentagem de hemólise, induzida após o tratamento do soro com P-MAPA.

\subsubsection{Via das Lectinas}

Para a avaliação da atividade do P-MAPA sobre a Via das Lectinas, placas de 96 poços foram sensibilizadas overnight e a $4{ }^{\circ} \mathrm{C}$, com $100 \mu \mathrm{g} / \mathrm{mL}$ de manose diluída em tampão PBS, em volume final de $100 \mu \mathrm{L} /$ poço. As placas foram lavadas e bloqueadas com PBS-BSA $1 \%$ durante 1 hora e a $37{ }^{\circ} \mathrm{C}$. Posteriormente, as placas foram incubadas, por 1 hora e a $37{ }^{\circ} \mathrm{C}$, com diluições seriadas do SHN (100 $\mu \mathrm{L} /$ poço), previamente tratado com P-MAPA. Como controle negativo, foram utilizadas amostras de $\mathrm{SHN}$ inativado por aquecimento a $56{ }^{\circ} \mathrm{C}$ por 30 minutos. As placas foram lavadas com tampão $B^{2+}\left(V^{2+} S^{2+}\right.$ e 0,1 \% BSA, pH 7,5), e amostras de anticorpos anti-C4 humano (1:1000) adicionadas às placas, para serem incubadas por $1 \mathrm{~h}$ a $37{ }^{\circ} \mathrm{C}$. Após este período, as placas foram novamente lavadas e incubadas com anticorpos específicos, conjugados com HRPO (diluído 1:5000) por 1 hora e a $37^{\circ} \mathrm{C}$. As placas foram lavadas e as reações reveladas pela adição de $50 \mu \mathrm{L}$ do substrato (1 mg OPD diluído em $1 \mathrm{~mL}$ de tampão citrato/ $\mathrm{H}_{2} \mathrm{O}_{2}$ 0,3\%). A reação foi interrompida pela adição de $\mathrm{H}_{2} \mathrm{SO}_{4} 4 \mathrm{~N}$ e as densidades óticas determinadas por leitura espectrofotométrica (Biotek ELx800, Biotek Instruments, Vermont, EUA) em $\lambda 492 \mathrm{~nm}$. Para cálculo da atividade da Via das lectinas, os valores obtidos para as amostras de SHN foram arbitrariamente fixados como 1000 unidades por $\mathrm{mL}$ (1000 UA/mL). 


\subsection{Modelo de sangue total: tratamento com LPS}

\subsubsection{Tratamento das amostras de sangue}

Os procedimentos descritos a seguir foram baseados nos protocolos estabelecidos por Brekke et al. (2007, 2008) e Mollnes et al. (2002). Amostras de sangue humano foram coletadas de voluntários saudáveis, em tubos de polipropileno contendo lepirudina (50 $\mu \mathrm{g} / \mathrm{mL}$ ), forma recombinante da hirudina com atividade anticoagulante e que não interfere na ativação do sistema complemento (BEXBORN et al., 2009; MOLLNES et al., 2002). O sangue foi, então, diluído em PBS, na proporção de $14 \%$ do volume total. Após a diluição, o sangue foi mantido por 5 minutos à temperatura ambiente e, a seguir, foram adicionados $100 \mu \mathrm{g} / \mathrm{mL}$ de LPS ou P-MAPA, com exceção do controle, que recebeu solução tampão. As amostras foram, então, incubadas a $37^{\circ} \mathrm{C}$, em banho-maria, sob agitação, por diferentes tempos. As amostras de sangue foram tratadas com diferentes concentrações de P-MAPA antes e depois do tratamento com LPS. Após o término da incubação, foi coletada uma alíquota de cada tubo para análise da expressão de marcadores celulares por citometria de fluxo (metodologia descrita em 3.4.4). Em seguida, os tubos foram centrifugados a $404 \mathrm{~g}, 4$ ${ }^{\circ} \mathrm{C}$, por 10 minutos, para coleta dos plasmas. Após adição de EDTA $10 \mathrm{mM}$, o plasma foi aliquotado e armazenado a $-80^{\circ} \mathrm{C}$, para análises posteriores.

\subsubsection{Inibição do componente C3 do Sistema Complemento}

Utilizando o mesmo protocolo descrito em 3.4.1, amostras de sangue humano foram coletadas de voluntários saudáveis, em tubos de polipropileno contendo lepirudina (50 $\mu \mathrm{g} / \mathrm{mL}$ ). Logo após a coleta, o sangue foi adicionado a tubos Falcon contendo PBS ou compstatina (1 mM) ou peptídeo controle $(1 \mathrm{mM})$, proporção de $14 \%$ do volume total. Os

tubos foram mantidos por 10 minutos à temperatura ambiente e, a seguir, foram adicionados $100 \mu \mathrm{g} / \mathrm{mL}$ de LPS ou $1000 \mu \mathrm{g} / \mathrm{mL}$ de P-MAPA, com exceção dos controles, que receberam solução tampão. As amostras foram, então, incubadas a $37^{\circ} \mathrm{C}$, em banho-maria, sob agitação, por 30 minutos. Terminada a incubação, foi coletada uma alíquota de cada tubo para análise da expressão de marcadores celulares por citometria de fluxo 
(metodologia descrita em 3.4.4.) e o sangue restante foi centrifugado a $404 \mathrm{~g}, 4{ }^{\circ} \mathrm{C}$, por 10 minutos, para coleta do plasma. Após adição de EDTA $10 \mathrm{mM}$, o plasma foi aliquotado e armazenado a $-80^{\circ} \mathrm{C}$, para análises posteriores.

\subsubsection{Ensaio hemolítico da Via Alternativa por ELISA}

Para avaliar a atividade hemolítica residual do plasma após o tratamento do sangue, como descrito em 3.4.1, placas de poliestireno de 96 poços (Costar ${ }^{\circledR}$, Corning Inc., Massachusetts, EUA) foram sensibilizadas com $1 \mu \mathrm{g} / \mu \mathrm{L}$ de LPS de Escherichia coli (0111:B4, Sigma-AldrichCo., Missouri, EUA) por poço e incubadas overnight a $4{ }^{\circ} \mathrm{C}$. Após este período, os poços foram lavados com $200 \mu \mathrm{L}$ de tampão PBS e bloqueados com $200 \mu \mathrm{L}$ de PBS-BSA $5 \%$, durante 3 horas, a $37^{\circ} \mathrm{C}$. Em seguida, a placa foi novamente lavada com $200 \mu \mathrm{L}$ de PBS e incubada com diluições seriadas do soro (100 $\mu \mathrm{L} /$ poço), por 1 hora e a $37^{\circ} \mathrm{C}$. Terminada a incubação e após a lavagem com PBS, os poços receberam anticorpos anti-C3 humano (1:2500) e a placa foi incubada por 1 hora a $37^{\circ} \mathrm{C}$. Após este período, as placas foram novamente lavadas e incubadas com anticorpos específicos conjugados com peroxidase (diluído 1:5000), por 1 hora e a $37{ }^{\circ} \mathrm{C}$. As placas foram lavadas e as reações reveladas pela adição de $50 \mu \mathrm{L}$ do substrato ( $1 \mathrm{mg}$ OPD diluído em $1 \mathrm{~mL}$ de tampão citrato/ $\mathrm{H}_{2} \mathrm{O}_{2}$ 0,3\%). A reação foi interrompida pela adição de $\mathrm{H}_{2} \mathrm{SO}_{4} 4 \mathrm{~N}$ e as densidades óticas determinadas por leitura espectrofotométrica (Biotek ELx800, Biotek Instruments, Vermont, EUA) em $\lambda$ de 492 nm. Para o cálculo da atividade da Via Alternativa, os valores obtidos para as amostras de SHN foram arbitrariamente fixados como 1000 unidades por $\mathrm{mL}(1000 \mathrm{UA} / \mathrm{mL}$ ).

\subsubsection{Dosagem de SC5b9 no plasma}

A presença do complexo terminal de ataque a membrana (TCC, SC5b9) foi analisada em amostras de plasma coletadas a partir dos ensaios de sangue total humano, tratadas conforme descrito em 3.4.1, utilizando o MicroVue SC5b-9 Plus EIA Kit (Quidel Corporation, Califórnia, EUA). Segundo as instruções do kit, amostras de plasma foram diluídas na proporção de 1:100, em Specimen Diluent, fornecido pelo kit, e adicionadas em placas de poliestireno de 96 poços (Costar ${ }^{\circledR}$, Corning Inc., Massachusetts, EUA), já preparadas com o anticorpo de captura. Uma curva padrão com concentrações conhecidas de SC5b-9 também 
foi preparada, conforme as instruções do kit, e adicionada em poços da mesma placa, que em seguida foi incubada por 1 hora, a temperatura ambiente. Após este período, o conteúdo dos poços foi descartado e a placa lavada com Wash Solution, antes de receber $50 \mu \mathrm{L}$ de SC5b-9 Plus Conjugate, ambos fornecidos pelo kit, para depois a placa ser incubada por 30 minutos, também a temperatura ambiente. Após este período, o conteúdo da placa foi dispensado e os poços lavados com Wash Solution, seguido da adição de $100 \mu \mathrm{L}$ de Substrate Solution por poço. Após por 15 minutos de incubação a temperatura ambiente, os poços receberam $100 \mu \mathrm{L}$ de Stop Solution, e as densidades óticas foram determinadas por leitura espectrofotométrica (Biotek ELx800, Biotek Instruments, Vermont, EUA) em $\lambda$ de $450 \mathrm{~nm}$. A concentração de CS5b-9 em cada amostra foi determinada com base na curva padrão.

\subsubsection{Análise da expressão de marcadores de superfície em leucócitos}

Amostras de sangue total humano, tratadas como descrito em 3.4.1, foram analisadas quanto a expressão de CD11b, CD14, TLR2, TLR4, C3aR e C5aR com o uso de anticorpos específicos, como descrito no item 3.2. Após a incubação, os eritrócitos foram lisados com BD FACS Lysing Solution (BD Biosciences, Califórnia, EUA). Em seguida, as células foram centrifugadas a $720 \mathrm{~g}, 4{ }^{\circ} \mathrm{C}$, por 10 minutos, ressuspendidas e fixadas com paraformaldeído 0,5\%, na proporção 1:1, para depois serem incubadas com os anticorpos monoclonais marcados com PE ou FITC, conforme descrito por Mollnes et al. (2002) e Brekke et al. $(2007,2008)$. As células foram incubadas por 15 minutos, no escuro, à temperatura ambiente, e analisadas em citômetro de fluxo FACSCanto II (BD Biosciences, Califórnia, EUA), utilizando o software BD FACSDiVa, versão 4.1 (BD Biosciences, Califórnia, EUA). Os resultados foram expressos como mediana de intensidade de fluorescência, determinada a partir da aquisição de 10 mil eventos na população de leucócitos totais.

\subsubsection{Dosagem de anafilatoxinas no sangue total humano}

A geração das anafilatoxinas C3a/C3a-desArg e C5a/C5a-desArg foi determinada usando o kit Opt Eia Human C3a, C5a Elisa (BD Biosciences, Califórnia, EUA). Amostras de plasma (50 $\mu \mathrm{L})$, coletadas como descrito em 3.4.1, foram diluídas (C3a, 1:30.000; C5a, 1:200), e adicionadas a placas de poliestireno de 96 poços (Costar ${ }^{\circledR}$, Corning Inc., 
Massachusetts, EUA), já preparadas com o anticorpo de captura. Uma curva padrão com concentrações conhecidas das anafilatoxinas C3a e C5a, também foi preparada, conforme as instruções do kit, e adicionada em poços da mesma placa. Em seguida, a placa foi incubada por 2 horas, no escuro e à temperatura ambiente. Após a incubação, a placa foi lavada com $200 \mu \mathrm{L}$ de wash buffer, fornecido pelo kit. Após a lavagem, os poços receberam $100 \mu \mathrm{L}$ de solução contendo o anticorpo de detecção e conjugado de estreptavidina-HRP, e uma nova incubação, por 1 hora, foi feita. Terminada a incubação, foram adicionados $50 \mu \mathrm{L}$ do substrato tetrametilbenzidina (TMB, BDBiosciences, Califórnia, EUA) nos poços, para revelação, e a placa foi logo levada à incubação por 30 minutos, no escuro e à temperatura ambiente. Finalizada a incubação, os poços receberam $50 \mu \mathrm{L}$ da solução STOP do kit e as reações foram analisadas em espectrofotômetro pela leitura da absorbância a $450 \mathrm{~nm}$ (Biotek ELx800, Biotek Instruments, Vermont, EUA).

\subsubsection{Dosagem de citocinas no sangue total humano}

Para a dosagem de citocinas TNF- $\alpha$, IL-6, IL-8, IL-1 $\beta$, IL-10, IL-12(p70), IFN- $\gamma$ e TGF- $\beta$, foram utilizados os kits BD OptEIA Human Set (BD Biosciences, Califórnia, EUA). Segundo as orientações do kit, placas high binding de 96 poços (Costar ${ }^{\circledR}$, Corning Inc., Massachusetts, EUA) foram sensibilizadas com anticorpo de captura (anti-TNF- $\alpha$, IL-6, IL-8, IL-1 $\beta$, IL-10, IL12 p70, IFN- $\gamma$ e TGF- $\beta$ ) e incubadas overnight a $4{ }^{\circ} \mathrm{C}$. Após a incubação, as placas foram lavadas com PBS/Tween-20 0,05\% e bloqueadas com soro fetal bovino (10\% de soro fetal bovino diluído em PBS) por 1 hora, a temperatura ambiente. Após o bloqueio, as placas foram lavadas com PBS/Tween-20 0,05\%, e em seguida, $50 \mu \mathrm{L}$ da curva padrão, preparadas de acordo com as orientações do kit, e $50 \mu \mathrm{L}$ das amostras foram adicionadas às placas. Após incubação por 2 horas, as placas foram novamente lavadas para depois receberem $50 \mu \mathrm{L}$ de solução contendo o anticorpo de detecção e conjugado de estreptavidina-HRP em cada poço, e uma nova incubação por 1 hora foi feita. Após este tempo, as placas foram lavadas e foram adicionados $50 \mu \mathrm{L}$ do substrato tetrametilbenzidina (TMB, BDBiosciences, Califórnia, EUA) nos poços, para revelação. Após 30 minutos, os poços receberam $50 \mu \mathrm{L}$ de $\mathrm{H}_{2} \mathrm{SO}_{4} 2 \mathrm{~N}$ para interromper as reações, que foram analisadas em espectrofotômetro, pela leitura da absorbância a 450 nm (Biotek ELx800, Biotek Instruments, Vermont, EUA). 


\subsubsection{Deteç̧ão de espécies reativas de oxigênio e nitrogênio}

A determinação da produção de superóxido e peróxinitrito em leucócitos foi realizada segundo a metodologia descrita por Bernardshawet al. (2007). Amostras de sangue humano contendo lepirudina $(50 \mu \mathrm{g} / \mathrm{mL})$ tratado com PBS, P-MAPA ou LPS, como descrito em 3.4.1, foram incubadas com DHE (dihidroetidina) (Sigma Aldrich, Missouri, EUA) ou DHR (dihidrorodamina-123) (Sigma Aldrich, Missouri, EUA), ambos com concentração final de 5 $\mu \mathrm{mol} / \mathrm{L}$. Em seguida, as amostras foram incubadas em estufa de $\mathrm{CO}_{2}$ a $37^{\circ} \mathrm{C}$, para $\mathrm{DHE}$, ou 30 ${ }^{\circ} \mathrm{C}$, para DHR, durante 1 hora. Terminada a incubação, os eritrócitos foram lisados com BD FACS Lysing Solution (BD Biosciences, Califórnia, EUA) e as amostras analisadas em citômetro de fluxo FACSCanto II (BD Biosciences, New Jersey, EUA). A análise da intensidade de fluorescência foi feita a partir do isolamento das populações de leucócitos em gates eletrônicos, utilizando o software BD FACSDiVa, versão 4.1 (BD Biosciences, Califórnia, EUA).

\subsection{Avaliação da dose letal ( $\left(L_{50}\right)$}

Para análise da ação tóxica do P-MAPA, foi determinada a DL50 utilizando camundongos da linhagem BALB/c. Grupos $(n=6)$ de camundongos foram inoculados, pela via intraperitoneal, com quantidades crescentes de P-MAPA ou PBS estéril (ressuspendido a partir de uma solução de ácido fórmico diluído em água destilada, e secada a vácuo). Com base na literatura e ensaios in vitro, foram testadas doses a partir de $100 \mathrm{mg} / \mathrm{kg}$ a 2000 $\mathrm{mg} / \mathrm{kg}$ de P-MAPA. Os animais do grupo Controle $(n=3)$ foram inoculados pela via intraperitoneal, com o mesmo volume de PBS estéril, ressuspendido a partir uma solução de água destilada $(2 \mathrm{~mL})$ contendo ácido fórmico $(125 \mu \mathrm{L})$, seco à vácuo. Após 72 horas, o número de mortes foi registrado e a dose letal para 50\% dos animais (DL50) foi calculada pela análise de transformação em probitos (FINNEY, 1971).

\subsection{Análise Estatística}

Os dados foram expressos como média \pm desvio padrão e analisados estatísticamente com o software GraphPad Prism, versão 5.1 (GraphPad Software, San Diego, EUA). Comparações entre mais de dois grupos quanto a uma variável foram feitas pela análise 
paramétrica One way ANOVA, complementada com teste de Tuckey ou Bonferroni, e para a comparação entre dois grupos experimentais, foi utilizado o teste t de Student. Nos testes realizados, foram consideradas diferenças estatisticamente significativas valores de $p<0,05$. 


\section{RESULTADOS}

\subsection{Ação do P-MAPA sobre o Sistema Complemento}

\subsubsection{Via Clássica}

A capacidade lítica residual do sistema complemento foi avaliada após a incubação de soro humano normal (SHN) com concentrações crescentes de P-MAPA, em ensaio hemolítico, sob condições para avaliar a ativação da via clássica, utilizando eritrócitos de carneiro sensibilizados com anticorpo. A Figura 3 mostra que o P-MAPA induziu uma pequena redução na atividade lítica desta via, com as concentrações de $250 \mu \mathrm{g} / \mathrm{mL}$ (19\%) e $500 \mu \mathrm{g} / \mathrm{mL}(20,3 \%)$.

Figura 3 - Ação do P-MAPA sobre a Via Clássica do Sistema Complemento

A)

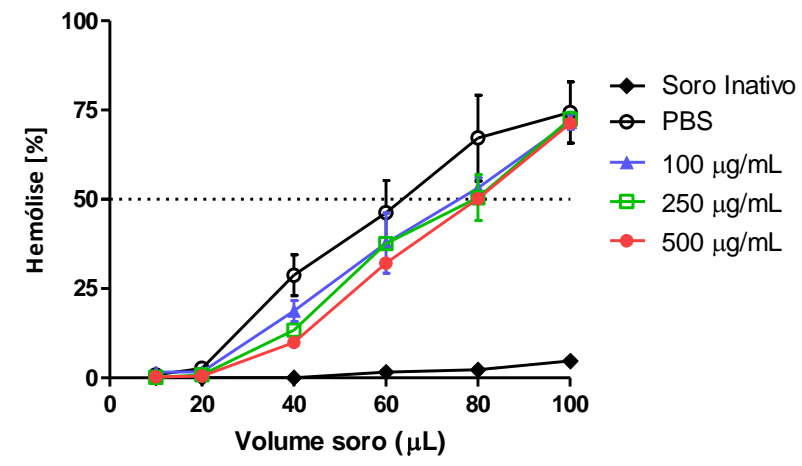

B)

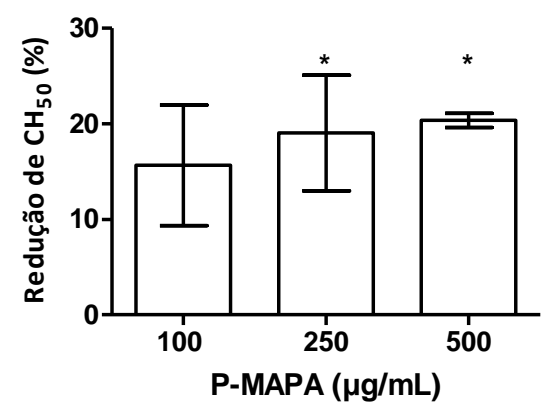

Amostras $(50 \mu \mathrm{L})$ de soro humano normal (SHN) foram incubadas com PBS ou P-MAPA, por 1 hora, a $37^{\circ} \mathrm{C}$. A atividade hemolítica residual da via clássica foi avaliada sobre eritrócitos de carneiro e a absorbância dos sobrenadantes determinada a $\lambda 414 \mathrm{~nm}$. O controle Soro Inativo corresponde ao tratamento de SHN com PBS aquecido a $56{ }^{\circ} \mathrm{C}$, por $1 \mathrm{~h}$. A) Hemólise de eritrócitos por SHN tratado com PBS ou P-MAPA. B) Redução da atividade hemolítica, em relação ao tratamento controle (PBS). Dados expressos como média \pm desvio padrão de duplicatas, representativos de 3 experimentos independentes. Análise estatística realizada por ANOVA, complementada com teste de Tuckey. $(*)$ Diferença significativa $(p<0,05)$ em relação ao controle. 


\subsubsection{Via Alternativa}

Amostras de SHN foram incubadas com doses crescentes de P-MAPA, e a atividade residual da via alternativa foi testada em ensaios hemolíticos, com eritrócitos de coelho. $\mathrm{A}$ Figura 4 mostra a redução da atividade hemolítica do soro após os tratamentos com PMAPA. A inibição promovida pelo composto ocorreu de forma dose-dependente, como mostrado pela redução da $\mathrm{AP}_{50}$ (Figura $4 \mathrm{~B}$ ), com inibição de $26 \%$ induzida pelo tratamento com P-MAPA $500 \mu \mathrm{g} / \mathrm{mL}$. A Figura 5 mostra que o P-MAPA não solubilizado requer uma alta concentração $(2000 \mu \mathrm{g} / \mathrm{mL})$ para promover uma redução significativa da atividade lítica da via alternativa.

Figura 4 - Ação do P-MAPA sobre a Via Alternativa do Sistema Complemento

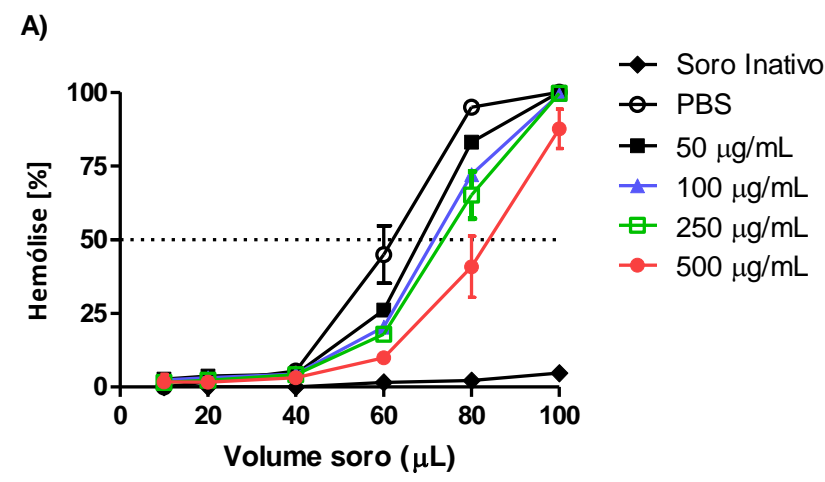

B)

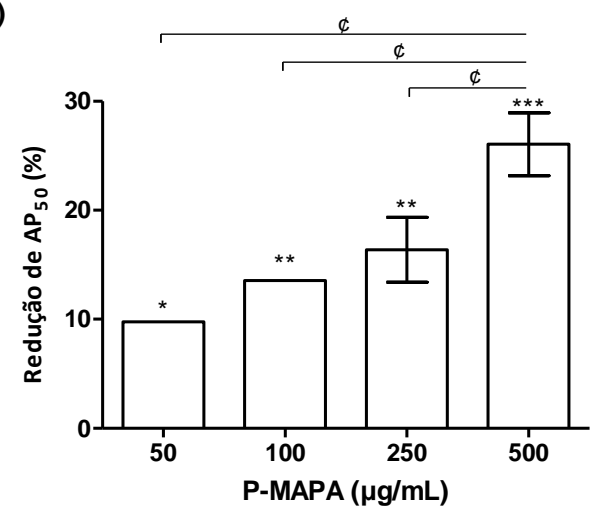

Amostras $(100 \mu \mathrm{L})$ de soro humano normal (SHN) foram incubadas com PBS ou P-MAPA, por 30 minutos, a 37 ${ }^{\circ} \mathrm{C}$. A atividade hemolítica residual da via alternativa foi avaliada sobre eritrócitos de coelho e a absorbância dos sobrenadantes, determinada a $\lambda 414 \mathrm{~nm}$. O controle Soro Inativo corresponde ao tratamento de SHN com PBS aquecido a $56{ }^{\circ} \mathrm{C}$, por 30 minutos. A) Hemólise de eritrócitos por SHN tratado com PBS ou P-MAPA. B) Redução da atividade hemolítica, em relação ao tratamento controle (PBS). Dados expressos como média \pm desvio padrão de duplicatas, representativos de 3 experimentos independentes. Análise estatística realizada por ANOVA, complementada com teste de Tuckey. $\left({ }^{*}\right) p<0,05,\left({ }^{* *}\right) p<0,01,\left(^{* * *}\right) p<0,001$ diferença estatística significativa em relação ao controle (PBS). (C) $p<0,05$, (C) $p<0,01$ diferença estatística significativa entre os tratamentos com P-MAPA. 
Figura 5 - Ação do P-MAPA não solubilizado sobre a Via Alternativa do Sistema Complemento

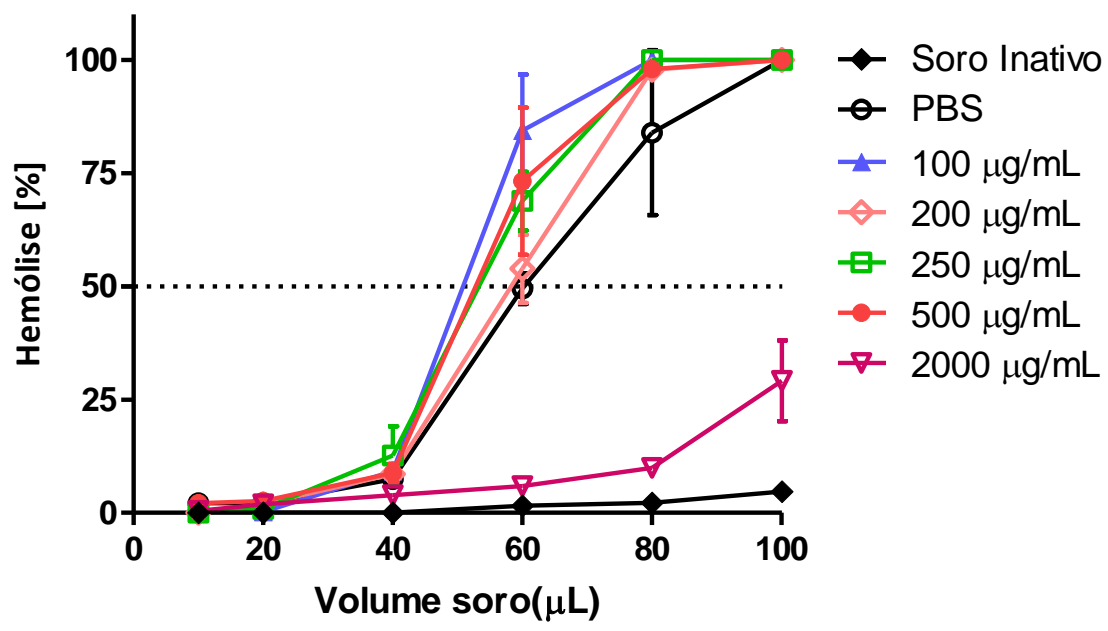

Hemólise de eritrócitos por SHN tratado com PBS ou cristais de P-MAPA. Neste ensaio, amostras (100 $\mu \mathrm{L})$ de soro humano normal (SHN) foram incubadas com PBS ou P-MAPA em cristais, por 30 minutos, a $37^{\circ} \mathrm{C}$. A atividade hemolítica residual da via alternativa foi avaliada sobre eritrócitos de coelho e a absorbância dos sobrenadantes, determinada a $\lambda 414 \mathrm{~nm}$. O controle Soro Inativo corresponde ao tratamento de SHN com PBS aquecido a $56^{\circ} \mathrm{C}$, por 30 minutos. Dados expressos como média \pm desvio padrão de duplicatas, representativos de 3 experimentos independentes. 


\subsubsection{Via das Lectinas}

Para avaliar a ação do P-MAPA sobre a Via das Lectinas, amostras de SHN foram incubadas com P-MAPA, e a atividade residual desta via foi determinada utilizando placas sensibilizadas com manose $(100 \mu \mathrm{g} / \mathrm{mL})$ que, após a incubação com os soros tratados, foram incubadas com anticorpo anti-C3. A Figura 6 mostra que o P-MAPA, nas concentrações utilizadas, não foi capaz de induzir ativação significativa da via das lectinas do complemento.

Figura 6 - Ação do P-MAPA sobre a Via das Lectinas do Sistema Complemento

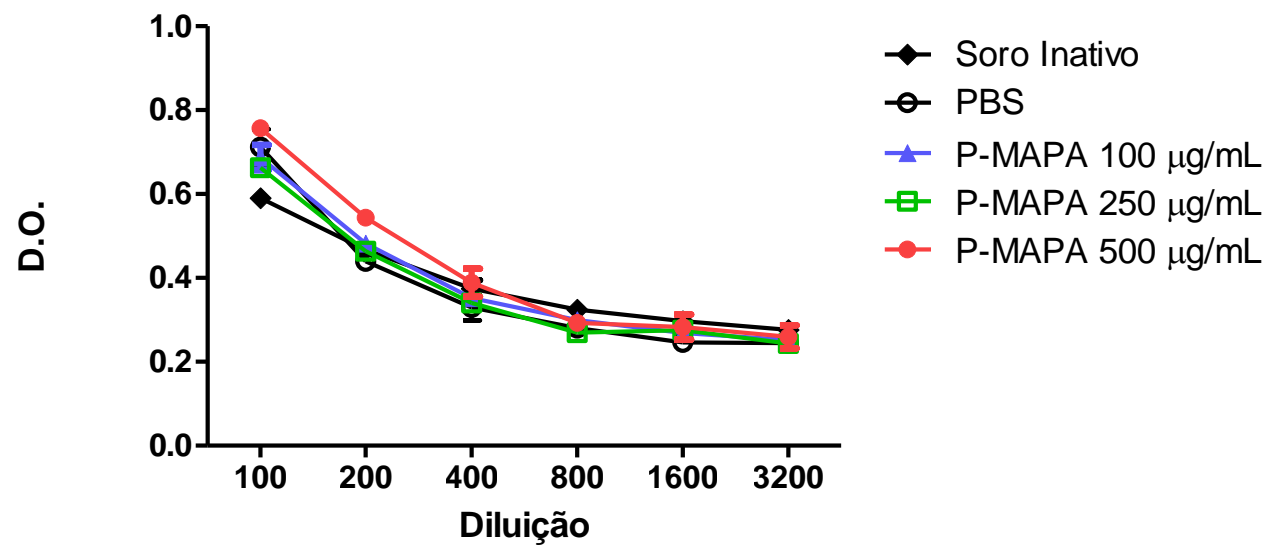

Amostras de $50 \mu \mathrm{L}$ de soro humano normal foram incubadas com $50 \mu \mathrm{L}$ de PBS ou com doses crescentes de PMAPA (para volume final de $100 \mu \mathrm{L}$ ), a $37^{\circ} \mathrm{C}$ por 30 minutos, e em seguida, diluições seriadas foram adicionadas às placas sensibilizadas com $100 \mu \mathrm{L} / \mathrm{mL}$ de manose e incubadas por 1 hora a $37^{\circ} \mathrm{C}$. Após, as placas foram lavadas e incubadas com anticorpo anti-C3 humano (1:5000), por 1 hora a $37{ }^{\circ} \mathrm{C}$. As placas foram incubadas com anticorpo conjugado com peroxidase (1:5000). A reação foi revelada por $\mathrm{OPD}$ e $\mathrm{H}_{2} \mathrm{O}_{2}$ e a leitura feita em $\lambda 492 \mathrm{~nm}$. O controle Soro Inativo corresponde ao tratamento de SHN com PBS aquecido a $56{ }^{\circ} \mathrm{C}$, por 30 minutos. Dados expressos como média \pm desvio padrão de duplicatas, representativos de 3 experimentos independentes. 


\subsection{Determinação da atividade residual da Via Alternativa do Sistema Complemento após os tratamentos experimentais em sangue total humano}

Após os tratamentos experimentais em sangue total (como descrito em 3.4.1), foi avaliada a ativação da via alternativa pela deposição de C3 presente no plasma, em placa sensibilizada com LPS de E. coli $(1 \mu \mathrm{g} / \mu \mathrm{L})$.

O P-MAPA induziu redução da ligação de C3, indicando que os tratamentos experimentais promoveram ativação da cascata do complemento, com consequente consumo de C3 (Figura 7). O tratamento do sangue com P-MAPA + LPS induziu aumento desse efeito, e de forma dose-dependente, como observado por comparação ao tratamento apenas com P-MAPA. No entanto, os tratamentos com LPS + P-MAPA induziram uma menor redução da ativação desta via. 
Figura 7 - Ativação da Via Alternativa após os tratamentos experimentais em sangue total

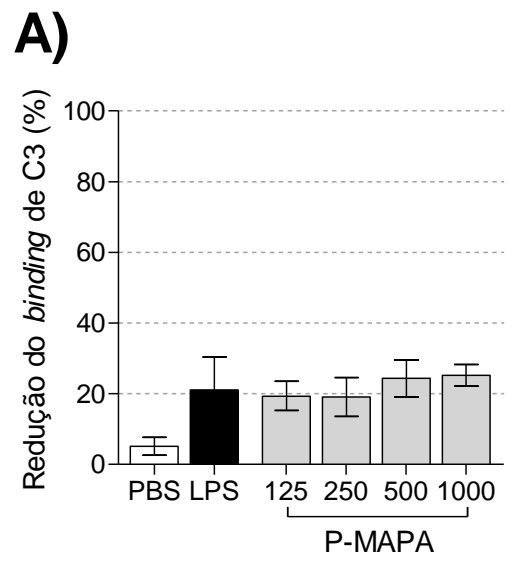

B)

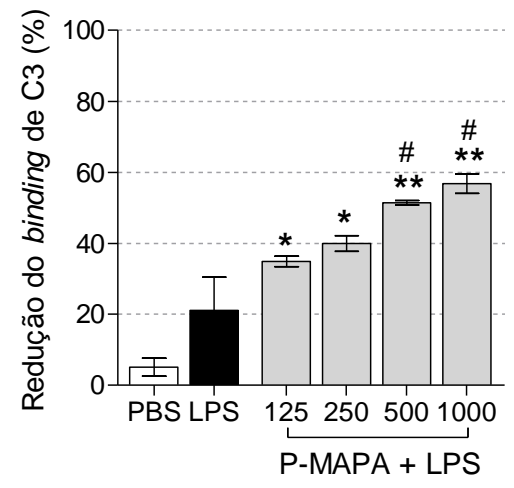

C)

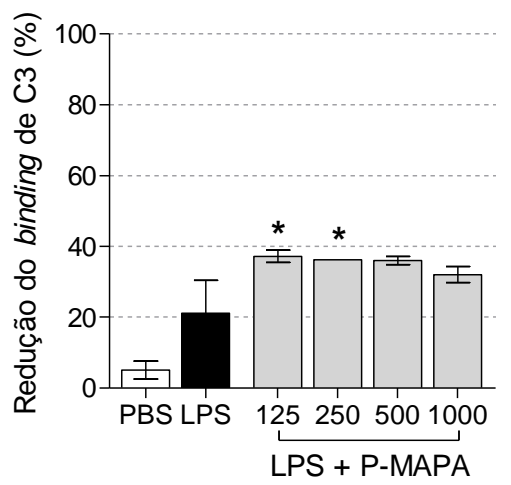

Amostras de sangue humano foram tratadas com PBS, P-MAPA $(\mu \mathrm{g} / \mathrm{mL})$ ou LPS $(100 \mu \mathrm{g} / \mathrm{mL})$, por 5 minutos e, em seguida, foi feita uma segunda adição de LPS $(100 \mu \mathrm{g} / \mathrm{mL})$ ou P-MAPA, seguido de incubação por 30 minutos a 37 ${ }^{\circ} \mathrm{C}$. Após a incubação, o plasma foi coletado e, em seguida, diluído e adicionado a placas sensibilizadas com $1 \mu \mathrm{g} / \mu \mathrm{L}$ de LPS de E. coli, para quantificação de C3 presente no plasma, por ELISA. A) Redução do binding de C3 após tratamento com concentrações crescentes de P-MAPA $(\mu \mathrm{g} / \mathrm{mL})$. B) Redução do binding de C3 após tratamento com concentrações crescentes de P-MAPA $(125,250,500$ ou $1000 \mu \mathrm{g} / \mathrm{mL})$ por 5 minutos, e posteriormente com LPS $(100 \mu \mathrm{g} / \mathrm{mL})$, por 30 minutos. C) Redução do binding de C3 após tratamento com LPS $(100 \mu \mathrm{g} / \mathrm{mL})$ por 5 minutos, e posteriormente com concentrações crescentes de P-MAPA (125, 250, 500 ou $1000 \mu \mathrm{g} / \mathrm{mL}$ ), por 30 minutos. Dados expressos como média \pm desvio padrão de duplicatas. Análise estatística realizada por ANOVA, complementada com teste de Bonferroni. $\left({ }^{*}\right) p<0,05,\left({ }^{* *}\right) p<0,01$, diferença estatística significativa em relação ao PBS. (\#) $p<0,05$ diferença estatística em relação ao LPS. 


\subsection{Dosagem de anafilatoxinas no sangue total humano}

\subsubsection{C3a}

A dosagem de C3a no plasma, obtido nas amostras de sangue tratadas como descrito em 3.4.1, revelou aumento na produção de C3a nos grupos tratados com concentrações crescentes de P-MAPA, em relação ao tratamento com PBS (Figura 8A). A combinação de PMAPA com LPS também induziu a produção de altos níveis de C3a, sendo estes, superiores ao tratamento somente com LPS (Figura 8B). No tratamento em que o LPS precedeu a adição de P-MAPA (Figura 8C), a produção de C3a ocorreu de maneira dose-dependente.

\subsection{2 $C 5 a$}

A Figura 9 mostra grande produção de C5a nas amostras de plasma obtidas após tratamento do sangue, como descrito em 3.4.1. Os tratamentos com P-MAPA foram capazes induzir a geração de C5a (Figura 9A), sendo que quando combinado ao LPS, a produção de C5a aumentou significativamente, quando comparada à produção induzida apenas por LPS (Figuras 9B e 9C). 
Figura 8 - Níveis plasmáticos de C3a/ C3a-desArg após os tratamentos experimentais
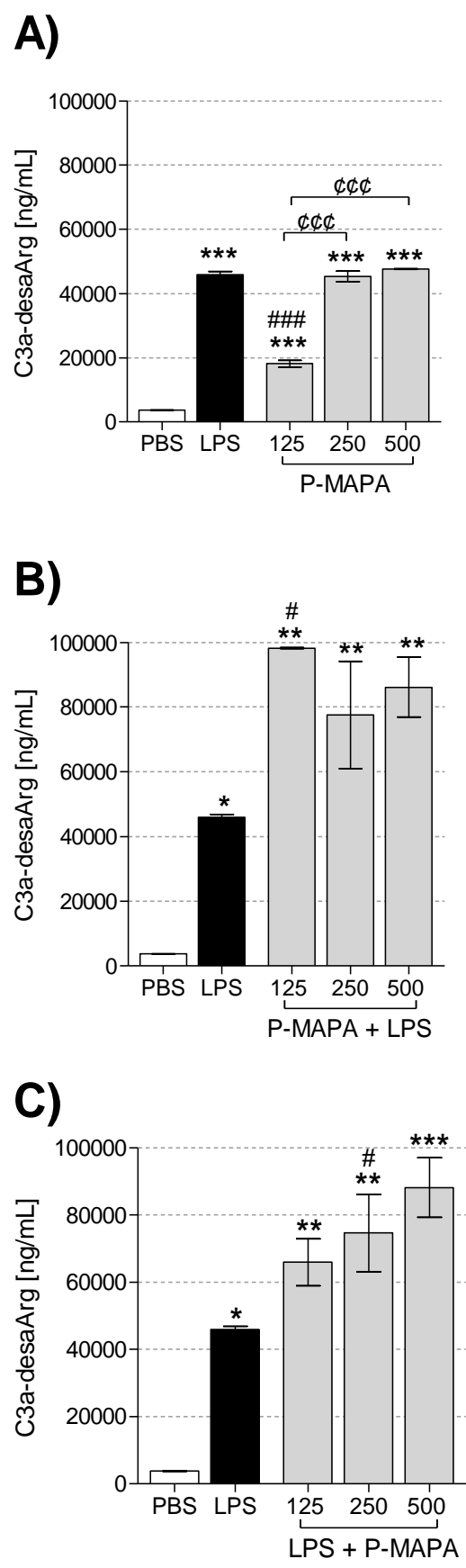

Amostras de sangue humano foram tratadas com PBS, P-MAPA $(\mu \mathrm{g} / \mathrm{mL})$ ou LPS $(100 \mu \mathrm{g} / \mathrm{mL})$, por 5 minutos, e em seguida, foi feita uma segunda adição de LPS $(100 \mu \mathrm{g} / \mathrm{mL})$ ou P-MAPA, seguido de incubação por 30 minutos a $37^{\circ} \mathrm{C}$. Após a incubação, o plasma foi coletado para dosagem de C3a por ELISA. A) Presença de C3a após tratamento com concentrações crescentes de P-MAPA $(\mu \mathrm{g} / \mathrm{mL})$. B) Presença de C3a após tratamento com concentrações crescentes de P-MAPA (125, 250, 500 ou $1000 \mu \mathrm{g} / \mathrm{mL})$ por 5 minutos, e posteriormente com LPS $(100 \mu \mathrm{g} / \mathrm{mL})$, por 30 minutos. C) Presença de C3a após tratamento com LPS $(100 \mu \mathrm{g} / \mathrm{mL})$ por 5 minutos, e posteriormente com concentrações crescentes de P-MAPA (125, 250, 500 ou $1000 \mu \mathrm{g} / \mathrm{mL})$, por 30 minutos. Dados expressos como média \pm desvio padrão de duplicatas. Análise estatística realizada por ANOVA, complementada com teste de Bonferroni. $\left({ }^{*}\right) p<0,05,\left(^{* *}\right) \quad p<0,01,\left(^{* * *}\right) \quad p<0,001$ diferença estatística significativa em relação ao PBS. (\#) $p<0,05$, (\#\#\#) $p<0,001$ diferença estatística em relação ao LPS. (çCఢ) $p<0,001$ diferença estatística significativa entre os tratamentos com P-MAPA. 
Figura 9 - Níveis plasmáticos de C5a/ C5a-desArg após os tratamentos experimentais

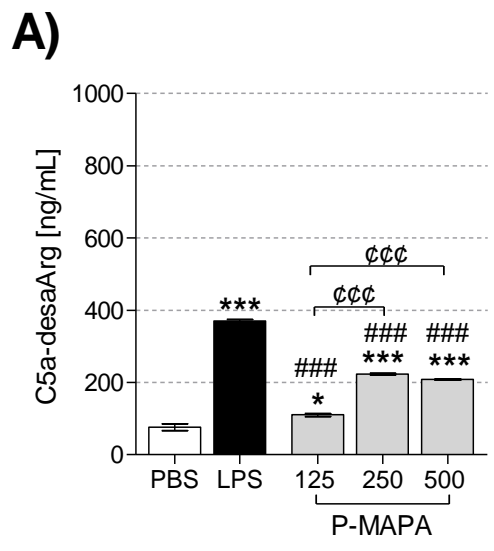

B)
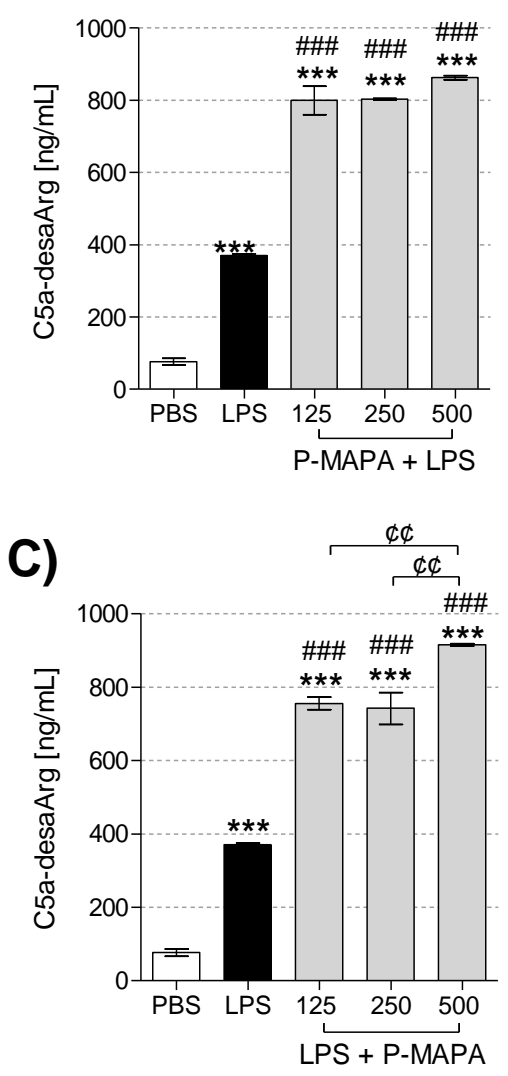

Amostras de sangue humano foram tratadas com PBS, P-MAPA $(\mu \mathrm{g} / \mathrm{mL})$ ou LPS $(100 \mu \mathrm{g} / \mathrm{mL})$, por 5 minutos, e em seguida, foi feita uma segunda adição de LPS $(100 \mu \mathrm{g} / \mathrm{mL})$ ou P-MAPA, seguido de incubação por 30 minutos a $37{ }^{\circ} \mathrm{C}$. Após a incubação, o plasma foi coletado para dosagem de C5a por ELISA. A) Presença de C5a após tratamento com concentrações crescentes de P-MAPA $(\mu \mathrm{g} / \mathrm{mL})$. B) Presença de C5a após tratamento com concentrações crescentes de P-MAPA (125, 250, 500 ou $1000 \mu \mathrm{g} / \mathrm{mL})$ por 5 minutos, e posteriormente com LPS $(100 \mu \mathrm{g} / \mathrm{mL})$, por 30 minutos. C) Presença de C5a após tratamento com LPS $(100 \mu \mathrm{g} / \mathrm{mL})$ por 5 minutos, e posteriormente com concentrações crescentes de P-MAPA (125, 250, 500 ou $1000 \mu \mathrm{g} / \mathrm{mL})$, por 30 minutos. Dados expressos como média \pm desvio padrão de duplicatas. Análise estatística realizada por ANOVA, complementada com teste de Bonferroni. $\left({ }^{*}\right) \mathrm{p}<0,05,\left({ }^{* *}\right) \mathrm{p}<0,001$ diferença estatística significativa em

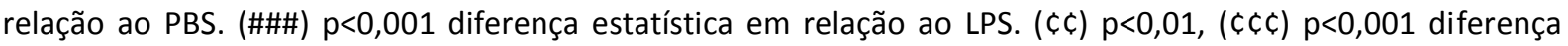
estatística significativa entre os tratamentos com P-MAPA. 


\subsection{Dosagem de SC5b9 no sangue total humano}

Para confirmar se a ativação das vias do complemento promovida pelo P-MAPA em sangue total culminava ou não com a formação do complexo terminal do complemento (TCC, SC5b-9), a presença de SC5b-9 foi determinada por ELISA, nos plasmas obtidos nos ensaios descritos em 3.4.1.

Os tratamentos experimentais mostraram que, em sangue total, o P-MAPA induz a geração de SC5b-9, e que, quando combinado com LPS, há uma maior ativação do complemento, como demonstrado pelo aumento da presença de SC5b-9 no plasma.

Figura 10 - Níveis plasmáticos de SC5b-9 após os tratamentos experimentais

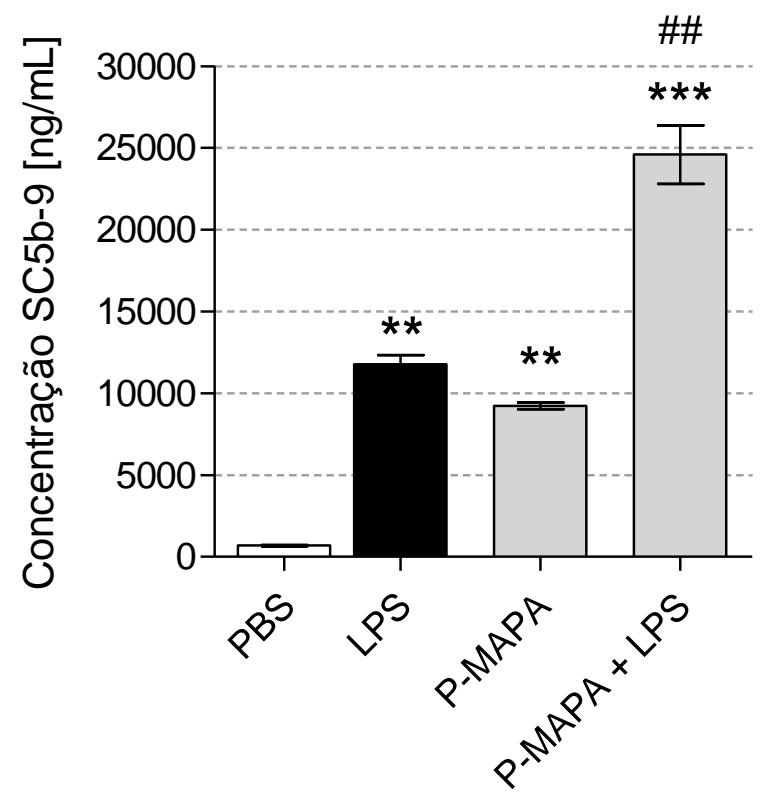

Amostras de sangue humano foram tratadas com PBS, P-MAPA $(1000 \mu \mathrm{g} / \mathrm{mL})$ ou LPS $(100 \mu \mathrm{g} / \mathrm{mL})$, por 5 minutos, e em seguida, foi feita uma segunda adição de LPS $(100 \mu \mathrm{g} / \mathrm{mL})$, seguido de incubação por 30 minutos a $37{ }^{\circ} \mathrm{C}$. Após a incubação, o plasma foi coletado para dosagem de SC5b-9 por ELISA. Dados expressos como média \pm desvio padrão de duplicatas. Análise estatística realizada por ANOVA, complementada com teste de Bonferroni. $\left({ }^{* *}\right) \mathrm{p}<0,01,\left({ }^{* *}\right) \mathrm{p}<0,001$ diferença estatística significativa em relação ao PBS. (\#\#) $\mathrm{p}<0,01$ diferença estatística em relação ao LPS. 


\subsection{Análise da expressão de marcadores de superfície em leucócitos tratados com P-MAPA e/ ou LPS}

Utilizando o software FlowJo (Versão 8.4, Tree Star Inc., Oregon, EUA), as populações de leucócitos analisadas em 3.4.4 foram separadas em gates (Apêndice A) para análise da intensidade de fluorescência em granulócitos e monócitos.

O tempo de incubação utilizado nos tratamentos e a concentração de $100 \mu \mathrm{g} / \mathrm{mL}$ de LPS, foram escolhidos com base nos dados da literatura (Brekke et al. 2007) e pela análise da cinética da expressão dos marcadores de superfície em leucócitos totais (Apêndice B). Estes ensaios iniciais mostraram que algumas moléculas, como CD11b, CD14, TLR2 e C5aR, apresentaram a expressão modulada de forma tempo dependente, após os tratamentos com P-MAPA ou LPS (Apêndice B).

Efeitos de tratamentos com controles adicionais, sobre a expressão das moléculas analisadas, podem ser encontrados no Apêndice C. O tratamento do sangue com PBS estéril, ressuspendido a partir de uma solução de ácido fórmico, sendo esta a mesma solução com a qual é preparado o P-MAPA (metodologia descrita em 3.1), não promoveu alterações na expressão das moléculas analisadas.

\subsubsection{Expressão de CD11b em leucócitos totais}

A Figura 11 mostra que o P-MAPA foi capaz de modular a expressão de CD11b na superfície de leucócitos. Quando tratadas com doses crescentes de P-MAPA, as células apresentaram aumento, de forma dose-dependente, da expressão do marcador (Figura 11A). O tratamento de P-MAPA com LPS (Figura 11B) elevou a expressão de CD11b, comparadas àquelas promovidas pelos tratamentos individuais com o composto. No entanto, quando a incubação com LPS ocorreu antes da adição de P-MAPA, houve diminuição dose-dependente da expressão desta molécula (Figura 11C), indicando que o momento da adição de P-MAPA neste sistema ex vivo promove efeitos distintos sobre o CD11b.

\subsubsection{Expressão de CD11b em diferentes populações celulares}


A Figura 12 mostra que tanto os granulócitos, como os monócitos apresentaram um padrão semelhante de expressão de $\operatorname{CD} 11 \mathrm{~b}$, mas com intensidades de fluorescência distintas. O tratamento somente com P-MAPA promoveu aumento da expressão do marcador, quando comparado ao PBS (Figura 12A). O momento da adição de P-MAPA no sistema in vitro gerou efeitos distintos: P-MAPA + LPS levou ao aumento da expressão de CD11b, não diferindo do tratamento com LPS. No entanto, o tratamento LPS + P-MAPA induziu redução da expressão do receptor de maneira dose dependente, em ambas as populações celulares (Figuras 12B e 12C, respectivamente). 
Figura 11 - Ação do P-MAPA e do LPS sobre a expressão de CD11b em leucócitos

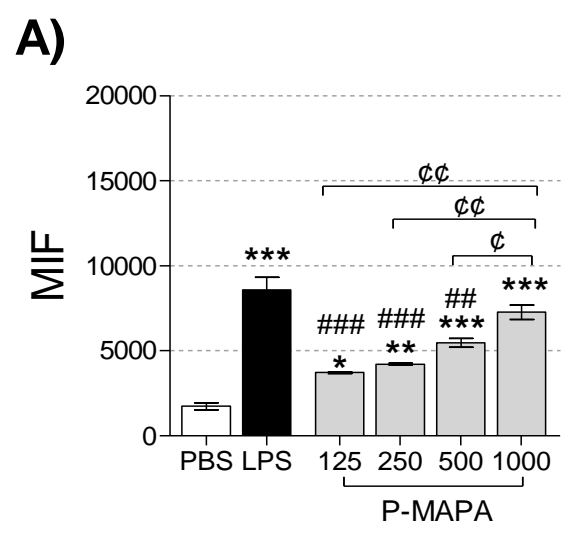

B)

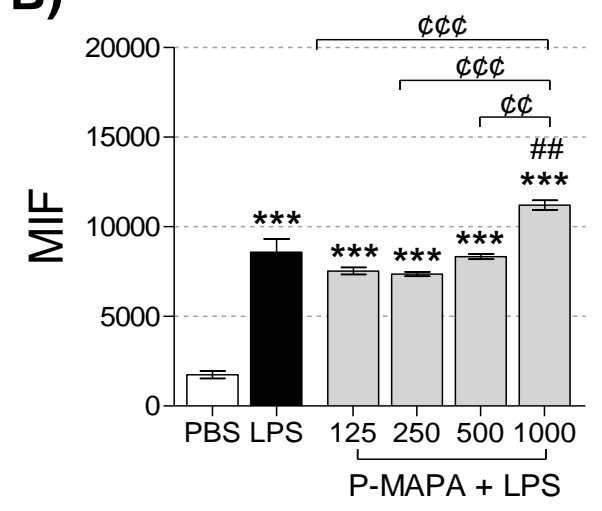

C)

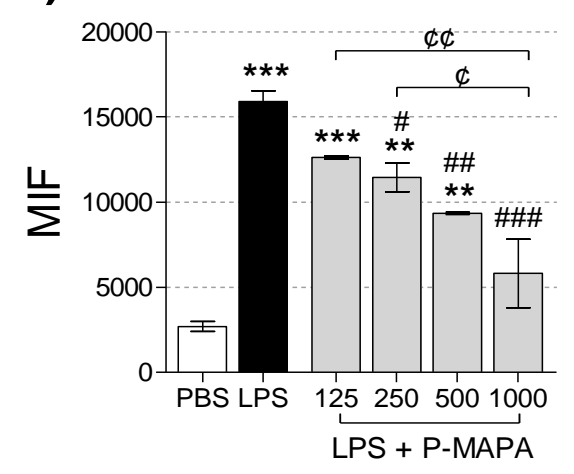

Amostras de sangue humano foram tratadas com PBS, P-MAPA $(\mu \mathrm{g} / \mathrm{mL})$ ou LPS $(100 \mu \mathrm{g} / \mathrm{mL})$, por 5 minutos, e em seguida, foi feita uma segunda adição de LPS $(100 \mu \mathrm{g} / \mathrm{mL})$ ou P-MAPA, seguido de incubação por 30 minutos a $37^{\circ} \mathrm{C}$. Após a incubação, os leucócitos foram coletados e analisados quanto à expressão de CD11b. A) Expressão de CD11b nos grupos tratados com concentrações crescentes de P-MAPA. B) Expressão de CD11b nos grupos tratados com concentrações crescentes de P-MAPA por 5 minutos e, posteriormente, incubados com LPS $(100 \mu \mathrm{g} / \mathrm{mL}$ ) por 30 minutos. C) Análise da expressão de CD11b nos grupos tratados com LPS (100 $\mu \mathrm{g} / \mathrm{mL}$ ) por 5 minutos e, posteriormente, incubados com concentrações crescentes de P-MAPA, por 30 minutos. Dados expressos como média \pm desvio padrão de duplicatas de 1 experimento representativo, entre 6 experimentos independentes. Análise estatística realizada por ANOVA, complementada com teste de Bonferroni. MIF = mediana de intensidade de fluorescência. $\left({ }^{*}\right) p<0,05,\left({ }^{* *}\right) p<0,01,\left({ }^{* * *}\right) p<0,001$ diferença estatística significativa em relação ao PBS. (\#) $p<0,05$, (\#\#) $p<0,01$, (\#\#\#) $p<0,001$ diferença estatística em relação ao LPS. (c) $p<0,05$, (ç) $p<0,01$, (çc) $p<0,001$ diferença estatística significativa entre os tipos de tratamento. 
Figura 12 - Ação do P-MAPA e do LPS sobre a expressão de CD11b em populações celulares distintas

\section{Granulócitos}

A)
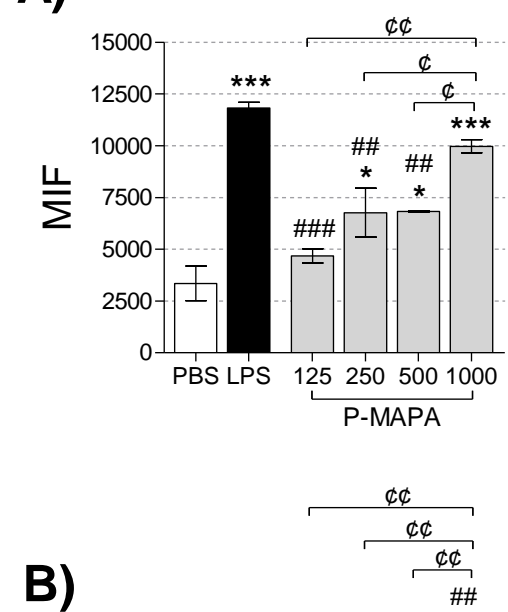

B)

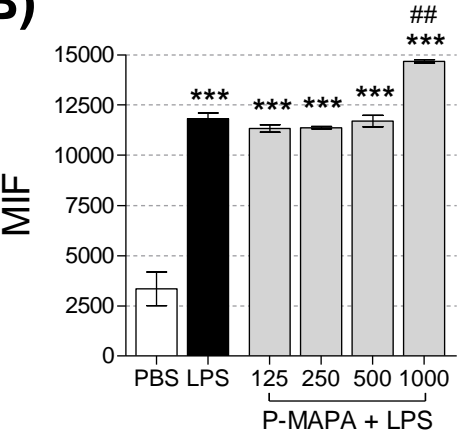

C)

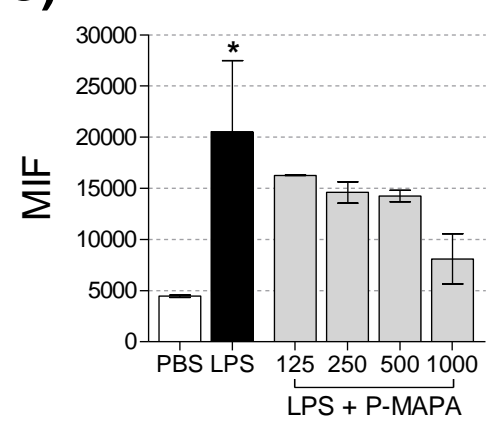

\section{Monócitos}
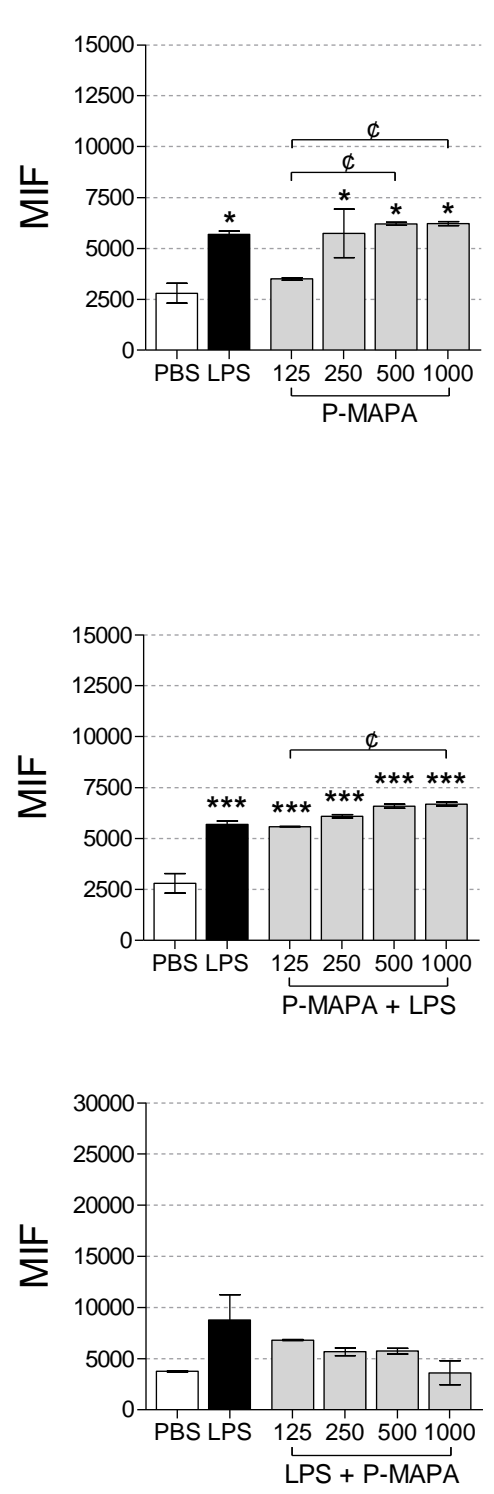

Amostras de sangue humano foram tratadas com PBS, P-MAPA ( $\mu \mathrm{g} / \mathrm{mL})$ ou LPS $(100 \mu \mathrm{g} / \mathrm{mL})$, por 5 minutos, e em seguida, foi feita uma segunda adição de LPS ou P-MAPA, seguido de incubação por 30 minutos a $37{ }^{\circ} \mathrm{C}$. Após a incubação, os leucócitos foram coletados e analisados separadamente, quanto à expressão de CD11b em dois tipos celulares. A) Expressão de CD11b após tratamento com concentrações crescentes de P-MAPA. B) Expressão de CD11b nos grupos tratados com concentrações crescentes de P-MAPA por 5 minutos e, posteriormente, incubados com LPS $(100 \mu \mathrm{g} / \mathrm{mL})$ por 30 minutos. C) Análise da expressão de CD11b nos grupos tratados com LPS $(100 \mu \mathrm{g} / \mathrm{mL})$ por 5 minutos e, posteriormente, incubados com concentrações crescentes de PMAPA, por 30 minutos. Dados expressos como média \pm desvio padrão de duplicatas de 1 experimento representativo, entre 6 experimentos independentes. Análise estatística realizada por ANOVA, complementada com teste de Bonferroni. MIF = mediana de intensidade de fluorescência. $\left(^{*}\right) p<0,05,\left({ }^{* * *}\right) p<0,001$ diferença estatística significativa em relação ao PBS. (\#\#) $p<0,01$, (\#\#\#) $p<0,001$ diferença estatística em relação ao LPS. (c) $p<0,05$, (c) $p<0,01$ diferença estatística significativa entre os tipos de tratamento. 


\subsubsection{Expressão de CD14 em leucócitos totais}

A avaliação da expressão de CD14 na superfície de leucócitos mostrou que o tratamento com $1000 \mu \mathrm{g} / \mathrm{mL}$ de P-MAPA foi capaz de induzir aumento da expressão deste marcador em células somente tratadas com P-MAPA ou com a combinação de tratamento com P-MAPA seguido de LPS (Figuras 13A, 13B), quando comparadas às células tratadas apenas com PBS $(p<0,05)$. Já o tratamento combinado de LPS, anterior à adição do P-MAPA, não foi capaz de alterar significativamente a expressão do receptor (Figura 13C).

\subsubsection{Expressão de CD14 em diferentes populações celulares}

Ao analisar as populações celulares separadamente, foi possível observar que o tratamento com P-MAPA $1000 \mu \mathrm{g} / \mathrm{mL}$, combinado ou não com LPS, levou ao aumento da expressão de CD14 por granulócitos e monócitos, em relação ao PBS (Figura 14A e 14B). Como mostrado na Figura 14C, observou-se que as populações celulares respondem de maneira distinta ao tratamento LPS + P-MAPA, tendo induzido aumento da expressão de CD14 em granulócitos e redução desta molécula na superfície de monócitos. 
Figura 13 - Ação do P-MAPA e do LPS sobre a expressão de CD14 em leucócitos

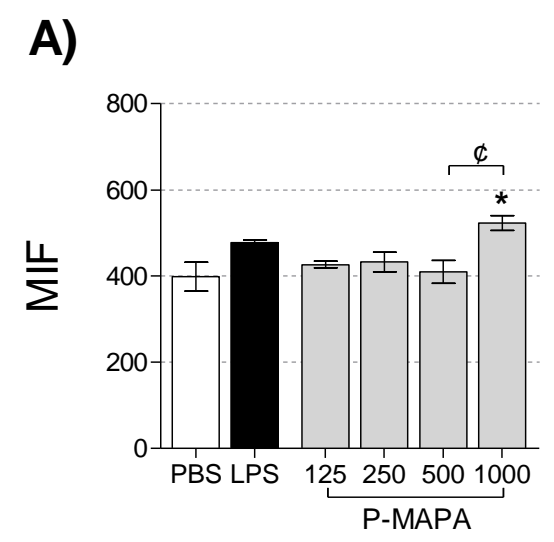

B)

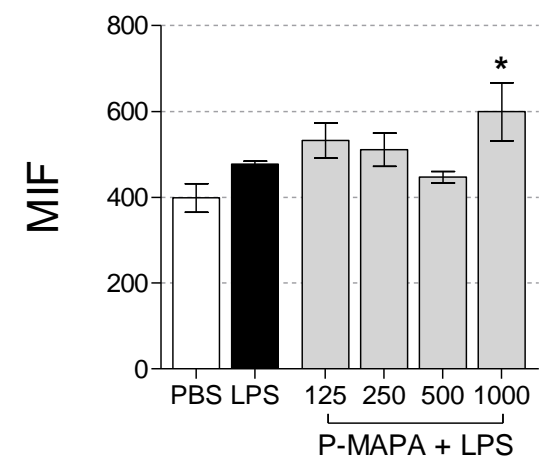

C)

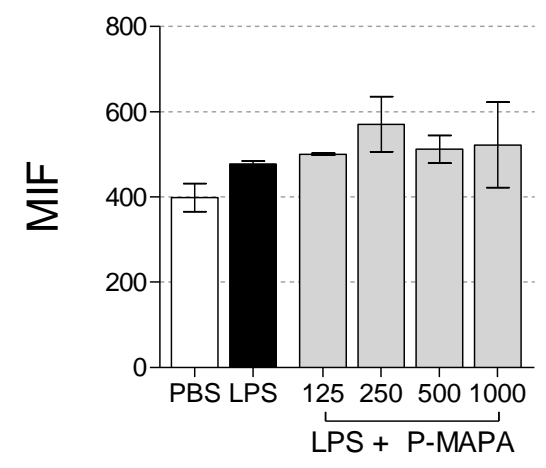

Amostras de sangue humano foram tratadas com PBS, P-MAPA $(\mu \mathrm{g} / \mathrm{mL})$ ou LPS $(100 \mu \mathrm{g} / \mathrm{mL})$, por 5 minutos, e em seguida, foi feita uma segunda adição de LPS $(100 \mu \mathrm{g} / \mathrm{mL})$ ou P-MAPA, seguido de incubação por 30 minutos a $37^{\circ} \mathrm{C}$. Após a incubação, os leucócitos foram coletados e analisados quanto à expressão de CD14. A) Expressão de CD14 nos grupos tratados com concentrações crescentes de P-MAPA. B) Expressão de CD14 nos grupos tratados com concentrações crescentes de P-MAPA por 5 minutos e, posteriormente, incubados com LPS $(100 \mu \mathrm{g} / \mathrm{mL})$ por 30 minutos. C) Análise da expressão de CD14 nos grupos tratados com LPS $(100 \mu \mathrm{g} / \mathrm{mL})$ por 5 minutos e, posteriormente, incubados com concentrações crescentes de P-MAPA, por 30 minutos. Dados expressos como média \pm desvio padrão de duplicatas de 1 experimento representativo, entre 6 experimentos independentes. Análise estatística realizada por ANOVA, complementada com teste de Bonferroni. MIF = mediana de intensidade de fluorescência. $\left({ }^{*}\right) p<0,05$ diferença estatística significativa em relação ao PBS. (c) $p<0,05$ diferença estatística significativa entre os tipos de tratamento. 
Figura 14 - Ação do P-MAPA e do LPS sobre a expressão de CD14 em populações celulares distintas

Granulócitos

A)

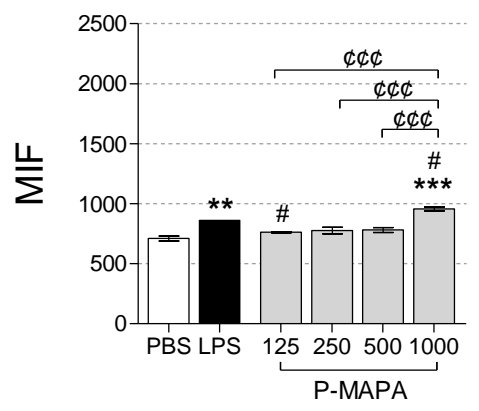

B)

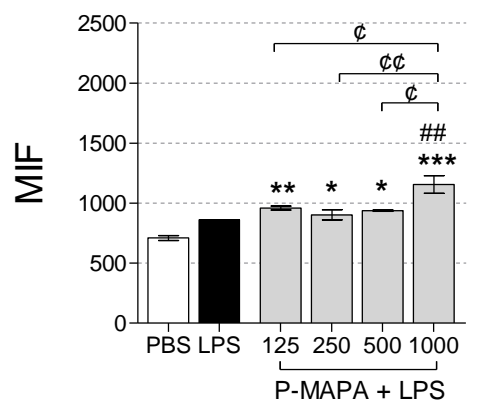

C)

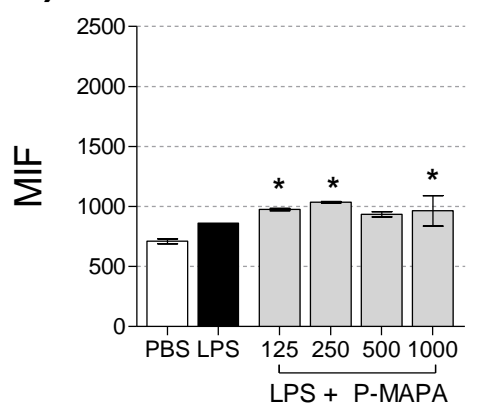

Monócitos
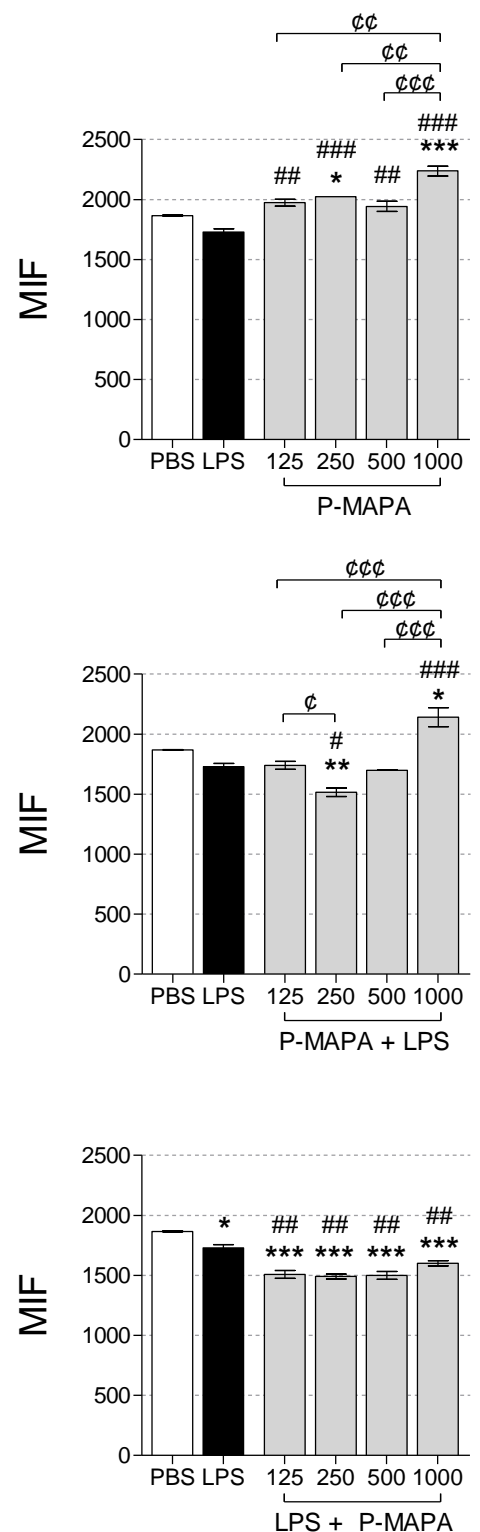

Amostras de sangue humano foram tratadas com PBS, P-MAPA ( $\mu \mathrm{g} / \mathrm{mL})$ ou LPS $(100 \mu \mathrm{g} / \mathrm{mL})$, por 5 minutos, e em seguida, foi feita uma segunda adição de LPS $(100 \mu \mathrm{g} / \mathrm{mL})$ ou P-MAPA, seguido de incubação por 30 minutos a $37^{\circ} \mathrm{C}$. Após a incubação, os leucócitos foram coletados e analisados separadamente, quanto à expressão de CD14 em dois tipos celulares. A) Expressão de CD14 após tratamento com concentrações crescentes de P-MAPA. B) Expressão de CD14 nos grupos tratados com concentrações crescentes de P-MAPA por 5 minutos e, posteriormente, incubados com LPS $(100 \mu \mathrm{g} / \mathrm{mL})$ por 30 minutos. C) Análise da expressão de CD14 nos grupos tratados com LPS $(100 \mu \mathrm{g} / \mathrm{mL})$ por 5 minutos e, posteriormente, incubados com concentrações crescentes de P-MAPA, por 30 minutos. Dados expressos como média \pm desvio padrão de duplicatas de 1 experimento representativo, entre 6 experimentos independentes. Análise estatística realizada por ANOVA, complementada com teste de Bonferroni. MIF = mediana de intensidade de fluorescência. $\left({ }^{*}\right)$ $p<0,05,\left({ }^{*}\right) p<0,01,\left(*^{* *}\right) p<0,001$ diferença estatística significativa em relação ao PBS. (\#) $p<0,05$, (\#\#) $p<0,01$,

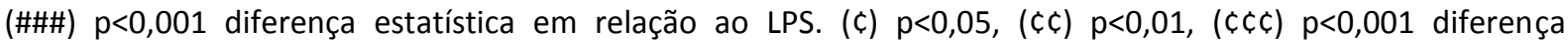
estatística significativa entre os tipos de tratamento. 


\subsubsection{Expressão de TLR2 em leucócitos totais}

A expressão de TLR2 nos leucócitos não sofreu modulação após o tratamento com LPS ou P-MAPA, como mostrado pela Figura 15A. O tratamento inicial com $125 \mu \mathrm{g} / \mathrm{mL}$ PMAPA, seguido de LPS (Figura 15B), induziu uma diminuição na expressão deste marcador em relação aos tratamentos controle. De maneira semelhante, o tratamento inicial com LPS, seguido de $1000 \mu \mathrm{g} / \mathrm{mL}$ P-MAPA promoveu redução da expressão de TLR2, porém, tal resultado não diferiu estatisticamente dos demais tratamentos experimentais (Figura 15C).

\subsubsection{Expressão de TLR2 em diferentes populações celulares}

Como apresentado na Figura 16A, doses crescentes de P-MAPA não induziram alterações significativas na expressão de TLR2 em granulócitos e monócitos. A adição de LPS ao tratamento com P-MAPA (Figura 16B) promoveu redução da presença do receptor em ambas as populações. Ainda, as duas populações celulares sofreram regulação negativa da expressão de TLR2, após o tratamento de LPS + P-MAPA $1000 \mu \mathrm{g} / \mathrm{mL}$ (Figura 16C). 
Figura 15 - Ação do P-MAPA e do LPS sobre a expressão de TLR2 na superfície de leucócitos

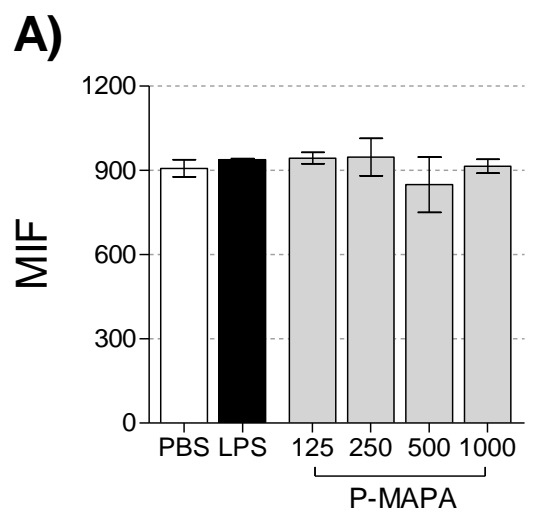

B)

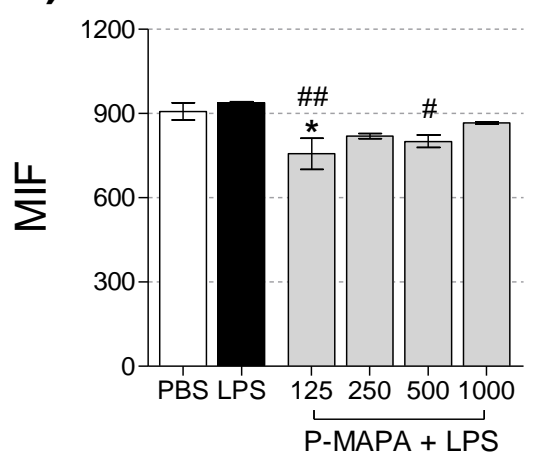

C)

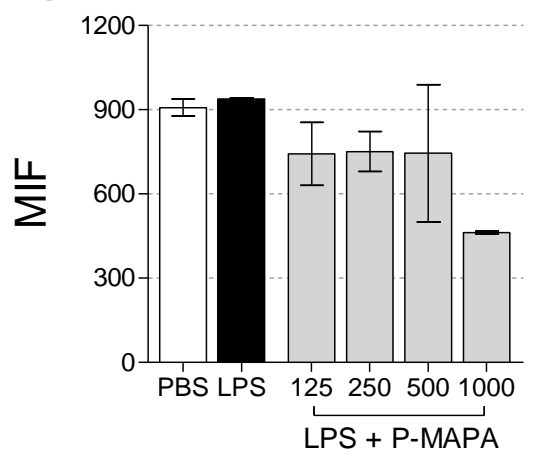

Amostras de sangue humano foram tratadas com PBS, P-MAPA $(\mu \mathrm{g} / \mathrm{mL})$ ou LPS $(100 \mu \mathrm{g} / \mathrm{mL})$, por 5 minutos, e em seguida, foi feita uma segunda adição de LPS $(100 \mu \mathrm{g} / \mathrm{mL})$ ou P-MAPA, seguido de incubação por 30 minutos a $37^{\circ} \mathrm{C}$. Após a incubação, os leucócitos foram coletados e analisados quanto à expressão de TLR2. A) Expressão de TLR2 nos grupos tratados com concentrações crescentes de P-MAPA. B) Expressão de TLR2 nos grupos tratados com concentrações crescentes de P-MAPA por 5 minutos e, posteriormente, incubados com LPS $(100 \mu \mathrm{g} / \mathrm{mL})$ por 30 minutos. C) Análise da expressão de TLR2 nos grupos tratados com LPS $(100 \mu \mathrm{g} / \mathrm{mL})$ por 5 minutos e, posteriormente, incubados com concentrações crescentes de P-MAPA, por 30 minutos. Dados expressos como média \pm desvio padrão de duplicatas de 1 experimento representativo, entre 6 experimentos independentes. Análise estatística realizada por ANOVA, complementada com teste de Bonferroni. MIF = mediana de intensidade de fluorescência. $\left({ }^{*}\right) p<0,05$ diferença estatística significativa em relação ao PBS. (\#) $p<0,05$, (\#\#) $p<0,01$ diferença estatística em relação ao LPS. 
Figura 16 - Ação do P-MAPA e do LPS sobre a expressão de TLR2 em populações celulares distintas

Granulócitos

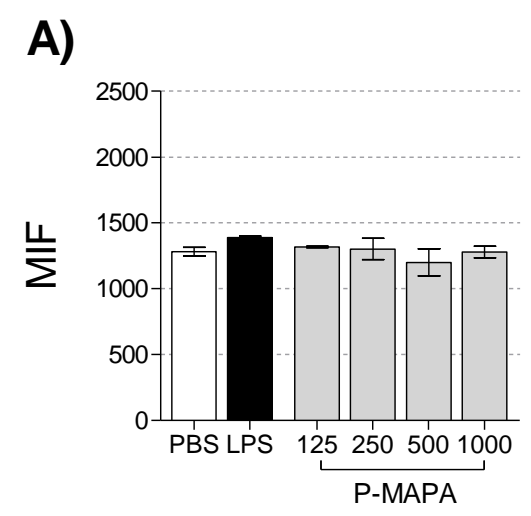

B)

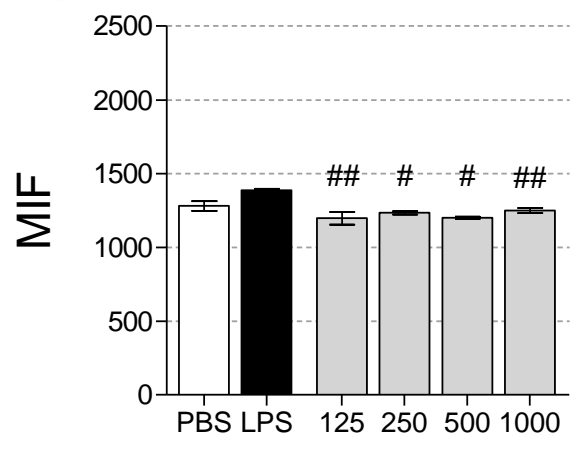

C)

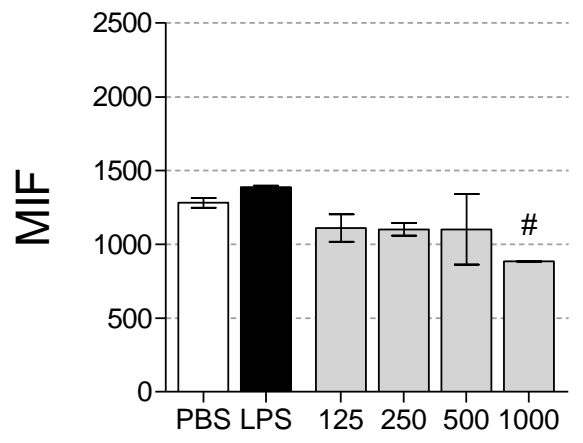

Monócitos
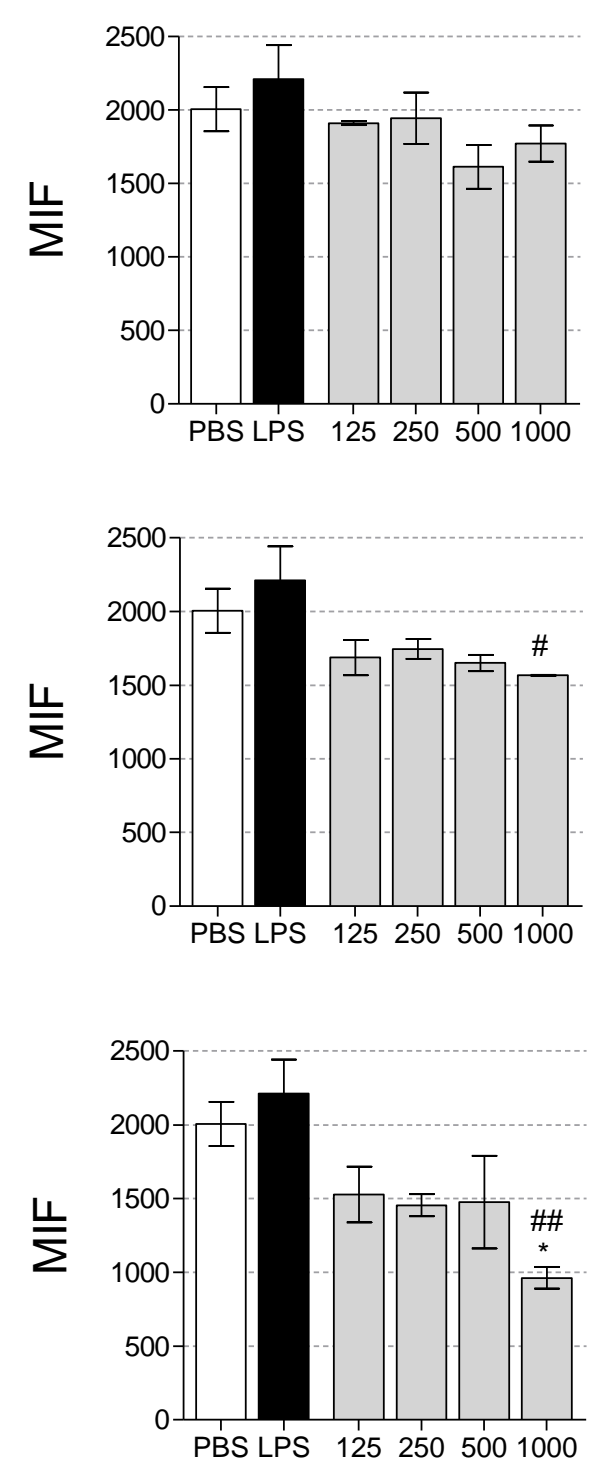

Amostras de sangue humano foram tratadas com PBS, P-MAPA $(\mu \mathrm{g} / \mathrm{mL})$ ou LPS $(100 \mu \mathrm{g} / \mathrm{mL})$, por 5 minutos, e em seguida, foi feita uma segunda adição de LPS $(100 \mu \mathrm{g} / \mathrm{mL})$ ou P-MAPA, seguido de incubação por 30 minutos a $37{ }^{\circ} \mathrm{C}$. Após a incubação, os leucócitos foram coletados e analisados separadamente, quanto à expressão de TLR2 em dois tipos celulares. A) Expressão de TLR2 após tratamento com concentrações crescentes de P-MAPA. B) Expressão de TLR2 nos grupos tratados com concentrações crescentes de P-MAPA por 5 minutos e, posteriormente, incubados com LPS $(100 \mu \mathrm{g} / \mathrm{mL})$ por 30 minutos. C) Análise da expressão de TLR2 nos grupos tratados com LPS $(100 \mu \mathrm{g} / \mathrm{mL})$ por 5 minutos e, posteriormente, incubados com concentrações crescentes de P-MAPA, por 30 minutos. Dados expressos como média \pm desvio padrão de duplicatas de 1 experimento representativo, entre 6 experimentos independentes. Análise estatística realizada por ANOVA, complementada com teste de Bonferroni. MIF = mediana de intensidade de fluorescência. $\left({ }^{*}\right) p<0,05$ diferença estatística significativa em relação ao PBS. (\#) p<0,05, (\#\#) p<0,01 diferença estatística em relação ao LPS. 


\subsubsection{Expressão de TLR4 em leucócitos totais}

Assim como para a expressão de TLR2, a expressão de TLR4 não foi modulada pelo tratamento com P-MAPA (Figura 17A). No tratamento das células com P-MAPA, anterior ao estímulo com LPS, a dose de $125 \mu \mathrm{g} / \mathrm{mL}$ de P-MAPA levou à redução significativa da expressão de TLR4 em relação ao controle negativo, PBS (Figura 17B). No entanto, as demais doses induziram aumento, dose-dependente, na expressão do receptor na superfície dos leucócitos. Já para o tratamento com LPS, seguido de P-MAPA (Figura 17C), houve redução, dose-dependente, da expressão do marcador, indicando que o momento do tratamento com P-MAPA interfere na expressão de TLR4, neste modelo experimental.

\subsubsection{Expressão de TLR4 em diferentes populações celulares}

A expressão de TLR4 na superfície de monócitos foi reduzida pelo tratamento com PMAPA ou em combinações com LPS, quando comparada a do tratamento com PBS (Figura 18). Na população de granulócitos, uma significativa modulação negativa de TLR4 foi observada na combinação LPS + P-MAPA (Figura 18C). 
Figura 17 - Ação do P-MAPA e do LPS sobre a expressão de TLR4 na superfície de leucócitos

A)

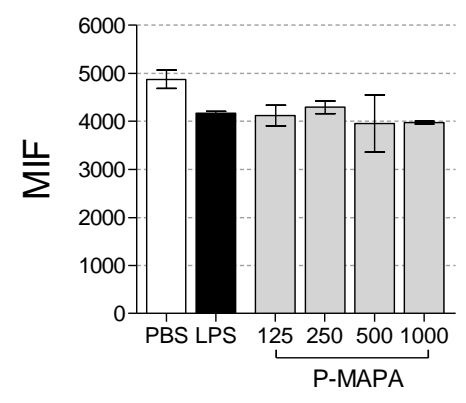

B)

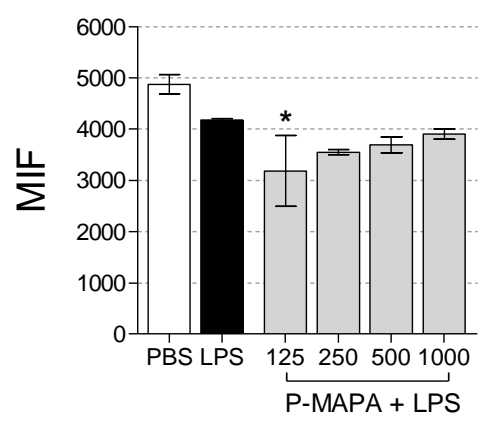

C)

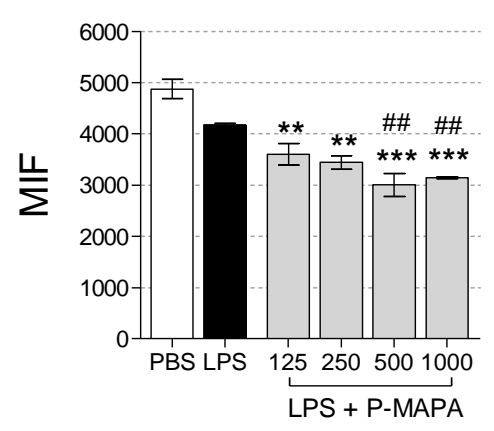

Amostras de sangue humano foram tratadas com PBS, P-MAPA ( $\mu \mathrm{g} / \mathrm{mL})$ ou LPS $(100 \mu \mathrm{g} / \mathrm{mL})$, por 5 minutos, e em seguida, foi feita uma segunda adição de LPS $(100 \mu \mathrm{g} / \mathrm{mL})$ ou P-MAPA, seguido de incubação por 30 minutos a $37^{\circ} \mathrm{C}$. Após a incubação, os leucócitos foram coletados e analisados quanto à expressão de TLR4. A) Expressão de TLR4 nos grupos tratados com concentrações crescentes de P-MAPA. B) Expressão de TLR4 nos grupos tratados com concentrações crescentes de P-MAPA por 5 minutos e, posteriormente, incubados com LPS $(100 \mu \mathrm{g} / \mathrm{mL})$ por 30 minutos. C) Análise da expressão de TLR4 nos grupos tratados com LPS $(100 \mu \mathrm{g} / \mathrm{mL})$ por 5 minutos e, posteriormente, incubados com concentrações crescentes de P-MAPA, por 30 minutos. Dados expressos como média \pm desvio padrão de duplicatas de 1 experimento representativo, entre 6 experimentos independentes. Análise estatística realizada por ANOVA, complementada com teste de Bonferroni. MIF = mediana de intensidade de fluorescência. $\left(^{*}\right) \mathrm{p}<0,05,\left({ }^{* *}\right) \mathrm{p}<0,01,\left({ }^{* * *}\right) \mathrm{p}<0,001$ diferença estatística significativa em relação ao PBS. (\#\#) $p<0,01$ diferença estatística em relação ao LPS. 
Figura 18 - Ação do P-MAPA e do LPS sobre a expressão de TLR4 em populações celulares distintas

Granulócitos

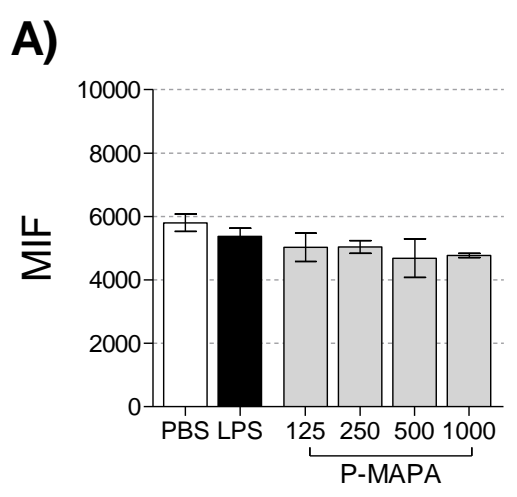

B)

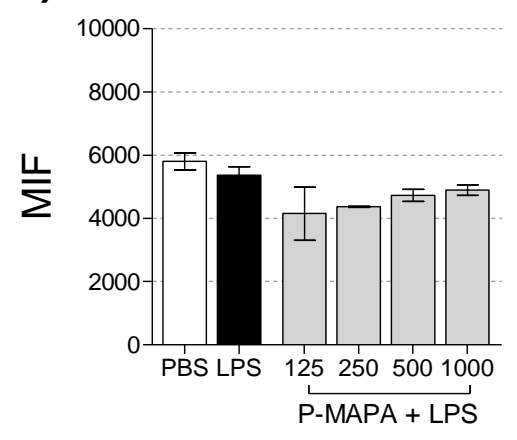

C)

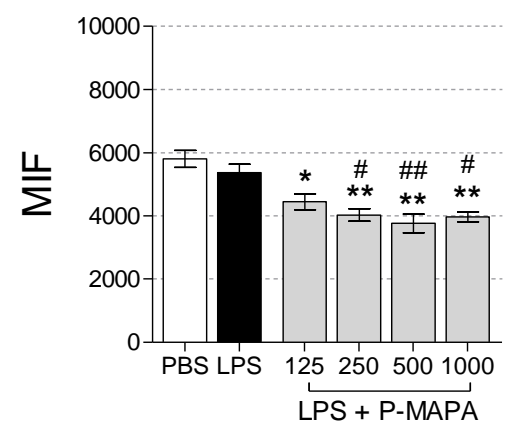

Monócitos
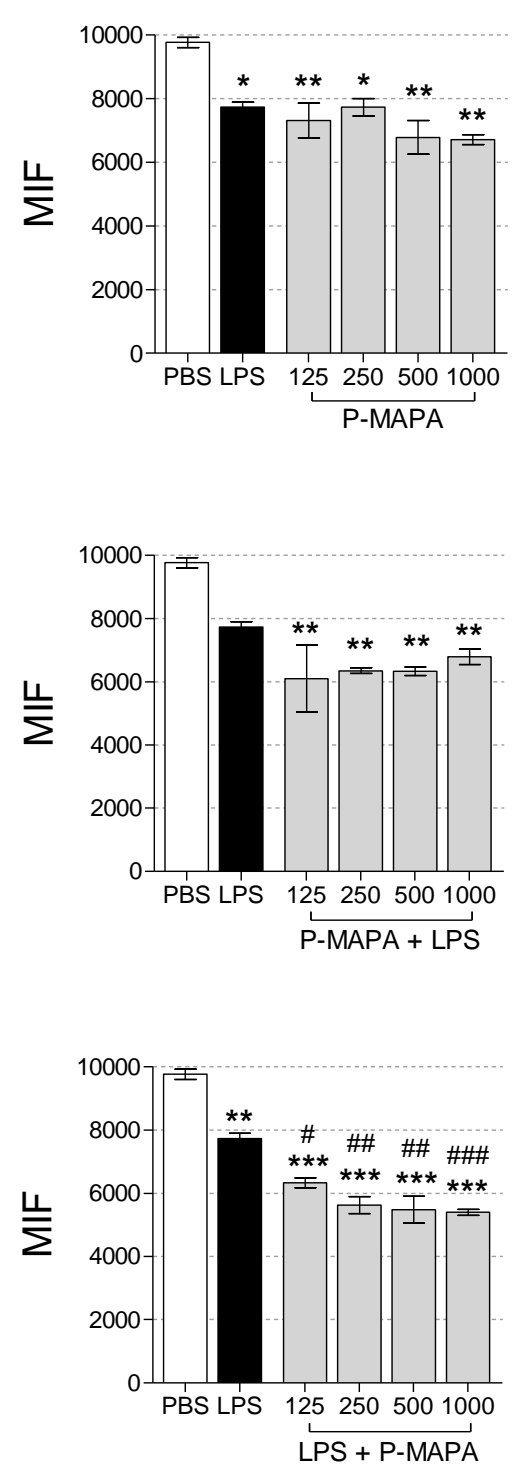

Amostras de sangue humano foram tratadas com PBS, P-MAPA ( $\mu \mathrm{g} / \mathrm{mL})$ ou LPS, por 5 minutos, e em seguida, foi feita uma segunda adição de LPS $(100 \mu \mathrm{g} / \mathrm{mL})$ ou P-MAPA, seguido de incubação por 30 minutos a $37^{\circ} \mathrm{C}$. Após a incubação, os leucócitos foram coletados e analisados separadamente, quanto à expressão de TLR4 em dois tipos celulares. A) Expressão de TLR4 após tratamento com concentrações crescentes de P-MAPA. B) Expressão de TLR4 nos grupos tratados com concentrações crescentes de P-MAPA por 5 minutos e, posteriormente, incubados com LPS por 30 minutos. C) Análise da expressão de TLR4 nos grupos tratados com LPS por 5 minutos e, posteriormente, incubados com concentrações crescentes de P-MAPA, por 30 minutos. Dados expressos como média \pm desvio padrão de duplicatas de 1 experimento representativo, entre 6 experimentos independentes. Análise estatística realizada por ANOVA, complementada com teste de Bonferroni. MIF = mediana de intensidade de fluorescência. $\left({ }^{*}\right) p<0,05,\left({ }^{* *}\right) p<0,01,\left({ }^{* * *}\right) p<0,001$ diferença estatística significativa em relação ao PBS. (\#) $p<0,05$, (\#\#) $p<0,01$, (\#\#\#) $p<0,001$ diferença estatística em relação ao LPS. 


\subsubsection{Expressão de C3aR em leucócitos totais}

A análise da expressão do receptor de C3aR em leucócitos mostrou que o tratamento somente com P-MAPA ou LPS não modulou de maneira significativa a expressão do receptor (Figura 19A). No entanto, os tratamentos com P-MAPA combinado com LPS, reduziram a expressão do marcador (Figura 19B e 19C).

\subsubsection{Expressão de C3aR em diferentes populações celulares}

A separação das populações de leucócitos mostrou que a expressão de C3aR, após os tratamentos experimentais, diferiu em granulócitos e monócitos. Doses crescentes de PMAPA promoveram aumento de C3aR na superfície de granulócitos (Figura 20A), assim como o tratamento simultâneo com LPS (Figura 20B). Ainda em granulócitos, a combinação LPS + P-MAPA levou à diminuição deste receptor na superfície celular em relação ao controle LPS (Figura 20C). Em monócitos, a expressão de C3aR apresentou grande variação, mas os resultados sugerem que o tratamento com concentrações altas de P-MAPA, sozinho ou combinado com LPS, poderia levar à diminuição de C3aR na superfície celular. 
Figura 19 - Ação do P-MAPA e do LPS sobre a expressão de C3aR em leucócitos

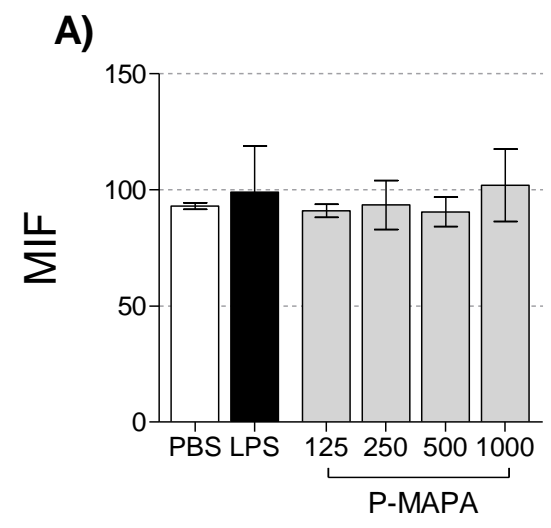

B)

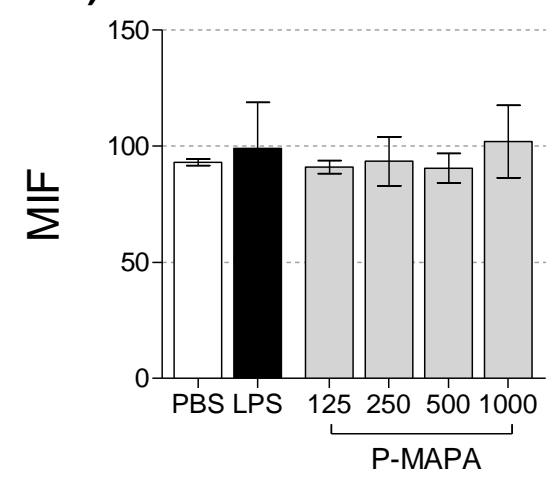

C)

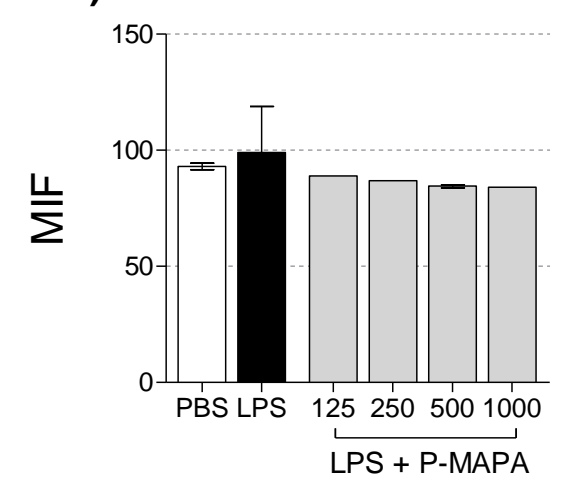

Amostras de sangue humano foram tratadas com PBS, P-MAPA $(\mu \mathrm{g} / \mathrm{mL})$ ou LPS $(100 \mu \mathrm{g} / \mathrm{mL})$, por 5 minutos, e em seguida, foi feita uma segunda adição de LPS ou P-MAPA, seguido de incubação por 30 minutos a $37^{\circ} \mathrm{C}$. Após a incubação, os leucócitos foram coletados e analisados quanto à expressão de C3aR. A) Expressão de C3aR nos grupos tratados com concentrações crescentes de P-MAPA. B) Expressão de C3aR nos grupos tratados com concentrações crescentes de P-MAPA por 5 minutos e, posteriormente, incubados com LPS (100 $\mu \mathrm{g} / \mathrm{mL})$ por 30 minutos. C) Análise da expressão de C3aR nos grupos tratados com LPS (100 $\mu \mathrm{g} / \mathrm{mL})$ por 5 minutos e, posteriormente, incubados com concentrações crescentes de P-MAPA, por 30 minutos. Dados expressos como média \pm desvio padrão de duplicatas de 1 experimento representativo, entre 6 experimentos independentes. Análise estatística realizada por ANOVA, complementada com teste de Bonferroni. MIF = mediana de intensidade de fluorescência. 
Figura 20 - Ação do P-MAPA e do LPS sobre a expressão de C3aR em populações celulares distintas

Granulócitos

A)

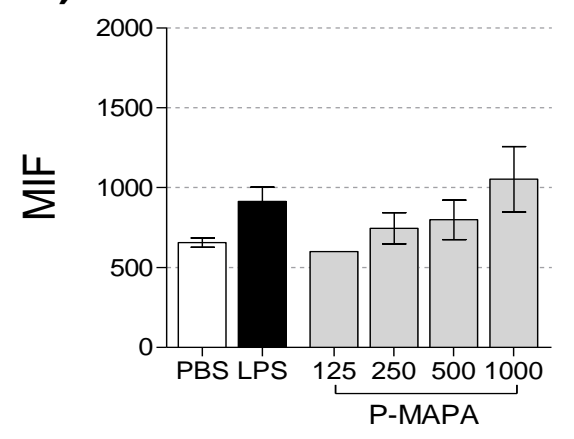

B)

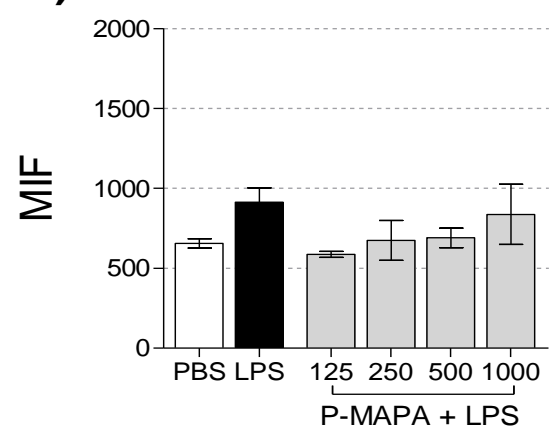

C)

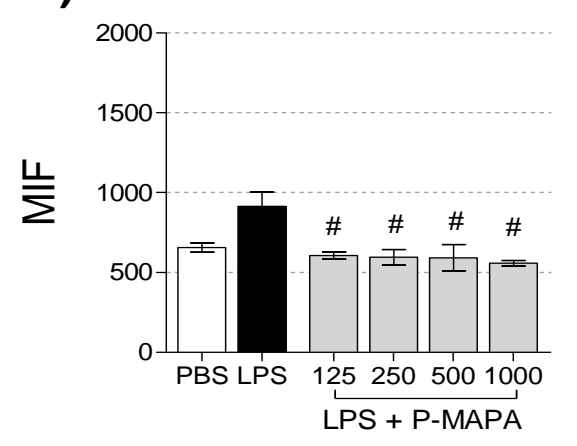

Monócitos
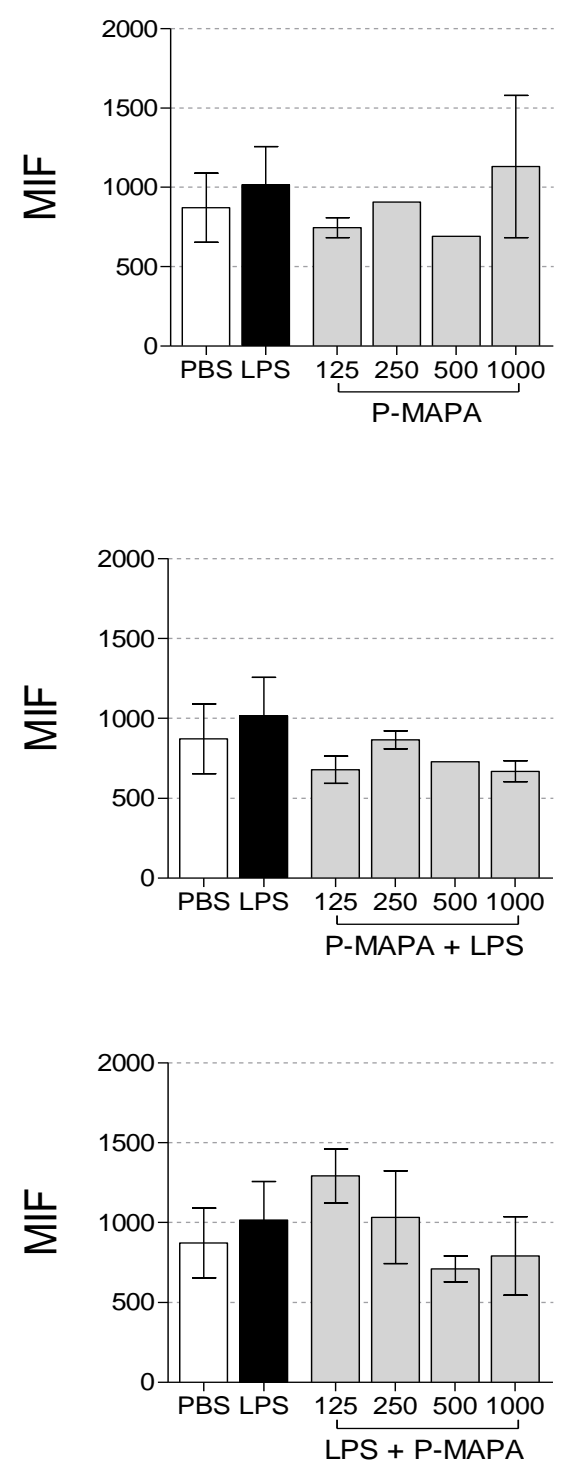

Amostras de sangue humano foram tratadas com PBS, P-MAPA $(\mu \mathrm{g} / \mathrm{mL})$ ou LPS $(100 \mu \mathrm{g} / \mathrm{mL})$, por 5 minutos, e em seguida, foi feita uma segunda adição de LPS ou P-MAPA, seguido de incubação por 30 minutos a $37^{\circ} \mathrm{C}$. Após a incubação, os leucócitos foram coletados e analisados separadamente, quanto à expressão de C3aR em dois tipos celulares. A) Expressão de C3aR após tratamento com concentrações crescentes de P-MAPA. B) Expressão de C3aR nos grupos tratados com concentrações crescentes de P-MAPA por 5 minutos e, posteriormente incubados com LPS $(100 \mu \mathrm{g} / \mathrm{mL})$ por 30 minutos. C) Análise da expressão de C3aR nos grupos tratados com LPS $(100 \mu \mathrm{g} / \mathrm{mL})$ por 5 minutos e, posteriormente, incubados com concentrações crescentes de PMAPA, por 30 minutos. Dados expressos como média \pm desvio padrão de duplicatas de 1 experimento representativo, entre 6 experimentos independentes. Análise estatística realizada por ANOVA, complementada com teste de Bonferroni. MIF = mediana de intensidade de fluorescência. (\#) $p<0,0$ diferença estatística em relação ao LPS. 


\subsubsection{Expressão de C5aR em leucócitos totais}

A análise da expressão de C5aR revelou diminuição, dose dependente, da expressão do receptor nas células tratadas apenas com P-MAPA (Figura 21A). A combinação de PMAPA com LPS também levou à diminuição da expressão do marcador, quando comparadas ao tratamento com PBS (Figura 21B), porém de maneira mais acentuada do que as observadas no tratamento apenas com P-MAPA. A adição de LPS anterior ao P-MAPA (Figura 21C), também induziu uma redução da expressão de C5aR em relação ao tratamento com PBS.

\subsubsection{Expressão de C5aR em diferentes populações celulares}

A expressão de C5aR apresentou padrões similares em ambas as populações celulares (Figura 22). P-MAPA, sozinho e em ambas as combinações com LPS, promoveu diminuição da expressão do receptor de maneira dose dependente, em relação aos tratamentos controle, assim como observado nos leucócitos totais, mostrado na Figura 22. 
Figura 21 - Ação do P-MAPA e do LPS sobre a expressão de C5aR em leucócitos

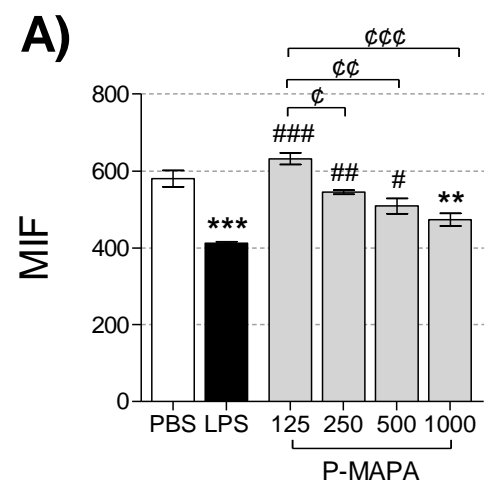

B)

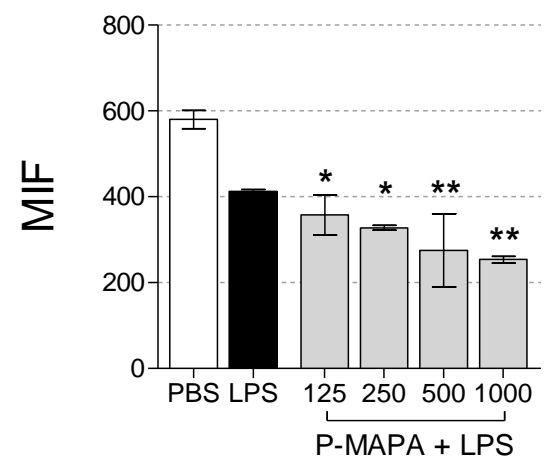

C)

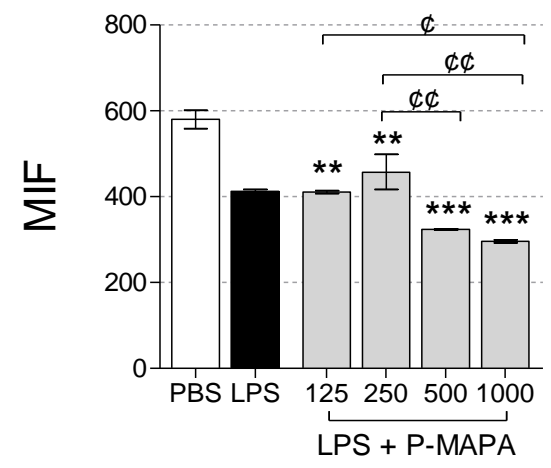

Amostras de sangue humano foram tratadas com PBS, P-MAPA $(\mu \mathrm{g} / \mathrm{mL})$ ou LPS $(100 \mu \mathrm{g} / \mathrm{mL})$, por 5 minutos, e em seguida, foi feita uma segunda adição de LPS ou P-MAPA, seguido de incubação por 30 minutos a $37^{\circ} \mathrm{C}$. Após a incubação, os leucócitos foram coletados e analisados quanto à expressão de C5aR. A) Expressão de C5aR nos grupos tratados com concentrações crescentes de P-MAPA. B) Expressão de C5aR nos grupos tratados com concentrações crescentes de P-MAPA por 5 minutos e, posteriormente, incubados com LPS (100 $\mu \mathrm{g} / \mathrm{mL}$ ) por 30 minutos. C) Análise da expressão de C5aR nos grupos tratados com LPS (100 $\mu \mathrm{g} / \mathrm{mL})$ por 5 minutos e, posteriormente, incubados com concentrações crescentes de P-MAPA, por 30 minutos. Dados expressos como média \pm desvio padrão de duplicatas de 1 experimento representativo, entre 6 experimentos independentes. Análise estatística realizada por ANOVA, complementada com teste de Bonferroni. MIF = mediana de intensidade de fluorescência. $\left(^{*}\right) \mathrm{p}<0,05,\left(^{* *}\right) \mathrm{p}<0,01,\left(^{* * *}\right) \mathrm{p}<0,001$ diferença estatística significativa em relação ao PBS. (\#) $p<0,05$, (\#\#) $p<0,01$, (\#\#\#) $p<0,001$ diferença estatística em relação ao LPS. (c) $p<0,05$, (ç) $p<0,01,(\zeta \zeta \zeta) p<0,001$ diferença estatística significativa entre os tratamentos com P-MAPA. 
Figura 22 - Ação do P-MAPA e do LPS sobre a expressão de C5aR em populações celulares distintas

Granulócitos

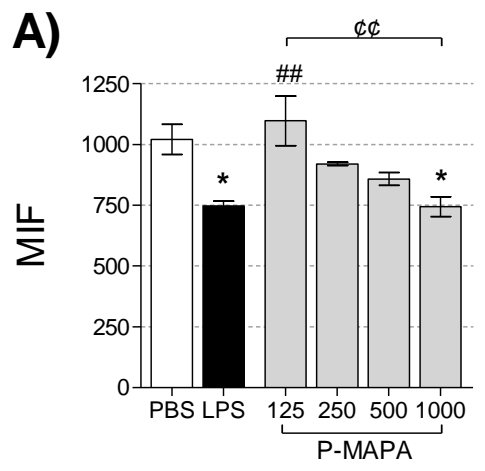

B)

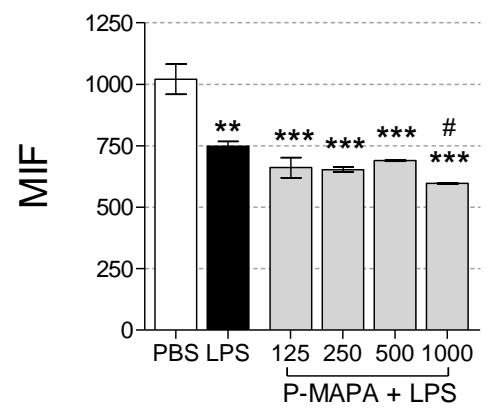

C)

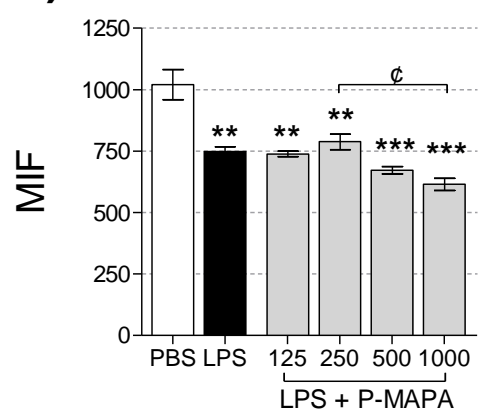

Monócitos
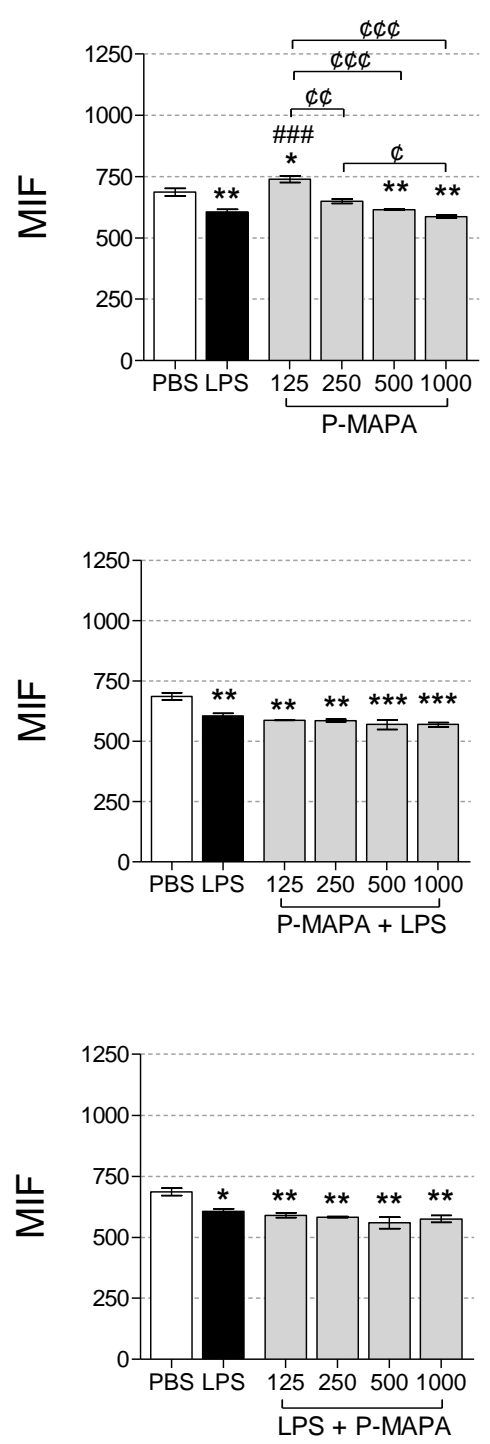

Amostras de sangue humano foram tratadas com PBS, P-MAPA ( $\mu \mathrm{g} / \mathrm{mL})$ ou LPS $(100 \mu \mathrm{g} / \mathrm{mL})$, por 5 minutos, e em seguida, foi feita uma segunda adição de LPS ou P-MAPA, seguido de incubação por 30 minutos a $37^{\circ} \mathrm{C}$. Após a incubação, os leucócitos foram coletados e analisados separadamente, quanto à expressão de C5aR em dois tipos celulares. A) Expressão de C5aR após tratamento com concentrações crescentes de P-MAPA. B) Expressão de C5aR nos grupos tratados com concentrações crescentes de P-MAPA por 5 minutos e, posteriormente incubados com LPS $(100 \mu \mathrm{g} / \mathrm{mL})$ por 30 minutos. C) Análise da expressão de C5aR nos grupos tratados com LPS $(100 \mu \mathrm{g} / \mathrm{mL})$ por 5 minutos e, posteriormente, incubados com concentrações crescentes de PMAPA, por 30 minutos. Dados expressos como média \pm desvio padrão de duplicatas de 1 experimento representativo, entre 6 experimentos independentes. Análise estatística realizada por ANOVA, complementada com teste de Bonferroni. MIF = mediana de intensidade de fluorescência. $\left({ }^{*}\right) p<0,05,\left({ }^{* *}\right) p<0,01,\left({ }^{* * *}\right) p<0,001$ diferença estatística significativa em relação ao PBS. (\#) $p<0,05$, (\#\#) $p<0,01$, (\#\#\#) p<0,001 diferença estatística

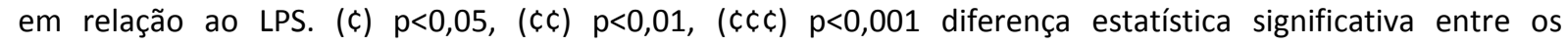
tratamentos com P-MAPA. 
4.6 Análise da expressão de marcadores de superfície em leucócitos tratados com P-MAPA não solubilizado

Para identificar se os cristais de P-MAPA produziam efeitos distintos sobre os marcadores de superfície em leucócitos, sangue humano foi tratado com P-MAPA (1000 $\mu \mathrm{g} / \mathrm{mL}$ ) não solubilizado, sob a forma de cristais ressuspendidos em PBS estéril, ou com PMAPA (1000 $\mu \mathrm{g} / \mathrm{mL}$ ) solubilizado (como descrito em 3.1), seguindo o protocolo estabelecido em 3.4.1.

A análise por citometria de fluxo (Figura 23) revelou que os tratamentos com PMAPA, solubilizado e ou sob a forma de cristais, não diferem entre si quanto à expressão de CD11b, TLR2, TLR4, C3aR e C5aR, em leucócitos. No entanto, o P-MAPA não solubilizado não induziu aumento da expressão de CD14, como o promovido pelo tratamento com P-MAPA solubilizado (Figura 23). 
Figura 23 - Ação do P-MAPA não solubilizado sobre a expressão marcadores de superfície, em leucócitos
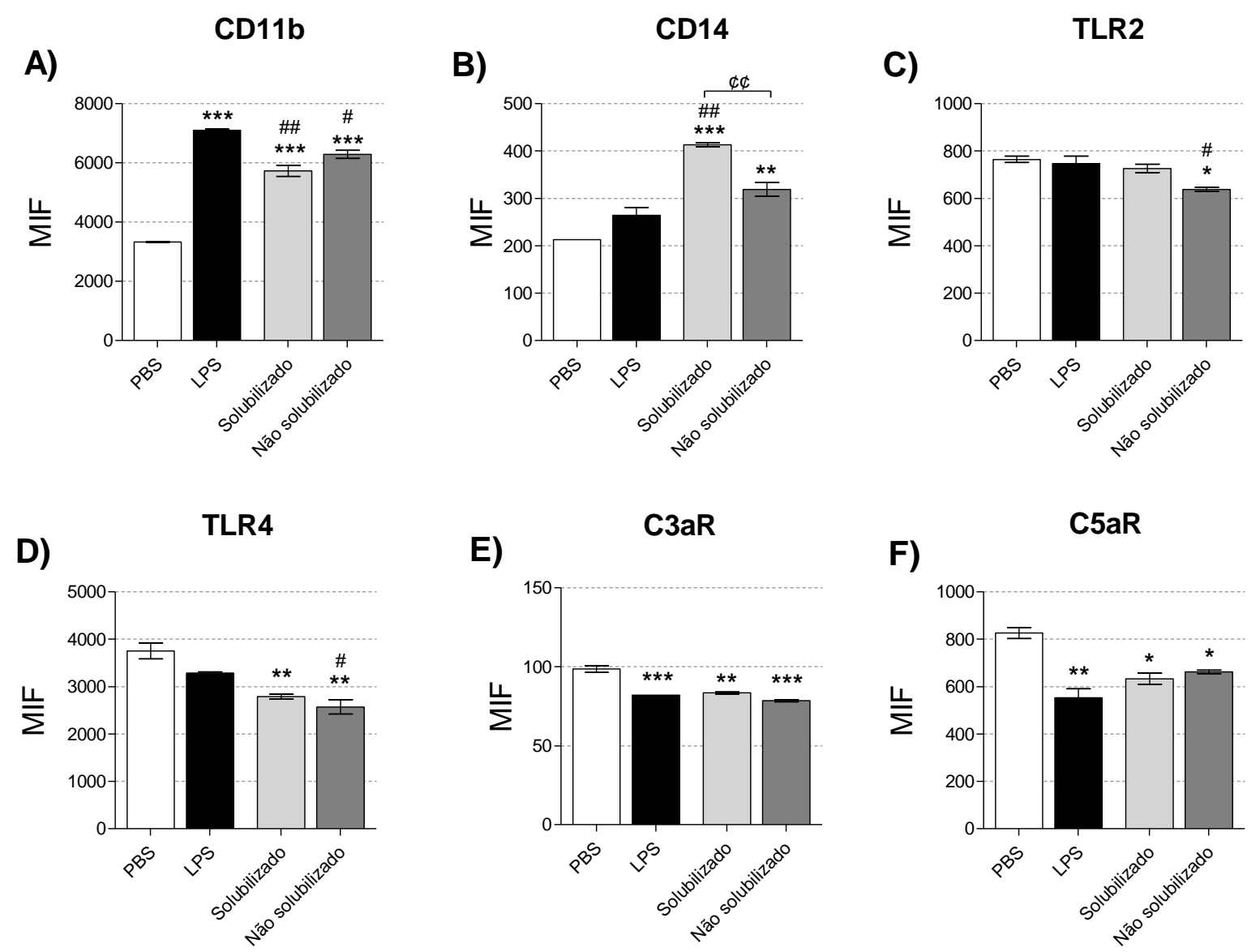

Amostras de sangue humano foram tratadas com PBS, P-MAPA (1000 $\mu \mathrm{g} / \mathrm{mL})$ solubilizado ou não, ou LPS (100 $\mu \mathrm{g} / \mathrm{mL}$ ), por 5 minutos, a temperatura ambiente, seguido de incubação por 30 minutos a $37^{\circ} \mathrm{C}$. Após a incubação, os leucócitos foram coletados e analisados quanto à expressão de marcadores de superfície. A) Expressão de CD11b. B) Expressão de CD14. C) Expressão de TLR2. D) Expressão de TLR4. E) Expressão de C3aR. F) Expressão de C5aR. Dados expressos como média \pm desvio padrão de duplicatas de 1 experimento representativo, entre 2 experimentos independentes. Análise estatística realizada por ANOVA, complementada com teste de Bonferroni. MIF = mediana de intensidade de fluorescência. $\left({ }^{*}\right) p<0,05,\left({ }^{* *}\right) p<0,01,\left({ }^{* * *}\right) p<0,001$ diferença estatística significativa em relação ao PBS. (\#) $p<0,05$, (\#\#) p<0,01 diferença estatística em relação ao LPS. (Ç) $p<0,01$ diferença estatística significativa entre os tratamentos com P-MAPA. 


\subsection{Dosagem de citocinas em sangue total humano após os tratamentos experimentais}

A dosagem das citocinas TNF- $\alpha$, IL-8, IL-12(p70), IFN- $\gamma$, TGF- $\beta$, IL-10, IL-6 e IL-1 $\beta$ nas amostras de plasma obtidas de sangue total tratado com LPS ou P-MAPA, por 30 minutos e a $37{ }^{\circ} \mathrm{C}$, foi realizada por ELISA. O P-MAPA $(250 \mu \mathrm{g} / \mathrm{mL}, 500 \mu \mathrm{g} / \mathrm{mL}$ e $1000 \mu \mathrm{g} / \mathrm{mL})$ induziu a produção de TNF- $\alpha$ pelos leucócitos, após o tratamento do sangue. Ambas as combinações de P-MAPA com LPS (Figura 24B e 24C) também induziram a produção desta citocina, porém em quantidades superiores a do tratamento com P-MAPA (Figura 24A), devido à presença do LPS.

O tratamento do sangue com P-MAPA também induziu a produção de IL-8 pelos leucócitos (Figura 25A). Os tratamentos combinados de P-MAPA com LPS (Figura 25B e 25C) induziram aumento da produção de IL-8, sendo os níveis plasmáticos desta citocina iguais à produção induzida por LPS, com exceção do tratamento LPS + P-MAPA (125 $\mu \mathrm{g} / \mathrm{mL})$.

Sob as mesmas condições experimentais, foi detectada a presença de IL-12p70 no plasma, após os tratamentos experimentais. A Figura 26A mostra que os tratamentos com PMAPA induziram aumento dose dependente desta citocina. As combinações de P-MAPA com LPS (Figura 26B e 26C) também levaram à produção de IL-12p70, porém em menor concentração, quando comparada à induzida pelo tratamento exclusivo com P-MAPA.

A dosagem de citocinas no plasma detectou também a produção de IFN- $\gamma$ pelos tratamentos experimentais. O P-MAPA promoveu diminuição da produção de IFN- $\gamma$ de modo dose-dependente (Figura 27A) e, também, quando combinado com LPS, como mostrado nas Figuras 27B e 27C.

A dosagem de citocinas mostrou que o P-MAPA pode induzir a produção de TGF- $\beta 1$, e que a combinação de LPS+P-MAPA parece elevar essa produção (Figura 28).

Não foi detectada a presença de IL-6, IL-1ß e IL-10 no plasma, após o tratamento do sangue por 30 minutos com P-MAPA (125 $\mu \mathrm{g} / \mathrm{mL}, 250 \mu \mathrm{g} / \mathrm{mL}, 500 \mu \mathrm{g} / \mathrm{mL}$ e $1000 \mu \mathrm{g} / \mathrm{mL}$ ). A detecção de IL-6 ocorreu apenas no plasma obtido do tratamento com LPS $(100 \mu \mathrm{g} / \mathrm{mL})$, por 1 hora, a $37^{\circ} \mathrm{C}$. Sob as mesmas condições experimentais, as concentrações testadas de PMAPA não induziram a produção de IL-6 (dados não mostrados). 
Figura 24 - Níveis plasmáticos de TNF- $\alpha$ após os tratamentos experimentais

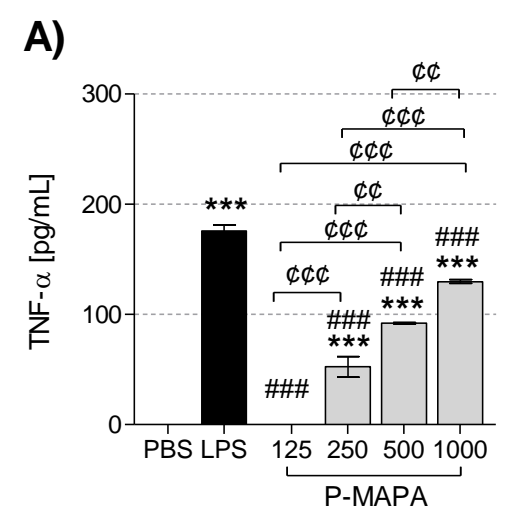

\section{B)}
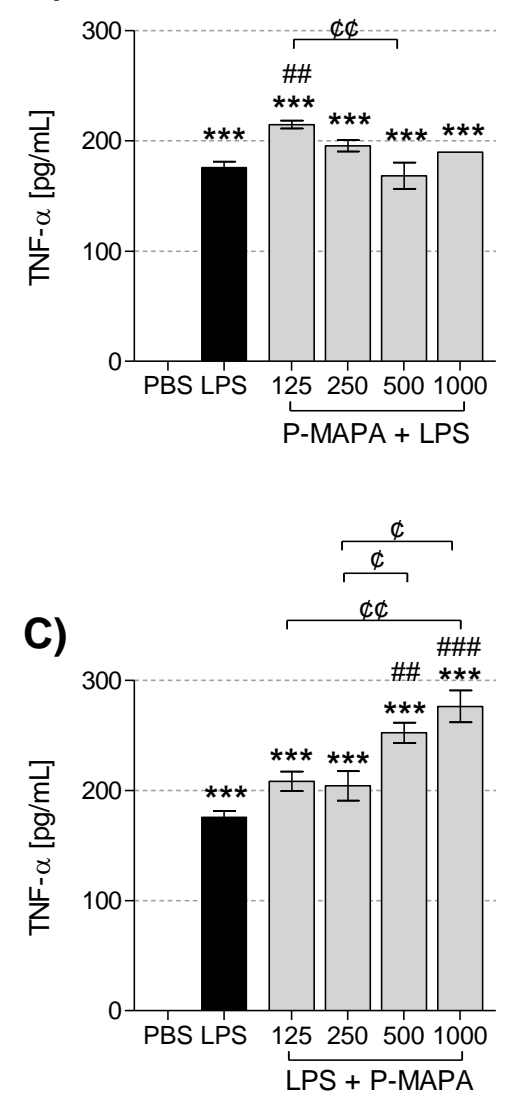

Amostras de sangue humano foram tratadas com PBS, P-MAPA $(\mu \mathrm{g} / \mathrm{mL})$ ou LPS $(100 \mu \mathrm{g} / \mathrm{mL})$, por 5 minutos, e em seguida, foi feita uma segunda adição de LPS ou P-MAPA, seguido de incubação por 30 minutos a $37^{\circ} \mathrm{C}$. Após a incubação, o plasma foi coletado para dosagem de TNF- $\alpha$ por ELISA. A) Produção de TNF- $\alpha$ após tratamento com concentrações crescentes de P-MAPA $(\mu \mathrm{g} / \mathrm{mL})$. B) Produção de TNF- $\alpha$ após tratamento com concentrações crescentes de P-MAPA $(\mu \mathrm{g} / \mathrm{mL}$ ) por 5 minutos e, posteriormente, com LPS (100 $\mu \mathrm{g} / \mathrm{mL})$, por 30 minutos. C) Produção de TNF- $\alpha$ após tratamento com LPS (100 $\mu \mathrm{g} / \mathrm{mL})$ por 5 minutos e, posteriormente, com concentrações crescentes de P-MAPA, por 30 minutos. Dados expressos como média \pm desvio padrão de duplicatas, representativos de 2 experimentos independentes. Análise estatística realizada por ANOVA, complementada com teste de Bonferroni. $\left.{ }^{* * *}\right) p<0,001$ diferença estatística significativa em relação ao PBS.

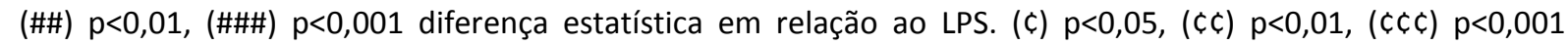
diferença estatística significativa entre os tipos de tratamento. 
Figura 25 - Níveis plasmáticos de IL-8 após os tratamentos experimentais

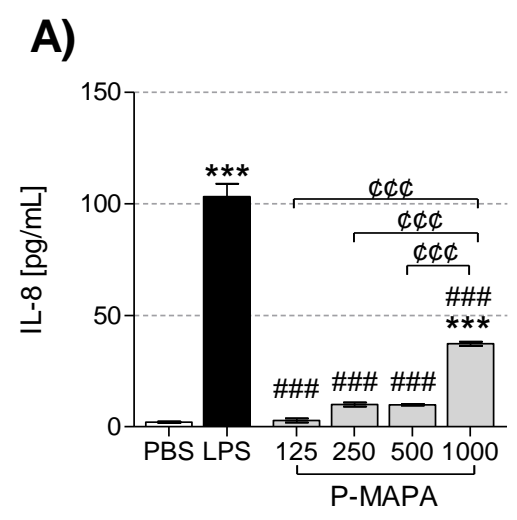

B)
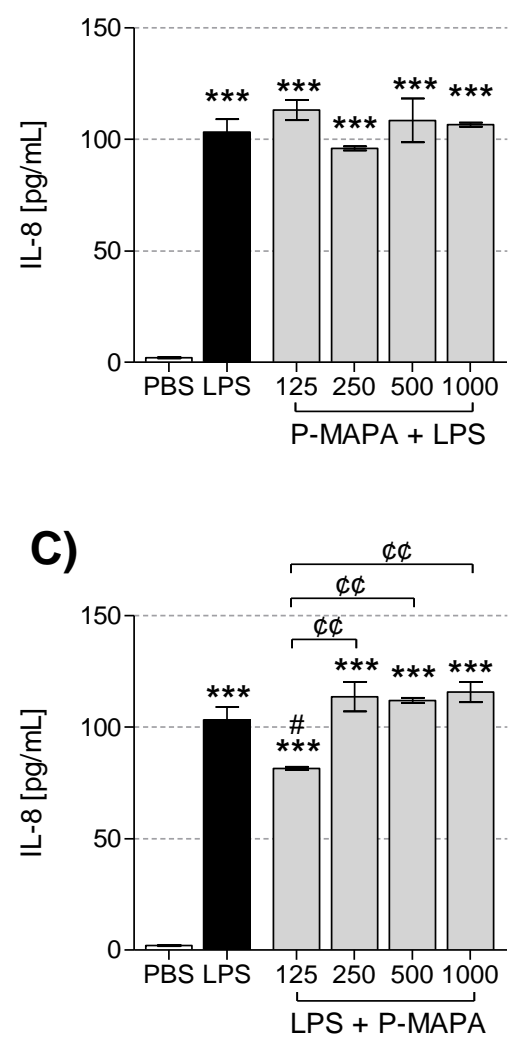

Amostras de sangue humano foram tratadas com PBS, P-MAPA $(\mu \mathrm{g} / \mathrm{mL})$ ou LPS $(100 \mu \mathrm{g} / \mathrm{mL})$, por 5 minutos, e em seguida, foi feita uma segunda adição de LPS ou P-MAPA, seguido de incubação por 30 minutos a $37^{\circ} \mathrm{C}$. Após a incubação, o plasma foi coletado para dosagem de IL-8 por ELISA. A) Produção de IL-8 após tratamento com concentrações crescentes de P-MAPA $(\mu \mathrm{g} / \mathrm{mL})$. B) Produção de IL-8 após tratamento com concentrações crescentes de P-MAPA ( $\mu \mathrm{g} / \mathrm{mL})$ por 5 minutos e, posteriormente, com LPS $(100 \mu \mathrm{g} / \mathrm{mL})$, por 30 minutos. C) Produção de IL-8 após tratamento com LPS $(100 \mu \mathrm{g} / \mathrm{mL})$ por 5 minutos e, posteriormente, com concentrações crescentes de P-MAPA, por 30 minutos. Dados expressos como média \pm desvio padrão de duplicatas, representativos de 2 experimentos independentes. Análise estatística realizada por ANOVA, complementada com teste de Bonferroni. $\left({ }^{* * *}\right) \mathrm{p}<0,001$ diferença estatística significativa em relação ao PBS. (\#\#) $p<0,01$, (\#\#\#) $p<0,001$ diferença estatística em relação ao LPS. (c) $p<0,05$, (ç) $p<0,01$, (çç) $p<0,001$ diferença estatística significativa entre os tipos de tratamento. 
Figura 26 - Níveis plasmáticos de IL-12p70 após os tratamentos experimentais

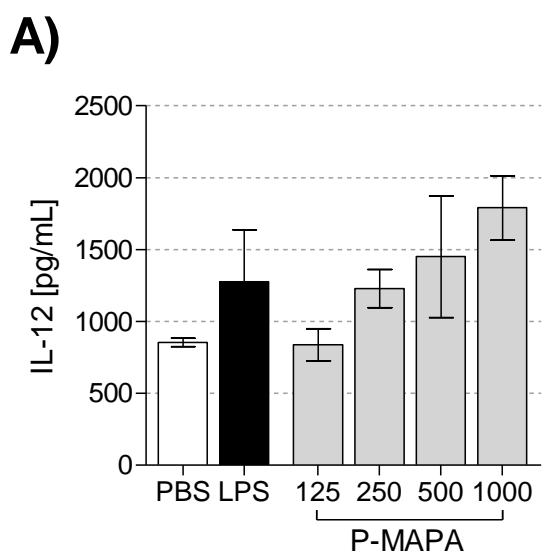

\section{B)}

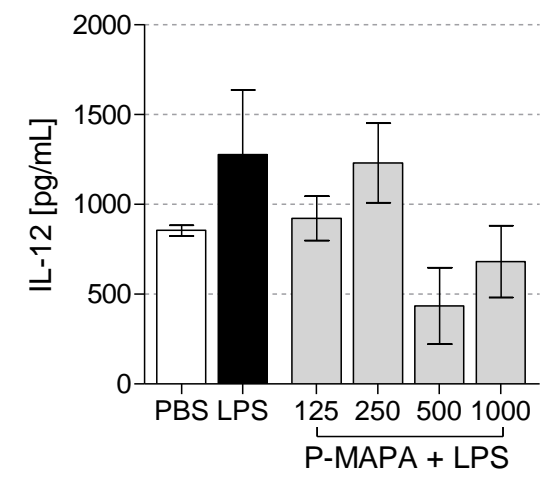

C)

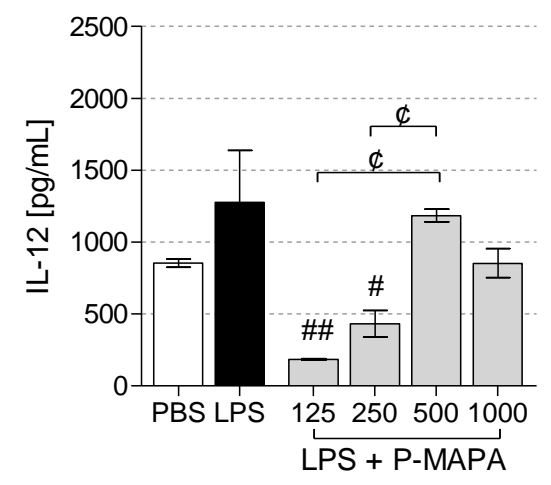

Amostras de sangue humano foram tratadas com PBS, P-MAPA $(\mu \mathrm{g} / \mathrm{mL})$ ou LPS $(100 \mu \mathrm{g} / \mathrm{mL})$, por 5 minutos, e em seguida, foi feita uma segunda adição de LPS ou P-MAPA, seguido de incubação por 30 minutos a $37^{\circ} \mathrm{C}$. Após a incubação, o plasma foi coletado para dosagem de IL-12p70 por ELISA. A) Produção de IL-12 (p70) após tratamento com concentrações crescentes de P-MAPA $(\mu \mathrm{g} / \mathrm{mL})$. B) Produção de IL-12 (p70) após tratamento com concentrações crescentes de P-MAPA $(\mu \mathrm{g} / \mathrm{mL})$ por 5 minutos e, posteriormente, com LPS $(100 \mu \mathrm{g} / \mathrm{mL})$, por 30 minutos. C) Produção de IL-12 (p70) após tratamento com LPS $(100 \mu \mathrm{g} / \mathrm{mL})$ por 5 minutos e, posteriormente, com concentrações crescentes de P-MAPA, por 30 minutos. Dados expressos como média \pm desvio padrão de duplicatas, representativos de 2 experimentos independentes. Análise estatística realizada por ANOVA, complementada com teste de Bonferroni. (\#) $p<0,05$, (\#\#) $p<0,01$ diferença estatística em relação ao LPS. (c) $p<0,05$ diferença estatística significativa entre os tipos de tratamento. 
Figura 27 - Níveis plasmáticos de IFN- $\gamma$ após os tratamentos experimentais
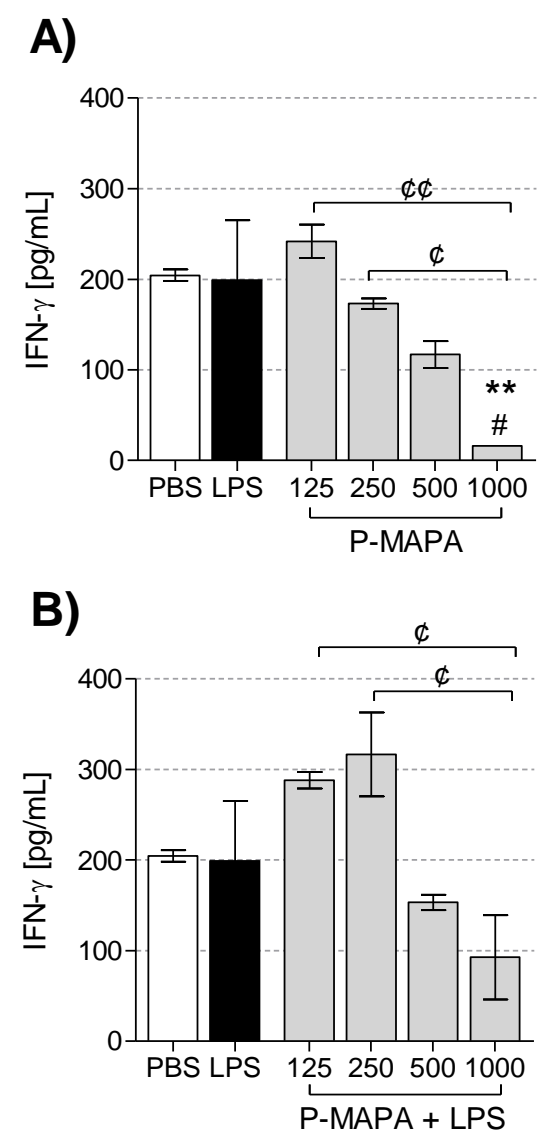

C)

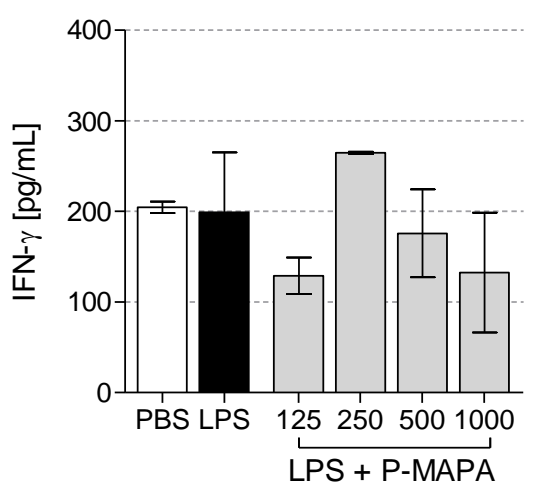

Amostras de sangue humano foram tratadas com PBS, P-MAPA $(\mu \mathrm{g} / \mathrm{mL})$ ou LPS $(100 \mu \mathrm{g} / \mathrm{mL})$, por 5 minutos, e em seguida, foi feita uma segunda adição de LPS ou P-MAPA, seguido de incubação por 30 minutos a $37^{\circ} \mathrm{C}$. Após a incubação, o plasma foi coletado para dosagem de IFN- $\gamma$ por ELISA. A) Produção de IFN- $\gamma$ após tratamento com concentrações crescentes de P-MAPA $(\mu \mathrm{g} / \mathrm{mL})$. B) Produção de IFN- $\gamma$ após tratamento com concentrações crescentes de P-MAPA $(\mu \mathrm{g} / \mathrm{mL})$ por 5 minutos e, posteriormente, com LPS $(100 \mu \mathrm{g} / \mathrm{mL})$, por 30 minutos. C) Produção de IFN- $\gamma$ após tratamento com LPS $(100 \mu \mathrm{g} / \mathrm{mL})$ por 5 minutos e, posteriormente, com concentrações crescentes de P-MAPA, por 30 minutos. Dados expressos como média \pm desvio padrão de duplicatas. Análise estatística realizada por ANOVA, complementada com teste de Bonferroni. $\left.{ }^{* *}\right) p<0,01$ diferença estatística em relação ao PBS. (\#) $p<0,05$ diferença estatística em relação ao LPS. (६) $p<0,05$, (Cఢ) $p<0,01$ diferença estatística significativa entre os tipos de tratamento. 
Figura 28 - Níveis plasmáticos de TGF- $\beta$ após os tratamentos experimentais

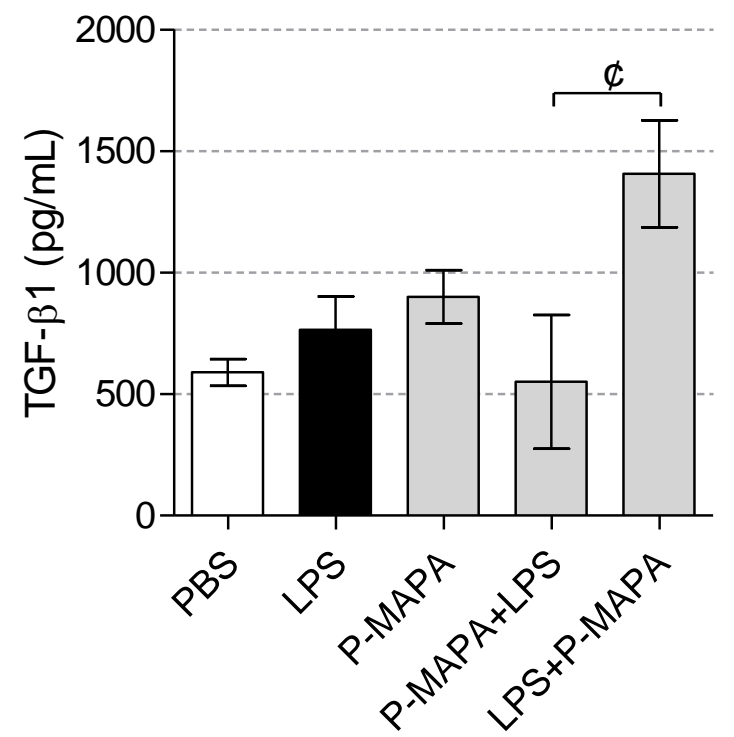

Amostras de sangue humano foram tratadas com PBS, P-MAPA ( $\mu \mathrm{g} / \mathrm{mL})$ ou LPS $(100 \mu \mathrm{g} / \mathrm{mL})$, por 5 minutos, e em seguida, foi feita uma segunda adição de LPS ou P-MAPA, seguido de incubação por 30 minutos a $37^{\circ} \mathrm{C}$. Após a incubação, o plasma foi coletado para dosagem de IFN- $\gamma$ por ELISA. A) Produção de IFN- $\gamma$ após tratamento com concentrações crescentes de P-MAPA $(\mu \mathrm{g} / \mathrm{mL})$. B) Produção de IFN- $\gamma$ após tratamento com concentrações crescentes de P-MAPA $(\mu \mathrm{g} / \mathrm{mL})$ por 5 minutos e, posteriormente, com LPS $(100 \mu \mathrm{g} / \mathrm{mL})$, por 30 minutos. C) Produção de IFN- $\gamma$ após tratamento com LPS $(100 \mu \mathrm{g} / \mathrm{mL})$ por 5 minutos e, posteriormente, com concentrações crescentes de P-MAPA, por 30 minutos. Dados expressos como média \pm desvio padrão de duplicatas. Análise estatística realizada por ANOVA, complementada com teste de Bonferroni. $\left({ }^{* *}\right) p<0,01$ diferença estatística em relação ao PBS. (\#) $p<0,05$ diferença estatística em relação ao LPS. (c) $p<0,05,(c \zeta)$ $p<0,01$ diferença estatística significativa entre os tipos de tratamento. 


\subsection{Análise da produção de espécies reativas de oxigênio e nitrogênio (superóxido e peróxinitrito)}

A análise da produção de espécies reativas de oxigênio (ROS) e nitrogênio (NOS) mostrou que os tratamentos com P-MAPA não induziram produção de superóxido $\left(\mathrm{O}_{2}^{-}\right)$, em relação ao tratamento com PBS, como mostrado na Figura 29A. Também foi analisada a presença de peróxinitrito $\left(\mathrm{ONOO}^{-}\right)$nos leucócitos. O peróxinitrito é um poderoso agente citotóxico, produto da reação do superóxido com o óxido nítrico. O tratamento das células com P-MAPA 1000 g/mL induziu aumento deste ânion, quando comparado ao tratamento com PBS (Figura 29B).

Figura 29 - Produção de ROS por leucócitos tratados com P-MAPA

A)

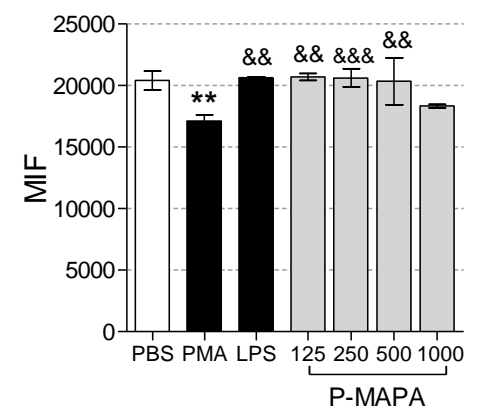

B)

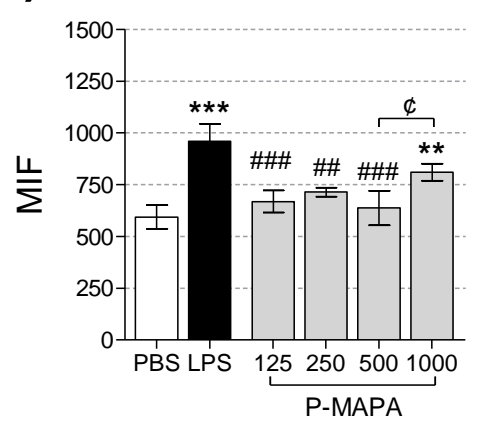

Amostras de sangue humano foram tratadas com PBS e PMA (100 nM) por 5 minutos, e em seguida foi feita a adição de P-MAPA $(\mu \mathrm{g} / \mathrm{mL})$ ou LPS $(100 \mu \mathrm{g} / \mathrm{mL})$, seguido de incubação por 30 minutos a $37^{\circ} \mathrm{C}$. Após a incubação, alíquotas de sangue foram incubadas por 1 hora, com DHE ou DHR a $37^{\circ} \mathrm{C}$ e $30^{\circ} \mathrm{C}$, respectivamente. Em seguida, os leucócitos foram analisados por FACS. A) Análise da produção de superóxido pelos tratamentos experimentais. B) Análise da produção de peróxinitrito pelos tratamentos experimentais. Dados expressos como média \pm desvio padrão de duplicatas, representativos de 2 experimentos independentes. Análise estatística realizada por ANOVA, complementada com teste de Bonferroni. MIF = mediana de intensidade de fluorescência. $\left(^{* *}\right) p<0,01,\left({ }^{* *}\right) p<0,001$ diferença estatística significativa em relação ao PBS. $(\&) p<0,05$, $(\& \& \&) p<0,001$ diferença estatística em relação ao PMA. (\#\#) $p<0,01$, (\#\#\#) $p<0,001$ diferença estatística em relação ao LPS. (c) $p<0,05$ diferença estatística significativa entre os tipos de tratamento. 


\subsection{Análise da expressão de marcadores de superfície em leucócitos após o bloqueio do componente $\mathrm{C} 3$ do complemento no sangue}

Para compreender o papel do complemento na modulação da expressão de receptores celulares promovida pelo P-MAPA, foram examinados os efeitos da inibição do componente C3 do complemento, com o inibidor compstatina, um tridecapeptídeo cíclico específico para esta proteína, e seu peptídeo controle (descritos em 3.2).

Primeiramente, foi determinada a concentração de compstatina necessária para inibir a ativação do sistema complemento, em ensaio hemolítico da via alternativa (descrito em 3.3.3.2). A Figura 30 mostra que a concentração de $1 \mathrm{mM}$ de compstatina foi suficiente para inibir a ação do complemento, do mesmo modo que o soro inativado, e impedir a hemólise dos eritrócitos de coelho, enquanto o tratamento de SHN com $1 \mathrm{mM}$ do peptídeo controle induziu níveis de hemólise semelhantes ao do tratamento com PBS.

Assim, conforme o protocolo estabelecido no item 3.4.1.1, amostras de sangue foram tratadas com os peptídeos ou PBS e pré-incubadas por 10 minutos a temperatura ambiente, antes de serem tratadas com LPS $(100 \mu \mathrm{g} / \mathrm{mL})$ ou P-MAPA $(1000 \mu \mathrm{g} / \mathrm{mL})$, incubadas por 30 minutos e a $37^{\circ} \mathrm{Ce}$, depois, processadas para análise por citometria de fluxo.

A Figura 31A mostra que a inibição do componente C3 pela compstatina foi eficaz em reduzir a expressão de CD11b na superfície das células tratadas com LPS. Porém, a inibição não parece afetar significativamente a expressão desta molécula nas células tratadas com PMAPA, indicando que outro componente, possivelmente o próprio P-MAPA, possa ser o responsável por modular a expressão de CD11b. As expressões de CD14, C3aR e TLR4 não apresentaram variação significativa após o tratamento com a compstatina, em sangue estimulado com LPS ou P-MAPA (Figuras 31B, 31D e 31E). A Figura $31 \mathrm{C}$ mostrou que a expressão de TLR2 foi aumentada após a inibição de C3 nos leucócitos estimulados com PMAPA, enquanto a expressão de C5aR foi também aumentada após o tratamento com compstatina nos tratamentos experimentais com LPS e P-MAPA (Figura 31F). No entanto, o tratamento com o peptídeo controle também promoveu alterações na expressão das moléculas analisadas e, assim, as modificações observadas na expressão dos marcadores não podem ser atribuídas exclusivamente a inibição do sistema complemento. 
Figura 30 - Ação da compstatina sobre a Via Alternativa do Sistema Complemento

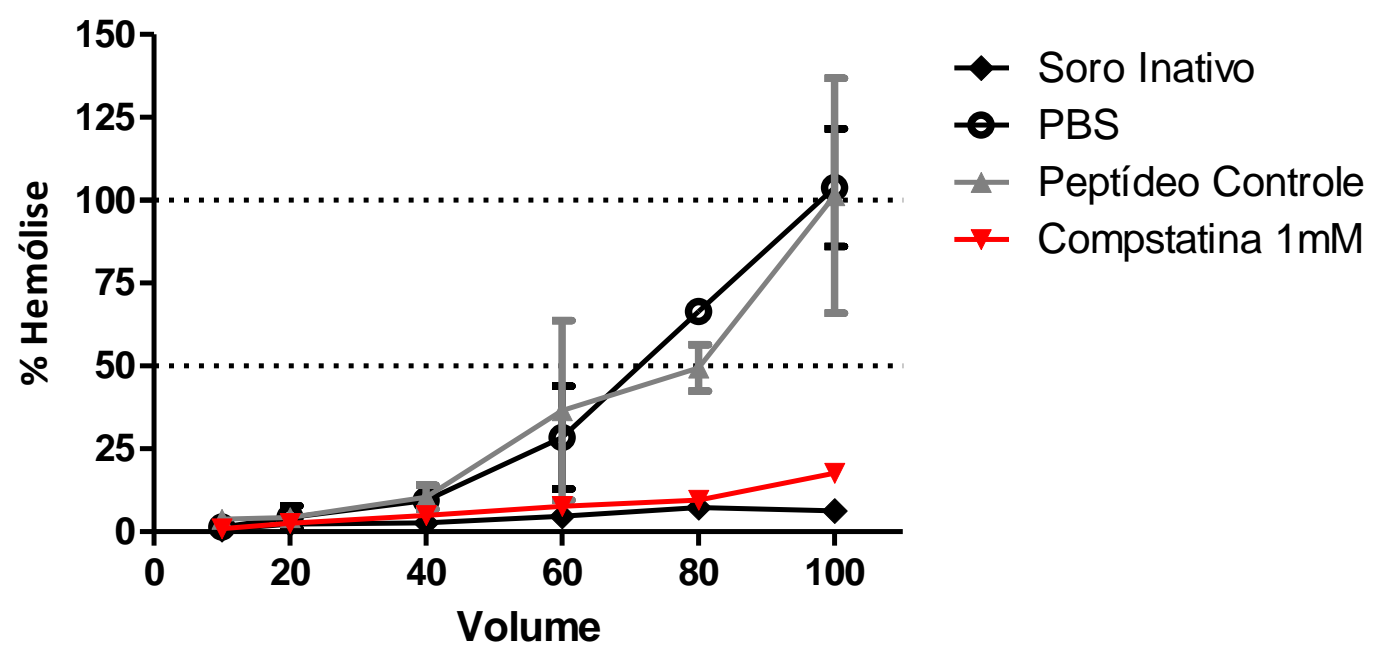

Amostras $(100 \mu \mathrm{L})$ de soro humano normal (SHN) foram incubadas com PBS, compstatina (1 mM) ou seu peptídeo controle $(1 \mathrm{mM})$, por 30 minutos, a $37^{\circ} \mathrm{C}$. O controle Soro Inativo corresponde ao tratamento de SHN com PBS aquecido a $56^{\circ} \mathrm{C}$, por 30 minutos. A atividade hemolítica residual da via alternativa foi avaliada sobre eritrócitos de coelho e a absorbância dos sobrenadantes, determinada a $\lambda 414 \mathrm{~nm}$. Dados expressos como média \pm desvio padrão de duplicatas. 
Figura 31 - Ação do P-MAPA e do LPS sobre a expressão de receptores celulares na presença de compstatina

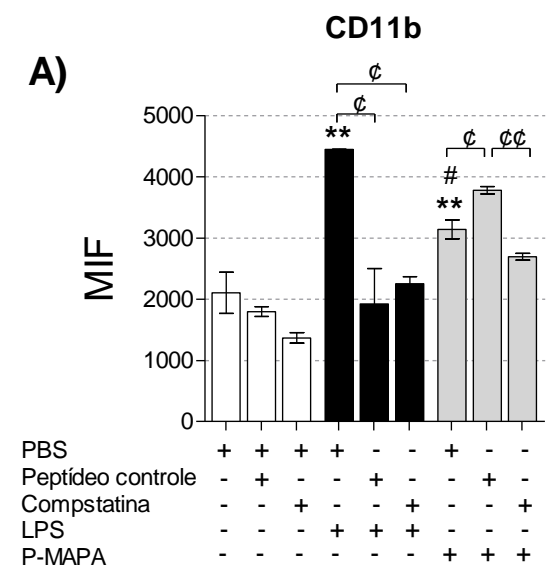

C)

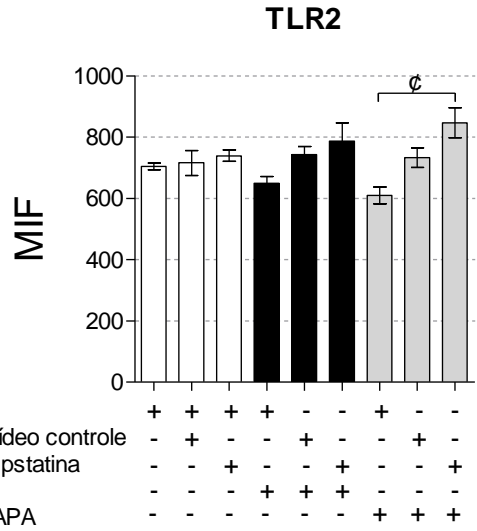

E)

C3aR

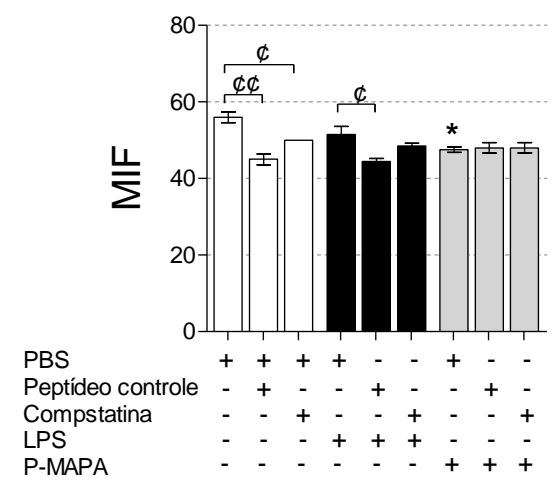

B)

CD14

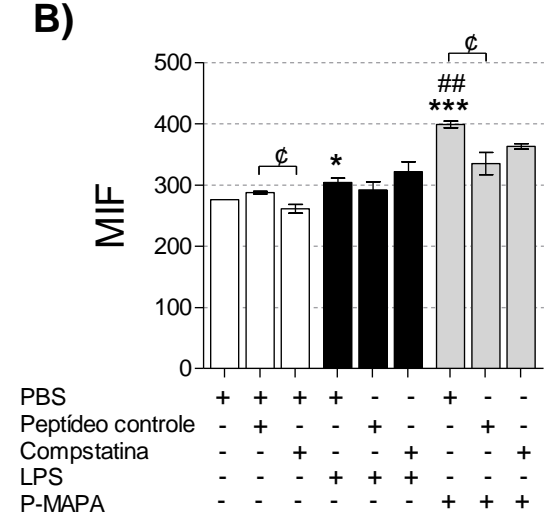

D)

TLR4

PBS

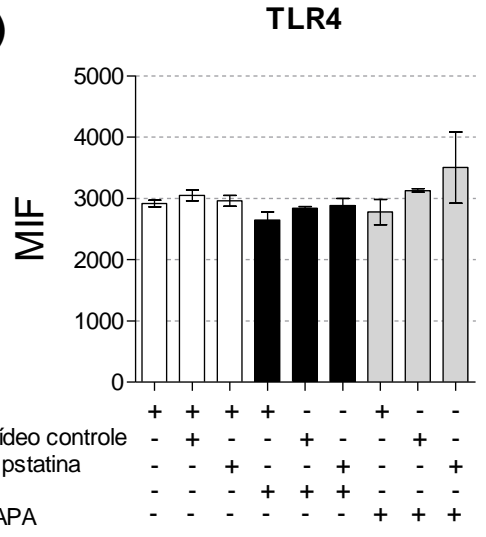

F)

C5aR

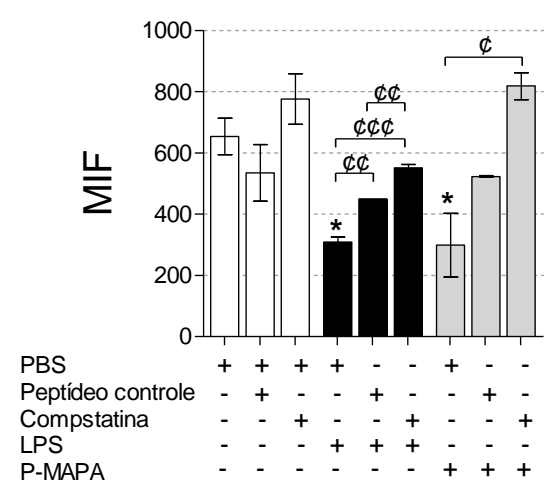

Amostras de sangue humano foram tratadas com PBS, compstatina ou seu peptídeo controle, por 10 minutos, e em seguida, foi feita a adição de LPS $(100 \mu \mathrm{g} / \mathrm{mL})$ ou P-MAPA $(1000 \mu \mathrm{g} / \mathrm{mL})$, seguido de incubação por 30 minutos a $37{ }^{\circ} \mathrm{C}$. Após a incubação, os leucócitos foram coletados e analisados quanto à expressão de marcadores de superfície. A) Expressão de CD11b. B) Expressão de CD14. C) Expressão de TLR2. D) Expressão de TLR4. E) Expressão de C3aR. F) Expressão de C5aR. Dados expressos como média \pm desvio padrão de duplicatas de 1 experimento representativo, entre 3 experimentos independentes. Análise estatística realizada por ANOVA, complementada com teste de Bonferroni. MIF = mediana de intensidade de fluorescência. $\left({ }^{*}\right)$ $p<0,05,\left({ }^{* *}\right) p<0,01,\left(*^{* *}\right) p<0,001$ diferença estatística significativa em relação ao PBS. (\#) $p<0,05,(\# \#) p<0,01$

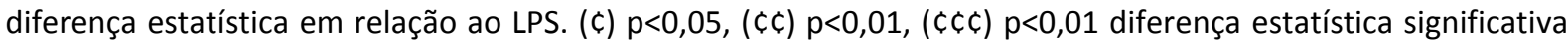
entre os tratamentos. 
4.10 Análise da expressão de marcadores de superfície em leucócitos após o tratamento de sangue total com ácido linoleico

Considerando a composição complexa do P-MAPA, foram feitos ensaios com um de seus componentes, o ácido linoleico, responsável por $12 \%$ de sua composição (DURÁN; NUNES, 1991), com a finalidade de esclarecer se os efeitos induzidos pelo P-MAPA, sobre a expressão de moléculas de superfície em leucócitos de sangue periférico, era induzida por este componente em particular.

As concentrações de ácido linoleico utilizadas foram determinadas com base na proporção equivalente deste componente $(12 \%)$, presente nas concentrações de P-MAPA utilizadas nos ensaios de sangue total $(125,250,500$ e $1000 \mathrm{mg} / \mathrm{mL})$.

O tratamento de sangue total com ácido linoleico (Figura 32) mostrou que, nas concentrações utilizadas, este lipídio não foi capaz de alterar a expressão de CD11b, CD14, TLR4 e C3aR. No entanto, o ácido linoleico promoveu redução da expressão de C5aR, em relação ao tratamento com LPS e TLR2, comparado aos tratamentos com PBS e LPS, indicando que este pode ser um dos componentes do P-MAPA responsáveis por interagir com estes receptores celulares. 
Figura 32 - Ação do ácido linoleico sobre a expressão de receptores celulares em leucócitos totais
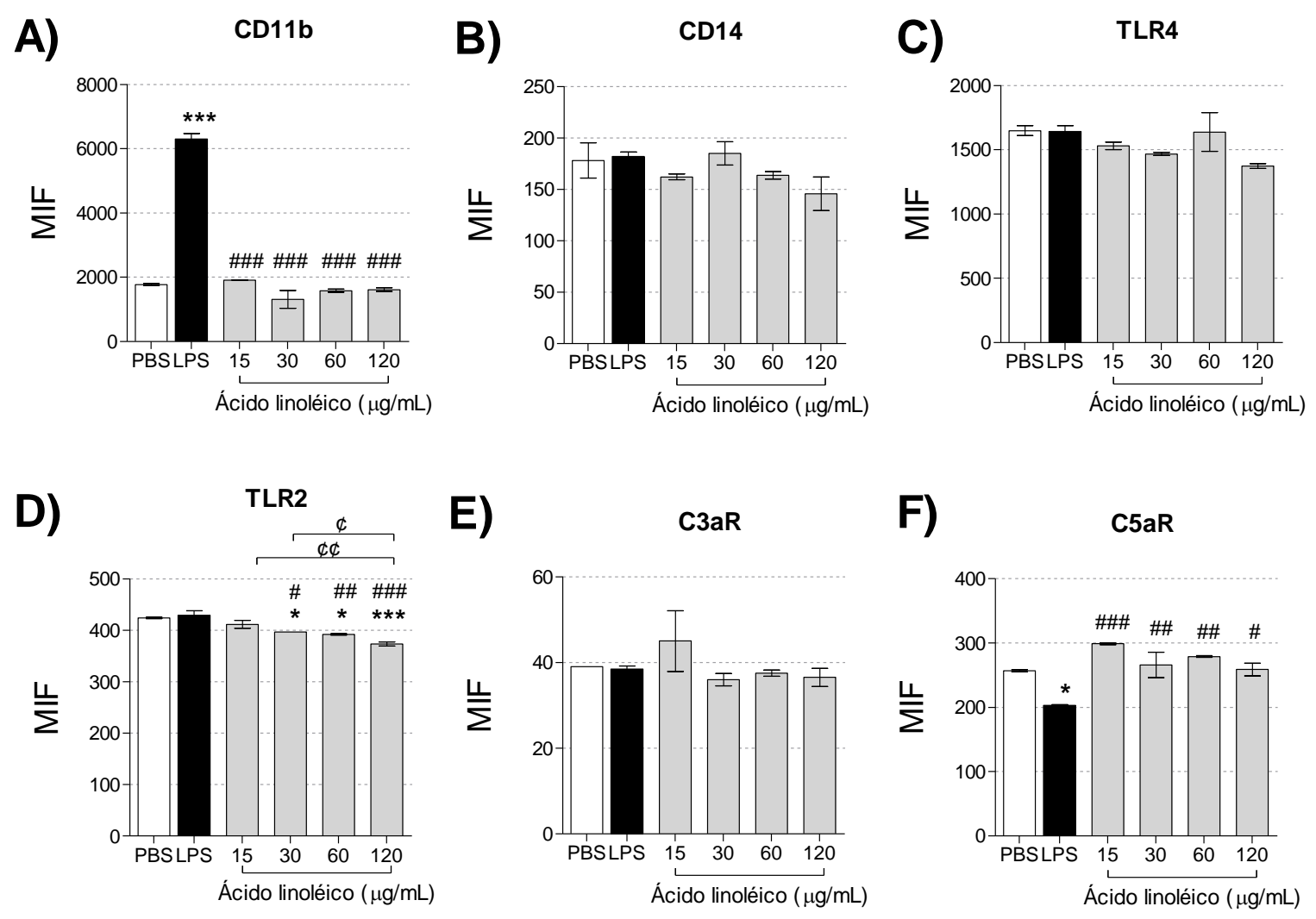

Amostras de sangue humano foram tratadas com PBS ou diferentes concentrações de ácido linoleico $(15,30$, 60 ou $120 \mu \mathrm{g} / \mathrm{mL}$ ), por 5 minutos, a temperatura ambiente, seguido de adição de LPS (100 $\mathrm{\mu g} / \mathrm{mL}$ ) ou PBS e incubação por 30 minutos a $37{ }^{\circ} \mathrm{C}$. Após a incubação, os leucócitos foram coletados e analisados quanto à expressão de marcadores de superfície. A) Expressão de CD11b. B) Expressão de CD14. C) Expressão de TLR2. D) Expressão de TLR4. E) Expressão de C3aR. F) Expressão de C5aR. Dados expressos como média \pm desvio padrão de duplicatas de 1 experimento representativo, entre 2 experimentos independentes. As concentrações de ácido linoleico foram determinadas com base na proporção equivalente deste componente, encontrada no P-MAPA (12\%, segundo DURÁN e NUNES, 1991), nas doses de 125, 250, 500 e $1000 \mu \mathrm{g} / \mathrm{mL}$. Análise estatística realizada por ANOVA, complementada com teste de Bonferroni. MIF = mediana de intensidade de fluorescência. $\left({ }^{*}\right) p<0,05,(* *) p<0,01,\left({ }^{* * *}\right) p<0,001$ diferença estatística significativa em relação ao PBS. (\#) $p<0,05$, (\#\#) $p<0,01$, (\#\#\#) p<0,001 diferença estatística significativa em relação ao LPS. (c) $p<0,05$, (ç) $p<0,01$ diferença estatística significativa entre tratamentos. 


\subsection{Avaliação da toxicidade da dose letal $\left(D^{50}\right)$}

A ação tóxica do P-MAPA solubilizado foi avaliada pela inoculação de doses crescentes do composto, em camundongos da linhagem BALB/c pela via intraperitoneal. Para os experimentos in vivo, a partida de P-MAPA cedida pela Farmabrasilis foi outra, identificada como NL-12. A comparação entre ambas as partidas utilizadas neste estudo é mostrada no Apêndice $D$.

Os ensaios com animais seguiram a metodologia descrita em 3.5 e, após o período de observação de 72 horas, a dose letal para $50 \%$ dos animais $\left(\mathrm{DL}_{50}\right)$ calculada, por análise de transformação em probitos, foi de $736,07 \mathrm{mg} / \mathrm{kg}$. 


\section{DISCUSSÃO}

O P-MAPA surgiu a partir de esforços individuais e colaborativos, visando torná-lo uma terapia alternativa ou complementar para o tratamento de câncer. Apesar de ter apresentado propriedades imunomodulatórias em muitos trabalhos, como eliminação de patógenos intracelulares (de MELO; JUSTO; de SOUZA QUEIROZ, 2001; DURAN et al., 2008, 2009; FÁVARO et al.; 2012, SANTIAGO et al., 2013) e atividade antineoplásica (FARMABRASILIS, 2010; FÁVARO et al., 2012; JUSTO; DURÁN; QUEIROZ, 2000), os mecanismos de ação do P-MAPA não estão totalmente esclarecidos. Neste trabalho, foi investigada a ação do P-MAPA sobre o sistema complemento e nas interações deste sistema com os leucócitos do sangue periférico, utilizando o modelo ex vivo de sangue total humano, estabelecido por Mollnes et al. (2002). Neste sistema, foram analisadas, também, as modulações induzidas pelo P-MAPA na presença de lipopolissacarídeo (LPS), utilizado como indutor de inflamação. Posteriormente, a toxicidade do composto foi avaliada in vivo, a fim de estabelecer a dose letal.

A ação do P-MAPA sobre o sistema complemento foi avaliada por ensaios hemolíticos, com os quais foram detectadas a ativação das vias clássica e alternativa pelo composto, bem como a geração das anafilatoxinas C3a/C3a desArg e C5a/C5a desArg e o complexo terminal do complemento, SC5b-9. A ativação da via clássica pode ter sido iniciada pela ligação da molécula iniciadora desta via, o C1q, ao ácido linoleico, um dos elementos presentes na composição do P-MAPA, através de seu domínio globular (BIRO; LING; ARLAUD, 2010). O ácido linoleico é um ácido graxo poliinsaturado usado na biossíntese do ácido araquidônico e na composição de membranas celulares, sendo um dos ácidos graxos essenciais da dieta humana (PATWARDHAN et al., 2009).

A via alternativa foi ativada por ambas as formas do composto, solubilizada e sólida (na forma de cristais). A complexidade de composição do P-MAPA pode ter contribuído para essa ativação, principalmente, nas condições de incubação do soro humano com cristais não solubilizados. Tal fato teria permitido a deposição de $C 3 b$, na superfície dos cristais, e iniciação da via alternativa. Contudo, a atividade observada sobre as vias clássica e alternativa pode também ser atribuída à presença da proteína, ainda não caracterizada, presente na estrutura do P-MAPA, ou por todo o complexo que compõe o composto. 
A produção de anafilatoxinas C3a/ C3a-desArg e C5a/ C5a-desArg ocorreu também nos tratamentos combinados de P-MAPA e LPS, demonstrando que os tratamentos induzem efeito pró-inflamatório. Nestes tratamentos, o aumento da produção das anafilatoxinas pode ser atribuído à presença de LPS no sistema in vitro, componente já conhecido como ativador do sistema complemento (LICHTENSTEIN et al., 1969; SLADOWSKI et al., 2001; SMEDEGARD; CUI; HUGLI, 1989). A produção de C3a e C5a, induzida pelo P-MAPA, parece ter ocorrido pela ativação da via alternativa, como observado no modelo de sangue total. Por outro lado, embora o tratamento com LPS + P-MAPA não tenha resultado em uma ativação mais potente desta via, a grande quantidade de anafilatoxinas observada no plasma, nesta condição, pode ser resultado da ativação simultânea das vias clássica e alternativa.

O tratamento com P-MAPA induziu expressões distintas dos receptores das anafilatoxinas, C3aR e C5aR. Embora a expressão de C3aR não tenha sido significativamente alterada, os tratamentos com P-MAPA diminuíram a expressão de C5aR, de modo ainda mais acentuado nos tratamentos conjuntos com LPS. O modelo de sangue total, no entanto, não permitiu definir se a redução da expressão de C5aR foi consequência da endocitose do complexo receptor-anafilatoxina, que é rapidamente internalizado e reciclado para retornar à membrana (NAIK et al., 1997; VAN EPPS et al., 1990), em um processo que leva cerca de 40 minutos, em neutrófilos bovinos (STEVENS et al., 2011), ou se ocorreu devido à presença de grandes concentrações de C5a (UNNEWEHR et al., 2013).

Outro fator que pode ter contribuído para a diminuição da expressão de C5aR na superfície celular é a ausência de IL-6. Estudos têm mostrado que esta citocina é capaz de induzir aumento na expressão de C5aR em neutrófilos e monócitos (RIEDEMANN; NEFF; et al., 2003), sendo que o P-MAPA não induziu produção de IL-6 no modelo de sangue humano. Quando a produção de C5a acontece em grandes quantidades, como durante a sepse, os neutrófilos, por expressarem um número significativo de C5aR na superfície celular, podem ter sua função reduzida e falhar na eliminação de bactérias (RIEDEMANN; GUO; WARD, 2003). Ainda, a diminuição da expressão de $C 5 a R$, em leucócitos de sangue periférico promovida pelos tratamentos com P-MAPA, na presença de LPS, é uma característica observada também em pacientes com sepse, no primeiro dia do diagnóstico (FUREBRING et al., 2002). Outro receptor de C5a, o C5L2, também está presente em neutrófilos e monócitos, mas suas funções ainda são controversas. Há indícios, no entanto, de que na 
presença de C5a, haja uma competição entre C5L2 e C5aR pela ligação de C5a, minimizando a ativação de C5aR (WARD, 2009). Todavia, a participação do C5L2 nas ações induzidas pelos tratamentos com P-MAPA não foi estudada, e nossos experimentos sugerem que a modulação de C5aR observada neste modelo, deveu-se a ativação do complemento induzida pelo composto.

Utilizando a compstatina, peptídeo inibidor específico para a proteína C3 do complemento (MORIKIS et al., 1998), há indícios do aumento da expressão de C5aR após o tratamento de leucócitos com P-MAPA, sugerindo que na ausência da ativação do complemento, não houve consequente clivagem de C5 e produção de C5a. Nestas condições, C5aR não seria endocitado, uma vez que não haveria ligação com C5a. Assim, estes dados sugerem que a ação do P-MAPA sobre a expressão de C5aR ocorre de maneira indireta, por ativação do complemento induzida pelo composto. No entanto, os ensaios demonstraram que o peptídeo controle da compstatina parece afetar a modulação da expressão dos receptores, não sendo um controle adequado.

A ativação de C5aR poderia ser a via responsável pela produção da citocina TNF- $\alpha$, detectada com o tratamento com o P-MAPA, pois a capacidade de C5a em induzir a produção de TNF- $\alpha$ já foi descrita na literatura (CAVAILLON; FITTING; HAEFFNER-CAVAILLON, 1990; OKUSAWA et al., 1988; SCHINDLER; GELFAND; DINARELLO, 1990).

Outro produto da clivagem espontânea de C3, que ocorre no plasma, é o iC3b, fração inativa cuja função é a opsonização. O receptor de iC3b é o complexo CD11b/CD18, conhecido como CR3 (complement receptor 3) (UEDA et al., 1994), que está presente na superfície de granulócitos, monócitos e macrófagos, e cuja função é mediar a adesão, migração e fagocitose por estas células (SABROE et al., 2002). O tratamento com P-MAPA induziu aumento deste receptor em leucócitos, de maneira dose e tempo dependentes (Apêndice B), enquanto a expressão de CD11b diferiu conforme os tratamentos conjuntos com LPS. Estas variações podem ter ocorrido devido à quantidade de iC3b produzida pelos tratamentos, mas também pelas interações entre CD11b e C5aR. Como foi observada redução da expressão de C5aR com o tratamento de LPS, seguido de P-MAPA, é possível que a baixa expressão de C5aR tenha afetado a via de sinalização de CD11b, impedindo o aumento de sua expressão na superfície celular (BREKKE et al., 2007; MOLLNES et al. 2002). Apesar de já ser descrito que C3a e C5a possuem a capacidade de modular a expressão de CD11b/CD18 na superfície celular (FOREMAN et al., 1996), a regulação positiva promovida 
pelo P-MAPA poderia ser, em parte, decorrente do ácido linoleico presente em sua composição. Esta propriedade do ácido linoleico foi relatada por MENA et al. (2013), que demonstraram que este lipídio promove aumento da expressão de CD11b em neutrófilos bovinos, além de induzir a liberação de grânulos bactericidas e MMP-9 (matrix metallopeptidase 9), fosforilação das vias de ativação MAPK p38 e ERK 1/2, e aumento da expressão de RNA mensageiro de COX-2 e IL-8. No entanto, testes realizados com ácido linoleico em sangue total não mostraram alteração da expressão de CD11b, o que indica que outro componente do P-MAPA possa ser o responsável pela modulação deste receptor.

A inibição de C3, promovida pela compstatina, regulou negativamente a expressão de CD11b em células tratadas com LPS, estando de acordo com publicações anteriores (BREKKE et al., 2007; MOLLNES et al. 2002; NILSSON et al., 1998; SOKOLOV et al., 2011), enquanto houve uma diminuição intermediária da expressão induzida por P-MAPA. Estes dados sugerem que possa haver outro fator, além do complemento, influenciando a expressão de CD11b na presença de P-MAPA.

Todas estas ativações compõem um perfil inflamatório e poderiam auxiliar na compreensão dos efeitos obtidos pelo tratamento com P-MAPA. A fagocitose induzida pela ativação de $\mathrm{CD} 11$ b é seguida pelo aumento das espécies reativas de oxigênio e nitrogênio, como superóxido $\left(\mathrm{O}_{2}^{-}\right)$e o produto de sua reação com óxido nítrico (NO), o peróxinitrito (ONOO') (BREKKE et al., 2008). Embora C5aR também esteja envolvido na indução de explosão respiratória, predominantemente em neutrófilos (BREKKE et al., 2008; MOLLNES et al., 2002), C5a não parece ter influenciado a produção de espécies reativas de oxigênio ou nitrogênio pelo P-MAPA, pois o composto não foi capaz de produzir superóxido, mas em dose alta $(1000 \mu \mathrm{g} / \mathrm{mL})$, produziu uma pequena concentração de peroxinitrito. É possível, no entanto, que o superóxido produzido pelo P-MAPA tenha sido consumido na reação com óxido nítrico, para formação de peroxinitrito, estando de acordo com o relato de que o composto induz a produção de óxido nítrico por macrófagos (BROMBERG et al., 2006). Tal produção poderia ser consequência da ativação de CD11b, que em conjunto com CD14 (BREKKE et al., 2008) e TLR4 (PERERA et al, 2001), tem sua função fagocítica potencializada (SENDIDE et al., 2005).

A ação do P-MAPA sobre CD14 foi também analisada, tendo sido observado que uma alta concentração do composto $(1000 \mu \mathrm{g} / \mathrm{mL})$ promove aumento desta molécula em leucócitos, assim como os tratamentos combinados com LPS. No entanto, a análise da 
expressão de CD14 em monócitos revelou uma diferença entre os diferentes tratamentos combinados, de maneira que o tratamento inicial com P-MAPA, seguido de LPS, parece promover um aumento deste receptor celular, enquanto o tratamento inicial com LPS, seguido da adição de P-MAPA, induziu a diminuição da expressão de CD14. Este perfil revela que a modulação do receptor é dependente do primeiro sinal que a célula recebe: P-MAPA ou LPS. Embora exista evidência de que o ácido linoleico possua isoformas capazes de modular negativamente a expressão de CD14, em macrófagos pré-tratados com o lipídeo e depois estimulados com LPS (DOWLING et al., 2013), a modulação de CD14 por P-MAPA não parece estar associada a este lipídeo, pois não foi observada alteração na expressão de CD14 após o tratamento com concentrações variadas de ácido linoleico.

A ativação de CD14, e o consequente aumento de sua expressão, poderia, ainda, ocorrer pelo estímulo por LPS (GOMES et al., 2010) e, também, por C5a (STEVENS et al., 2011). Por não possuir cauda transmembrana, acredita-se que o CD14 possa interagir extracelularmente com receptores do complemento como C3aR e C5aR e, através dessas interações, aumentar a expressão destes receptores e mediar diversas ações biológicas, como produção de TNF- $\alpha$ (BREKKE et al., 2007; BREKKE, et al., 2008).

Os efeitos dos tratamentos com P-MAPA sobre TLR2 e TLR4, receptores para os quais CD14 é co-receptor também foram estudados. O P-MAPA parece promover redução da expressão de TLR2 e TLR4 em leucócitos, mas os tratamentos combinados com LPS induziram uma redução significativa deste receptor. Deste modo, nossos resultados divergem de outros estudos, nos quais foi reportado que o P-MAPA possui capacidade de induzir aumento de TLR2 e TLR4 (FÁVARO et al., 2012; MELO et al., 2010). Tais diferenças podem ser devidas aos modelos experimentais utilizados e à forma de administração do PMAPA. Melo et al. (2010) e Melo et al. (2014) trataram células mononucleadas de cães, infectados com leishimaniose visceral, com P-MAPA não solubilizado, sob a forma de cristais $(2,5,5,10 \mu \mathrm{g} / \mathrm{mL})$, enquanto FÁVARO et al. (2012) trataram ratas Fisher 344 com injeções intravesicais de P-MAPA ( $5 \mathrm{mg} / \mathrm{kg}$ ), a cada duas semanas, por 8 semanas.

A redução da expressão de TLR4 apresentada em nosso trabalho, predominantemente por monócitos, células que expressam maior quantidade deste receptor (SABROE et al., 2002), pode ter ocorrido por internalização do receptor após a ligação com seu agonista. Husebye e colaboradores (2006) mostraram que nas primeiras horas de tratamento de monócitos humanos com LPS, ocorre internalização do complexo 
TLR4-LPS, seguida da detecção de LPS e TLR4 em endossomos. Estas internalizações foram demonstradas como sendo dependentes de CD14 (SHUTO et al., 2005). É possível que a redução da expressão de TLR4 induzida por P-MAPA, na presença e ausência de LPS, também tenha sido regulada por CD11b. Segundo Han et al. (2010), CD11b modula negativamente a expressão de TLRs pela fosforilação de MyD88 e TRIF, proteínas envolvidas na via de sinalização destes receptores, por Syk, uma tirosina quinase ativada por CD11b. Após a fosforilação, MyD88 e TRIF são degradados, impedindo a translocação de fatores de transcrição para o núcleo e prevenindo a ativação exacerbada dos leucócitos. Ainda, a ativação de TLR4 pela deteç̧ão de LPS, aciona a cascada de sinalização via MyD88 que leva à translocação do fator de transcrição NFkB para o núcleo, e produção de citocinas próinflamatórias, como TNF- $\alpha$ (AKIRA; TAKEDA, 2004; SATO et al., 2000), e aumento da explosão respiratória (REMER; BRCIC; JUNGI, 2003), produtos encontrados após nossos tratamentos experimentais.

Os efeitos biológicos da ativação do TLR4 podem também ter ocorrido de maneira indireta, por crosstalk com receptor C5aR. C5aR pode ativar o complexo TLR4/CD14, interferindo na via de sinalização de TLR4 (STEVENS et al., 2011), aumentando a ativação de NFkB, na presença de grandes quantidades de C3a e C5a (ZHANG et al., 2007) em monócitos e granulócitos. A contribuição de TLR4 para a produção de TNF- $\alpha$ pode também acontecer por meio do crosstalk com C5aR e C3aR, possivelmente através de MAPK e PI3K (HAJISHENGALLIS; LAMBRIS, 2010). Além disso, foi observada uma relação entre a grande produção de C5a e a diminuição da presença de IL-12 no plasma, após tratamento com LPS+P-MAPA. É possível que C5a tenha interferido negativamente na produção desta citocina, uma vez que já está descrito na literatura que C5a regula negativamente a produção de IL-12 e de outras citocinas desta mesma família, induzida pela ativação de TLR4, por meio da inibição de PI3K (BRAUN; LAHEY; KELSALL, 2000; HAWLISCH et al., 2005; WITTMANN et al., 1999; ZAAL et al., 2013). A produção de IL-8 induzida por TLR4 também pode ser modulada no crosstalk entre complemento e receptores tipo Toll. Ao comparar a produção de C5a e IL-8 nos tratamentos com P-MAPA e combinações com LPS, observam-se padrões similares, sugerindo que a grande produção de C5a por estes tratamentos combinados poderia estar associada à produção de IL-8 pela interação de C5aR com TLR4. Segundo Wang, Han et al. (2010), a presença de C5a amplifica a produção de IL-8, induzida por TLR4, pelas vias de sinalização ERK1/2 e p38. 
A produção de IL-8 por LPS depende também de TLR2, conforme mostrado por KurtJones et al. (2002). Assim como TLR4, a expressão de TLR2 foi também modulada negativamente pelos tratamentos combinados de P-MAPA e LPS, diferentemente do que reportado em trabalhos anteriores com o P-MAPA (FÁVARO et al., 2012; MELO et al., 2010; MELO et al., 2014). Apesar de não ser o principal receptor para LPS, a redução da expressão de TLR2 em monócitos está associada à hiporresponsividade à endotoxina, característica apresentada por pacientes que falecem devido à septicemia (ARMSTRONG et al., 2004; SCHAAF et al., 2009). Nestas condições, é possível que o tratamento associado de P-MAPA com LPS, independente do momento do estímulo, induza um perfil prejudicial, de supressão da função celular, como visto em trabalhos que relatam que o crosstalk entre C5aR e TLR2 suprime a produção de óxido nítrico, envolvido na destruição de bactérias, por meio da via de sinalização por cAMP, em macrófagos (WANG, KRAUSS et al., 2010). A influência do complemento sobre a expressão de TLR2 induzida por P-MAPA ou LPS é sugerida após a utilização da compstatina, cujo tratamento parece promover aumento da expressão de TLR2, indicando que o complemento regularia negativamente a expressão de TLRs, de acordo com a literatura (WEAVER, et al., 2010). Assim, a atuação do P-MAPA sobre TLR2 poderia ocorrer de maneira indireta, através da ativação do complemento, ou indireta, uma vez que o tratamento com ácido linoleico, lipídio presente no polímero, induziu redução da expressão deste receptor. Já foi descrito que o ácido linoleico pode reduzir a indução de COX-2 por TLR2 (LEE et al., 2003), mas não foram encontradas evidências na literatura de que tal componente possa modular a expressão deste TLR.

Neste estudo, os tratamentos com P-MAPA não induziram a produção de IL-1ß. Tal ausência indica que o P-MAPA não induz a ativação de inflamassomas. Estes complexos multiproteicos intracelulares detectam sinais de estresse celular e induzem a ativação de enzimas da família cisteína-aspartato proteases (caspases), como a caspase-1. Como consequência, a indução desta leva à produção de IL-1 $\beta$ e morte celular por piroptose (revisado por LATZ; XIAO; STUTZ, 2013). A citocina TGF- $\beta 1$ foi também detectada no plasma, após o tratamento com LPS+P-MAPA, em consequência da presença de LPS (ASSOIAN et al., 1987).

Trabalhos descreveram que o P-MAPA induz aumento dos níveis de IFN- $\gamma$ e diminuição dos níveis de IL-10, em modelos animais (de MELO; JUSTO; de SOUZA QUEIROZ, 2001; JUSTO; DURÁN; QUEIROZ, 2003; SANTIAGO et al., 2013). Em contraposição, no 
presente estudo observou-se diminuição dos níveis de IFN- - pelos tratamentos com P-MAPA e, na combinação de P-MAPA+LPS, sendo que não foi detectada a presença de IL-10 no plasma. O P-MAPA, no modelo de sangue total, induziu a produção de IL-12, citocina responsável por estimular a diferenciação de linfócitos $\mathrm{T}^{\mathrm{C}} \mathrm{CD}^{+}$em $\mathrm{T}_{\mathrm{h}} 1$, e estimular a produção de IFN- $\gamma$ pelas células NK. A diminuição de IFN- $\gamma$ no plasma pode estar relacionada ao tempo de tratamento utilizado neste estudo, uma vez que a IL-12, gerada neste modelo, poderia induzir a produção tardia de IFN- $\gamma$. A ausência de IL-10 no plasma reforçam o potencial próinflamatório do P-MAPA.

Este trabalho foi o primeiro a avaliar os efeitos do P-MAPA solubilizado. Como trabalhos anteriores haviam relatado que o composto induzia aumento da expressão de receptores do tipo Toll 2 e 4, realizamos testes para verificar se os cristais de P-MAPA induziriam efeitos distintos nestes receptores no modelo de sangue total. Os resultados mostraram que o composto não foi capaz de promover modulações quando utilizado sob a forma de cristais, não solubilizados. É provável que esta estrutura complexa tenha prejudicado a interação com os receptores, assim como a ativação do complemento. Estas observações estão de acordo com os resultados aqui apresentados, de que para a ativação da via alternativa é necessária uma maior concentração de P-MAPA não solubilizado, quando comparada à ativação promovida pelo composto solubilizado.

A toxicidade do P-MAPA solubilizado foi testada in vivo, estabelecendo-se a dose letal $\mathrm{DL}_{50}=736,07 \mathrm{mg} / \mathrm{kg}$. Logo após a injeção do composto, os animais que receberam doses de $1000 \mathrm{mg} / \mathrm{kg}$ ou $2000 \mathrm{mg} / \mathrm{kg}$ mostraram-se prostrados, vindo a óbito cerca de 1 hora após a administração do composto.

Os principais eventos de crosstalk entre complemento e TLRs envolvem amplificação de vias de sinalização, que culminam no aumento da produção de citocinas. As relações entre o sistema complemento e receptores do tipo Toll têm sido descritas em estudos relativamente recentes e, muitos mecanismos de interação, ainda não estão totalmente esclarecidos. Por ter uma estrutura complexa, é difícil atribuir as ações do P-MAPA em sangue total a um único elemento de sua composição. Neste aspecto, uma avaliação sobre os efeitos de cada porção de sua composição poderia esclarecer qual porção do composto induz a ativação de receptores dos leucócitos, como por exemplo, o palmitoleato, que é capaz de diminuir a expressão de MCP-1 em adipócitos de camundongos, como demonstrado por Cao et al. (2008). 
Os resultados aqui apresentados mostram que o composto é capaz de agir sobre o sistema complemento e que esta ativação possa talvez promover amplificação das modulações induzidas pelo P-MAPA sobre os vários receptores celulares. A produção de citocinas TNF- $\alpha$, IL-8 e IL-12 pelo P-MAPA indica que o composto é capaz de ativar os leucócitos do sangue periférico, promover quimiotaxia de neutrófilos e auxiliar na diferenciação de linfócitos $\mathrm{TCD}^{+}$para o perfil $\mathrm{T}_{\mathrm{h}} 1$, conforme também indicado em estudos anteriores (de MELO; JUSTO; de SOUZA QUEIROZ, 2001; JUSTO; DURÁN; QUEIROZ, 2003; SANTIAGO et al., 2013).

Devido aos efeitos pró-inflamatórios promovidos pelo P-MAPA, o composto pode ser utilizado como imunoestimulante, podendo servir como terapia complementar em casos de imunossupressão. 


\section{CONCLUSÕES}

Em conjunto, os resultados deste estudo mostram que o P-MAPA promove uma série de efeitos pró-inflamatórios, relacionadas, principalmente, à sua capacidade de ativar o sistema complemento pelas vias clássica e alternativa. Tais ativações parecem ser importantes para a modulação da expressão de marcadores celulares em leucócitos de sangue periférico humano e produção de citocinas.

A ativação do complemento pelo P-MAPA resultou na geração das anafilatoxinas C5a e C3a, que contribuíram para ativar os receptores celulares estudados, de maneira direta ou indireta. O composto demonstrou capacidade de modular a expressão de marcadores celulares em leucócitos de sangue periférico humano, aumentando a expressão de CD11b e CD14, e reduzindo a expressão de C5aR, TLR4 e TLR2, mas não alterou a expressão de C3aR. O P-MAPA parece agir diretamente sobre TLR2, por meio do ácido linoleico presente em sua composição. Nossos dados sugerem que o composto ativa diretamente o receptor CD11b, sendo que não foi identificado o componente responsável por tal interação.

Os dados de inibição do complemento sugerem que o P-MAPA possa interagir com TLR2 e TLR4 de maneira direta ou indireta, e que por meio dessas interações, o P-MAPA induziria a produção de citocinas. Como resultado da ação do P-MAPA sobre os diferentes receptores, observou-se a produção de TNF- $\alpha$, IL-8, IL-12(p70), e peróxinitrito, mas não de IL-6, IL-1 $\beta$, IL-10, IFN- $\gamma$, TGF- $\beta$ e superóxido. Quando combinado ao LPS, mesmo em diferentes momentos, o P-MAPA pareceu acentuar as modificações na expressão dos receptores, indicando que o composto é capaz de ativar as células com consequente produção de mediadores pró-inflamatórios. 


\section{REFERÊNCIAS ${ }^{2}$}

AKIRA, S.; TAKEDA, K. Toll-like receptor signalling. Nat. Rev. Immunol., v. 4, n. 7, p. 499-511, 2004.

ARMSTRONG, L.; MEDFORD, A. R.; HUNTER, K. J.; UPPINGTON, K. M.; MILLAR, A. B. Differential expression of Toll-like receptor (TLR)-2 and TLR-4 on monocytes in human sepsis. Clin. Exp. Immunol., v. 136, n. 2, p. 312-319, 2004.

ASSOIAN, R. K.; FLEURDELYS, B. E.; STEVENSON, H. C.; MILLER, P. J.; MADTES, D. K. ; RAINES, E. W.; ROSS, R.; SPORN, M. B. Expression and secretion of type beta transforming growth factor by activated human macrophages. Proc. Natl. Acad. Sci. USA, v. 84, n. 17, p. 60206024, 1987.

BANNENBERG, G. L.; CHIANG. N.; ARIEL, A.; ARITA, M.; TJONAHEN, E.; GOTLINGER, K. H.; HONG, S.; SERHAN, C. N. Molecular circuits of resolution: formation and actions of resolvins and protectins. J. Immunol., v. 174, n. 7, p. 4345-4355, 2005.

BAUMANN, C. L.; ASPALTER, I. M.; SHARIF, O.; PICHLMAIR, A.; BLÜML, S.; GREBIEN, F.; BRUCKNER, M.; PASIERBEK, P.; AUMAYR, K.; PLANYAVSKY, M.; BENNETT, K. L.; COLINGE, J.; KNAPP, S.; SUPERTI-FURGA, G. CD14 is a co-receptor of Toll-like receptors 7 and 9. J. Exp. Med., v. 207, n. 12, p. 2689-2701, 2010.

BERCZI, I.; QUINTANAR-STEPHANO, A.; KOVACS, K. Immunoconversion in acute phase response. In: FAITH, R. E.; MURGO, A. J.; GOOD, R. A.; PLOTNIKOFF, N. P. (Ed.). Cytokines: stress and immunity. Boca Raton, FL, EUA: CRC Press, 2006. Chapter 14. p. 215-254.

BEXBORN, F.; ENGBERG, A. E.; SANDHOLM, K.; MOLLNES, T. E.; HONG, J.; EKDAHL, K. N. Hirudin versus heparin for use in whole blood in vitro biocompatibility models. J. Biomed. Mater. Res. A, v. 89, n. 4, p. 951-959, 2009.

BIRO, A.; LING, W. L.; ARLAUD, G. J. Complement protein C1q recognizes enzymatically modified low-density lipoprotein through unesterified fatty acids generated by cholesterol esterase. Biochemistry, v. 49, n. 10, p. 2167-2176, 2010.

BRAUN, M. C.; LAHEY, E.; KELSALL, B. L. Selective Suppression of IL-12 Production by Chemoattractants. J. Immunol., v. 164, p. 3009-3017, 2000.

BREKKE, O. L.; CHRISTIANSEN, D.; FURE, H.; FUNG, M.; MOLLNES, T.E. The role of complement C3 opsonization, C5a receptor, and CD14 in E. coli- induced up-regulation of granulocyte and monocyte CD11b/CD18 (CR3), phagocytosis, and oxidative burst in human whole blood. J. Leukoc. Biol., v. 81, n. 6, p. 1404-1413, 2007.

BREKKE, O.L.; CHRISTIANSEN, D.; FURE, H.; PHARO, A.; FUNG, M.; RIESENFELD, J.; MOLLNES, T.E. Combined inhibition of complement and CD14 abolish E. coli-induced cytokine-,

${ }^{2}$ De acordo com:

ASSOCIAÇÃO BRASILEIRA DE NORMAS TÉCNICAS. NBR 6023: informação e documentação: referências: elaboração. Rio de Janeiro, 2002. 
chemokine- and growth factor-synthesis in human whole blood. Mol. Immunol., v. 45, n. 14, p. 3804-3813, 2008.

BROMBERG, N.; JUSTO, G.Z.; SEABRA, A. B.; DURÁN, N. Macrophage nitric oxide (NO) stimulation by an immunomodulator: P-MAPA. Nitric Oxide, v. 14, p. A37, 2006.

CAO, H.; GERHOLD, K.; MAYERS, J. R.; WIEST, M. M.; WATKINS, S. M.; HOTAMISLIGIL, G. S. Identification of a lipokine, a lipid hormone linking adipose tissue to systemic metabolism. Cell, v. 134, n. 6, p. 933-944, 2008.

CAVAILLON, J. M.; FITTING, C.; HAEFFNER-CAVAILLON, N. Recombinant C5a enhances interleukin 1 and tumor necrosis factor release by lipopolysaccharide-stimulated monocytes and macrophages. Eur. J. Immunol., v. 20, p. 253-257, 1990.

CHOW, J. C.; YOUNG, D. W.; GOLENBOCK, D. T.; CHRIST, W. J.; GUSOVSKY, F. Toll-like receptor-4 mediates lipopolysaccharide-induced signal transduction. J. Biol. Chem., v. 274, n. 16, p. 10689-10692, 1999.

CHRISTIANSEN, D.; BREKKE, O. L,; STENVIK, J.; LAMBRIS, J. D.; ESPEVIK, T.; MOLLNES, T. E. Differential effect of inhibiting MD-2 and CD14 on LPS- versus whole $E$. coli bacteria-induced cytokine responses in human blood. Adv. Exp. Med. Biol., v. 946, p. 237-251, 2012.

de MELO, A.; JUSTO, G. Z.; DE SOUZA QUEIROZ, M. L. Stimulation of myelopoiesis in Listeria monocytogenes-infected mice by an aggregated polymer isolated from Aspergillus oryzae. Hum. Exp. Toxicol., v. 20, p. 38-45, 2001.

DOWLING, J. K.; MCCOY, C. E.; DOYLE, S. L.; BENLARBI, N.; CANAVAN, M.; O'NEILL, L. A.; LOSCHER, C. E. Conjugated linoleic acid suppresses IRF3 activation via modulation of CD14. J Nutr Biochem, v. 24, n. 5, p. 920-928, 2013.

DURÁN, M.; MARCATO, P. D.; TASIC, L. J.; DURÁN, N. Nanonization on biotechnological product: Nanocrystals and its polymorphisms. Disponível em: http://www.farmabrasilis.org.br/dbarquivos/Nanonization_82795152.pdf. Acesso em: 17 out. 2013.

DURAN, N. E. C.; NUNES, O. D. Polymeric anhydride of magnesium and proteic ammonium phospholinoleate with antiviral, antineoplastic and immunostimulant properties. Brasil, 1991, US Pat. 5073630.

DURÁN, N.; GOWEN, B. B.; COSTA, F. T. M.; JUSTO, G. Z.; BROCCHI, M.; NUNES, O. S.; NUNES, I. S. A biotechnological product and its potential as a new immunomodulator for treatment of animal phlebovirus infection: Punta Toro virus. Antiviral Res., v. 83, p. 143-147, 2009.

EGGE, K. H.; THORGERSEN, E. B.; LINDSTAD, J. K.; PHARO, A.; LAMBRIS, J.D.; BARRATT-DUE, A.; MOLLNES, T. E. Post-challenge inhibition of C3 and CD14 attenuates Escherichia coliinduced inflammation in human whole blood. Innate Immun., v. 20, n. 1, p. 68-77, 2013. 
FARMABRASILIS. P-MAPA Immunomodulator - General Product Information. 2010.

FARMABRASILIS. P-MAPA: Overview, 2008.

FÁVARO, W. J.; NUNES, O. S.; SEIVA, F. R. F.; NUNES, I. S.; WOOLHISER, L. K.; DURÁN, N.; LENAERTS, A. J. Effects of P-MAPA Immunomodulator on Toll-Like Receptors and p53: Potential Therapeutic Strategies for Infectious Diseases and Cancer. Infect. Agent. Cancer., v. 7, n. 1, p. 14, 2012.

FERNANDEZ, H. N.; HENSON, P. M.; OTANI, A.; HUGLI, T. E. Chemotactic response to human C3a and C5a anaphylatoxins. I. Evaluation of C3a and C5a leukotaxis in vitro and under stimulated in vivo conditions. J. Immunol., v. 120, n. 1, p. 109-115, 1978.

FIORAVANTI, C. H. Fungos, instituições, máquinas e pessoas em negociação: o percurso do fármaco P-MAPA. 2010. 259 f. Tese (Doutorado em Política Científica e Tecnológica) Instituto de Geociências, Universidade Estadual de Campinas, Campinas, SP, 2010.

FINNEY, D. J. Probit analysis. 3rd ed. London: Cambridge University Press, 1971. 333 p.

FOREMAN, K. E.; GLOVSKY, M. M.; WARNER, R. L.; HORVATH, S. J.; WARD, P. A. Comparative effect of $\mathrm{C} 3 \mathrm{a}$ and $\mathrm{C} 5 \mathrm{a}$ on adhesion molecule expression on neutrophils and endothelial cells. Inflammation, v. 20, n. 1, p. 1-9, 1996.

FUREBRING, M.; HAKANSSON, L. D.; VENGE, P.; NILSSON, B.; SJOLIN, J. Expression of the C5a receptor (CD88) on granulocytes and monocytes in patients with severe sepsis. Crit. Care., v. 6, n. 4, p. 363-370, 2002.

GOMES, N. E.; BRUNIALTI, M. K. C.; MENDES, M. E.; FREUDENBERG, M.; GALANOS, C.; SALOMAO, R. Lipopolysaccharide-induced expression of cell surface receptors and cell activation of neutrophils and monocytes in whole human blood. Braz. J. Med. Biol. Res., v. 43, n. 9, p. 853-859, 2010.

HAJISHENGALLIS, G.; LAMBRIS, J. D. Crosstalk pathways between Toll-like receptors and the complement system. Trends Immunol., v. 31, n. 4, p. 154-163, 2010.

HAJISHENGALLIS, G.; LAMBRIS, J. D. Microbial manipulation of receptor crosstalk in innate immunity. Nat. Rev. Immunol., v. 3, p. 187-200, 2011.

HAN, C.; JIN, J.; XU, S.; LIU, H.; LI, N.; CAO, X. Integrin CD11b negatively regulates TLRtriggered inflammatory responses by activating Syk and promoting degradation of MyD88 and TRIF via Cbl-b. Nat. Immunol., v. 11, n. 8, p. 734-742, 2010.

HAWLISCH, H.; BELKAID, Y.; BAELDER, R.; HILDEMAN, D.; GERARD, C.; KÖHL, J. C5a negatively regulates Toll-like receptor 4-induced immune responses. Immunity, v. 22, n. 4, p. 415-426, 2005. 
HEUMANN, D.; ROGER, T. Initial responses to endotoxins and Gram-negative bacteria. Clin. Chim. Acta., v. 323, n. 1-2, p. 59-72, 2002.

HUSEBYE, H.; HALAAS, $\varnothing$.; STENMARK, H.; TUNHEIM, G.; SANDANGER, $\varnothing$.; BOGEN, B.; BRECH, A.; LATZ, E.; ESPEVIK, T. Endocytic pathways regulate Toll-like receptor 4 signaling and link innate and adaptive immunity. EMBO. J., v. 25, n. 4, p. 683-692, 2006.

JUSTO, G. Z.; DURÁN, N.; QUEIROZ, M. L. S. Myelopoietic response in tumour-bearing mice by an aggregated polymer isolated from Aspergillus oryzae. Eur. J. Pharmacol., v. 388, p. 219-226, 2000.

JUSTO, G. Z.; DURÁN, N.; QUEIROZ, M. L. S. Natural killer cell activity, lymphocyte proliferation and cytokine profile in tumor-bearing mice treated with MAPA, a magnesium aggregated polymer from Aspergillus oryzae. Immunopharmacol. Immunotoxicol., v. 25, n. 3, p. 305-319, 2003.

KAWAI, T.; AKIRA, S. Toll-like Receptors and Their Crosstalk with Other Innate Receptors in Infection and Immunity. Immunity, v. 34, n. 5, p. 637-650, 2011.

KLOS, A.; TENNER, A. J.; JOHSWICH, K. O.; AGER, R. R.; REIS, E. S.; KOHL, J. The role of the anaphylatoxins in health and disease. Mol. Immunol., v. 46, n. 14, p. 2753-2766, 2009.

KURT-JONES, E. A.; MANDELL L.; WHITNEY, C.; PADGETT, A.; GOSSELIN, K.; NEWBURGER, P. E.; FINBERG, R. W. Role of Toll-like receptor 2 (TLR2) in neutrophil activation: GM-CSF enhances TLR2 expression and TLR2-mediated interleukin 8 responses in neutrophils. Blood, v. 100, n. 5, p. 1860-1868, 2002.

LANGKABEL, P.; ZWIRNER, J.; OPPERMANN, M. Ligand-induced phosphorylation of anaphylatoxin receptors $\mathrm{C} 3 \mathrm{aR}$ and $\mathrm{C} 5 \mathrm{aR}$ is mediated by $\mathrm{G}$ protein-coupled receptor kinases. Eur. J. Immunol., v. 9, p. 3035-3046, 1999.

LAPPEGÅRD, K. T.; CHRISTIANSEN, D.; PHARO, A.; THORGERSEN, E. B.; HELLERUD, B. C.; LINDSTAD, J.; NIELSEN, E. W.; BERGSETH, G.; FADNES, D.; ABRAHAMSEN, T. G.; HØIBY, E. A.; SCHEJBEL, L.; GARRED, P.; LAMBRIS, J. D.; HARBOE, M.; MOLLNES, T. E. Human genetic deficiencies reveal the roles of complement in the inflammatory network: lessons from nature. Proc. Natl. Acad. Sci. USA., v. 106, n. 37, p. 15861-15866, 2009.

LATZ, E.; XIAO, T. S.; STUTZ, A. Activation and regulation of the inflammasomes. Nat. Rev. Immunol., v. 13, n. 6, p. 397-411, 2013.

LEE, J. Y.; PLAKIDAS, A.; LEE, W. H.; HEIKKINEN, A.; CHANMUGAM, P.; BRAY, G., HWANG, D. $H$. Differential modulation of Toll-like receptors by fatty acids: preferential inhibition by $n-3$ polyunsaturated fatty acids. J. Lipid. Res., v. 44, n. 3, p. 479-486, 2003.

LICHTENSTEIN, L. M.; GEWURZ, H.; ADKINSON, N. F., JR.; SHIN, H. S.; MERGENHAGEN, S. E. Interactions of the complement system with endotoxic lipopolysaccharide: the generation of an anaphylatoxin. Immunology, v. 16, n. 3, p. 327-336, 1969. 
MARTIN, U.; BOCK, D.; ARSENIEV, L.; TORNETTA, M. A.; AMES, R. S.; BAUTSCH, W.; KOHL, J.; GANSER, A.; KLOS, A. The human C3a receptor is expressed on neutrophils and monocytes, but not on B or T lymphocytes. J. Exp. Med., v. 186, n. 2, p. 199-207, 1997.

MATHISON, J.; WOLFSON, E.; STEINEMANN, S.; TOBIAS, P.; ULEVITCH, R. Lipopolysaccharide (LPS) recognition in macrophages. Participation of LPS-binding protein and CD14 in LPSinduced adaptation in rabbit peritoneal exudate macrophages. J. Clin. Invest., v. 92, n. 4, p. 2053-2059, 1993.

MELO, L. M.; ANDRADE, M. C. M.; LIMA, V. M. F. Increased TRL2 and TLR4 expression in mononuclear cells from dogs naturally infected by Leishmania $s p$. after immunomodulator treatment. In: ANNUAL MEETING OF THE BRAZILIAN SOCIETY OF PROTOZOOLOGY, 26., 2010, Foz do Iguaçu. Abstracts... Foz do Iguaçu, 2010. p. 173. Disponível em: <http://itpack31.itarget.com.br/uploads/spz/arquivos/14_imunologia_2010> Acesso em: 4 jul. 2011.

MELO, L. M.; PEROSSO, J.; ALMEIDA, B. F.; SILVA, K. L.; SOMENZARI, M. A.; de LIMA, V. M. Effects of P-MAPA immunomodulator on Toll-like receptor 2, ROS, nitric oxide, MAPKp38 and IKK in PBMC and macrophages from dogs with visceral leishmaniasis. Int. Immunopharmacol., v. 2, p. 373-378, 2014.

MENA, J.; MANOSALVA, C.; RAMIREZ, R.; CHANDIA, L.; CARROZA, D.; LOAIZA, A.; BURGOS, R. A.; HIDALGO, M. A. Linoleic acid increases adhesion, chemotaxis, granule release, intracellular calcium mobilisation, MAPK phosphorylation and gene expression in bovine neutrophils. Vet. Immunol. Immunopathol., v. 151, n. 3-4, p. 275-284, 2013.

MOLLNES, T.E.; BREKKE, O.L.; FUNG, M.; FURE, H.; CHRISTIANSEN, D.; BERGSETH, G.; VIDEM, V.; LAPPEGÅRD, K.T.; KÖHL, J.; LAMBRIS, J.D. Essential role of the C5a receptor in E. coliinduced oxidative burst and phagocytosis revealed by a novel lepirudin-based human whole blood model of inflammation. Blood, v. 100, n. 5, p. 1869-1877, 2002.

MORESCO, E. M. Y.; LAVINE, D.; BEUTLER, B. Toll-like receptors. Current Biology, v. 21, n. 13, p. R488-R493, 2011.

MORIKIS, D.; ASSA-MUNT, N.; SAHU, A.; LAMBRIS, J.D. Solution structure of Compstatin, a potent complement inhibitor. Protein. Sci., v. 7, n. 3, p. 619-627, 1998.

NAIK, N.; GIANNINI, E.; BROUCHON, L.; BOULAY, F. Internalization and recycling of the C5a anaphylatoxin receptor: evidence that the agonist-mediated internalization is modulated by phosphorylation of the C-terminal domain. J. Cell. Sci., v. 110, p. 2381-2390, 1997.

NDUKA, O.; PARRILLO, J. The pathophysiology of septic shock. Crit. Care. Clin., v. 23, n. 1, p. 41-66, 2011. 
NILSSON, B.; LARSSON, R.; HONG, J.; ELGUE, G.; EKDAHL, K. N.; SAHU, A.; LAMBRIS, J. D. Compstatin inhibits complement and cellular activation in whole blood in two models of extracorporeal circulation. Blood, v. 92, n. 5, p. 1661-1667, 1998.

OKAZAKI, N.; HAZEKI, K.; IZUMI, T.; NIGORIKAWA, N.; HAZEKI, O. C5a controls TLR-induced IL10 and IL-12 production independent of phosphoinositide 3-kinase. J. Biochem., v. 149, n. 3, p. 265-274, 2011.

OKUSAWA, S.; YANCEY, K. B.; VAN DER MEER, J. W.; ENDRES, S.; LONNEMANN, G.; HEFTER, K.; FRANK, M. M.; BURKE, J. F.; DINARELLO, C. A.; GELFAND, J. A. C5a stimulates secretion of tumor necrosis factor from human mononuclear cells in vitro. Comparison with secretion of interleukin 1 beta and interleukin 1 alpha. J. Exp. Med., v. 168, p. 443-448, 1988.

PAPADOPOULOS, G.; WEINBERG, E. O.; MASSARI, P.; GIBSON, F. C. 3rd; WETZLER, L. M.; MORGAN, E. F.; GENCO, C .A. Macrophage-specific TLR2 signaling mediates pathogeninduced TNF-dependent inflammatory oral bone loss. J. Immunol., v. 190, n. 3, p. 1148-1157, 2013.

PATWARDHAN, A. M.; SCOTLAND, P. E.; AKOPIAN, A. N.; HARGREAVES, K. M. Activation of TRPV1 in the spinal cord by oxidized linoleic acid metabolites contributes to inflammatory hyperalgesia. Proc. Natl. Acad. Sci. USA, v. 106, n. 44, p. 18820-18824, 2009.

PERERA, P.Y.; MAYADAS, T.N.; TAKEUCHI, O.; AKIRA, S.; ZAKS-ZILBERMAN, M.; GOYERT, S.M.; VOGEL, S.N. CD11b/CD18 Acts in Concert with CD14 and Toll-Like Receptor (TLR) 4 to Elicit Full Lipopolysaccharide and Taxol-Inducible Gene Expression. J. Immunol., v. 166, p. 574581, 2001.

RABY, A. C.; HOLST, B.; LE BOUDER, E.; DIAZ, C.; FERRAN, E.; CONRAUX, L.; GUILLEMOT, J. C.; COLES, B.; KIFT-MORGAN, A.; COLMONT, C. S.; SZAKMANY, T.; FERRARA, P.; HALL, J. E.; TOPLEY, N.; LABÉTA, M. O. Targeting the TLR Co-Receptor CD14 with TLR2-Derived Peptides Modulates Immune Responses to Pathogens. Sci. TransI. Med., v. 5, n. 185, 2013.

RABY, A.C.; HOLST, B.; DAVIES, J.; COLMONT, C.; LAUMONNIER, Y.; COLES, B.; SHAH, S.; HALL, J.; TOPLEY, N.; KÖHL, J.; MORGAN, B.P.; LABÉTA, M.O. TLR activation enhances C5a-induced pro-inflammatory responses by negatively modulating the second C5a receptor, C5L2. Eur. J. Immunol., v. 41, n. 9, p. 2741-2752, 2011.

REIS, L.; FERREIRA, U.; BILLIS, A.; CASTELLO, A.; NUNES, I.; DURÁN, N.; CAGNON, V.; FÁVARO, W. Putative cancer stem cells (CSCS) signaling after immunotherapy with bacillus calmetteguerin (BCG) and P-MAPA in the superficial bladder cancer (SBC). The Journal of Urology, $v$. 185, n. 4S , 2011. Supplement.

REMER, K. A.; BRCIC, M.; JUNGI, T. W. Toll-like receptor-4 is involved in eliciting an LPSinduced oxidative burst in neutrophils. Immunol. Lett., v. 85, n. 1, p. 75-80, 2003.

RICKLIN, D.; HAJISHENGALLIS, G.; YANG, K.; LAMBRIS, J. D. Complement: a key system for immune surveillance and homeostasis. Nat. Immunol., v. 9, p. 785-797, 2010. 
RIEDEMANN, N. C.; GUO, R. F.; WARD, P. A. A key role of C5a/C5aR activation for the development of sepsis. J. Leukoc. Biol., v. 74, n. 6, p. 966-970, 2003.

RIEDEMANN, N. C.; NEFF, T. A.; GUO, R. F.; BERNACKI, K. D.; LAUDES, I. J.; SARMA, J. V.; LAMBRIS, J. D.; WARD, P. A. Protective effects of IL-6 blockade in sepsis are linked to reduced C5a receptor expression. J. Immunol., v. 170, n. 1, p. 503-507, 2003.

ROSS, G. D.; VĔTVICKA, V. CR3 (CD11b, CD18): a phagocyte and NK cell membrane receptor with multiple ligand specificities and functions. Clin. Exp. Immunol., v. 92, n. 2, p. 181-184, 1993.

SABROE, I.; JONES, E. C.; USHER, L. R.; WHYTE, M. K.; DOWER, S. K. Toll-like receptor (TLR)2 and TLR4 in human peripheral blood granulocytes: a critical role for monocytes in leukocyte lipopolysaccharide responses. J. Immunol., v. 168, n. 9, p. 4701-4710, 2002.

SANTIAGO, M. E.; NETO, L. S.; ALEXANDRE, E. C.; MUNARI, D. P.; ANDRADE, M. M.; SOMENZARI, M. A.; CIARLINI, P. C.; de LIMA, V. M. Improvement in clinical signs and cellular immunity of dogs with visceral leishmaniasis using the immunomodulator P-MAPA. Acta Trop., v. 127, n. 3, p. 174-180, 2013.

SARMA, J. V.; WARD, P. A. The complement system. Cell Tissue Res., v. 343, n. 1, p. 227-235, 2011.

SATO, S.; NOMURA, F.; KAWAI, T.; TAKEUCHI, O.; MUHLRADT, P. F.; TAKEDA, K.; AKIRA, S. Synergy and cross-tolerance between toll-like receptor (TLR) 2- and TLR4-mediated signaling pathways. J. Immunol., v. 165, n. 12, p. 7096-7101, 2000.

SCHAAF, B.; LUITJENS, K.; GOLDMANN, T.; VAN BREMEN, T.; SAYK, F.; DODT, C.; DALHOFF, K.; DROEMANN, D. Mortality in human sepsis is associated with downregulation of Toll-like receptor 2 and CD14 expression on blood monocytes. Diagn. Pathol., v. 4, 2009.

SCHINDLER, R.; GELFAND, J. A.; DINARELLO, C. A. Recombinant C5a stimulates transcription rather than translation of interleukin-1 (IL-1) and tumor necrosis factor: translational signal provided by lipopolysaccharide or IL-1 itself. Blood, v. 76, p. 1631-1638, 1990.

SENDIDE, K.; REINER, N. E.; LEE, J. S.; BOURGOIN, S.; TALAL, A.; HMAMA, Z. Cross-talk between CD14 and complement receptor 3 promotes phagocytosis of mycobacteria: regulation by phosphatidylinositol 3-kinase and cytohesin-1. J. Immunol., v. 174, n. 7, p. 4210-4219, 2005.

SETTMACHER, B.; BOCK, D.; SAAD, H.; GARTNER, S.; RHEINHEIMER, C.; KOHL, J.; BAUTSCH, W.; KLOS, A. Modulation of C3a activity: internalization of the human C3a receptor and its inhibition by C5a. J. Immunol., v. 162, n. 12, p. 7409-7416, 1999.

SHUTO, T.; KATO, K.; MORI, Y.; VIRIYAKOSOL, S.; OBA, M.; FURUTA, T.; OKIYONEDA, T.; ARIMA, H.; SUICO, M. A.; KAI, H. Membrane-anchored CD14 is required for LPS-induced TLR4 
endocytosis in TLR4/MD-2/CD14 overexpressing CHO cells. Biochem. Biophys. Res. Commun., v. 338, n. 3, p. 1402-1409, 2005.

SLADOWSKI, D.; KINSNER, A.; LANGEZAAL, I.; KAY, S.; COECKE, S. Activation of the complement system as an indicator of pyrogenic reaction to lipopolysaccharide (LPS). Toxicol. In Vitro, v. 15, n. 4-5, p. 339-342, 2001.

SMEDEGARD, G.; CUI, L. X.; HUGLI, T. E. Endotoxin-induced shock in the rat. A role for C5a. Am. J. Pathol., v. 135, n. 3, p. 489-497, 1989.

SOKOLOV, A.; HELLERUD, B. C.; LAMBRIS, J. D.; JOHANNESSEN, E. A.; MOLLNES, T. E. Activation of polymorphonuclear leukocytes by candidate biomaterials for an implantable glucose sensor. J. Diabetes Sci. Technol., v. 5, n. 6, p. 1490-1498, 2011.

STEVENS, M. G.; VAN POUCKE, M.; PEELMAN, L. J.; RAINARD, P.; DE SPIEGELEER, B.; ROGIERS, C.; VAN DE WALLE, G. R.; DUCHATEAU, L.; BURVENICH, C. Anaphylatoxin C5ainduced toll-like receptor 4 signaling in bovine neutrophils. J. Dairy Sci., v. 94, n. 1, p. 152164, 2011.

TOBIAS, P. S.; MATHISON, J.; MINTZ, D.; LEE, J. D.; KRAVCHENKO, V.; KATO, K.; PUGIN, J.; ULEVITCH, R.J. Participation of lipopolysaccharide-binding protein in lipopolysaccharidedependent macrophage activation. Am. J. Respir. Cell. Mol. Biol., v. 7, n. 3, p. 239-245, 1992.

UEDA, T.; RIEU, P.; BRAYER, J.; ARNAOUT, M. A. Identification of the complement iC3b binding site in the beta 2 integrin CR3 (CD11b/CD18). Proc. Natl. Acad. Sci. U S A, v. 91, n. 22, p. 10680-10684, 1994.

UEMATSU, S.; AKIRA, S. Toll-Like receptors (TLRs) and their ligands. Handb. Exp. Pharmacol., v. 183, p. 1-20, 2008.

UNNEWEHR, H.; RITTIRSCH, D.; SARMA, J. V.; ZETOUNE, F.; FLIERL, M. A.; PERL, M.; DENK, S.; WEISS, M.; SCHNEIDER, M. E.; MONK, P. N.; NEFF, T.; MIHLAN, M.; BARTH, H.; GEBHARD, F.; WARD, P. A.; HUBER-LANG, M. Changes and regulation of the $\mathrm{C} 5$ a receptor on neutrophils during septic shock in humans. J. Immunol., v. 190, n. 8, p. 4215-4225, 2013.

VAN EPPS, D. E.; SIMPSON, S.; BENDER, J. G.; CHENOWETH, D. E. Regulation of C5a and formyl peptide receptor expression on human polymorphonuclear leukocytes. J. Immunol., v. 144, n. 3, p. 1062-1068, 1990.

VIRIYAKOSOL, S.; TOBIAS, P.S.; KITCHENS, R.L.; KIRKLAND, T.N. MD-2 binds to bacterial lipopolysaccharide. J. Biol. Chem., v. 276, p. 38044-38051, 2001.

WANG, L.; HAN, G.; WANG, R.; CHEN, G.; XU, R.; XIAO, H.; LI, X.; GENG, S.; LI, Y.; LI, X.; WANG, J.; FENG, J.; RIEDEMANN, N. C.; GUO, R.; SHEN, B.; LI, Y. Regulation of IL-8 production by complement-activated product, $\mathrm{C} 5 \mathrm{a}$, in vitro and in vivo during sepsis. Clin. Immunol., v. 137, n. 1, p. 157-165, 2010. 
WANG, M.; KRAUSS, J. L.; DOMON, H.; HOSUR, K. B.; LIANG, S.; MAGOTTI, P.; TRIANTAFILOU, M.; TRIANTAFILOU, K.; LAMBRIS, J. D.; HAJISHENGALLIS, G. Microbial hijacking of complement-toll-like receptor crosstalk. Sci. Signal., v. 3, n. 109, p. ra11, 2010.

WARD, P. A. Functions of C5a receptors. J. Mol. Med. (Berl.), v. 87, n. 4, p. 375-378, 2009.

WEAVER, D. J. Jr; REIS, E. S.; PANDEY, M. K.; KÖHL, G.; HARRIS, N.; GERARD, C.; KÖHL J. C5a receptor-deficient dendritic cells promote induction of Treg and Th17 cells. Eur. J. Immunol., v. 40, n. 3, p. 710-721, 2010.

WEBSTER, R. O.; ZANOLARI, B.; HENSON, P. M. Neutrophil chemotaxis in response to surface-bound C5a. Exp. Cell. Res., v. 129, n. 1, p. 55-62, 1980.

WITTMANN, M.; ZWIRNER, J.; LARSSON, V-A.; KIRCHHOFF, K.; BEGEMANN, G., KAPP, A.; GÖTZE, O., WERFEL, T. C5a Suppresses the Production of IL-12 by IFN- $\gamma$-Primed and Lipopolysaccharide-Challenged Human Monocytes. J. Immunol., v. 162, p. 6763-6769, 1999.

WU, J. J.; PANG, K. R.; HUANG, D. B.; TYRING, S. K. Advances in antiviral therapy. Dermatologic Clinics, v. 23, p. 313-322, 2005.

WU, M. C.; BRENNAN, F. H.; LYNCH, J. P.; MANTOVANI, S.; PHIPPS, S.; WETSEL, R. A.; RUITENBERG, M. J.; TAYLOR, S. M.; WOODRUFF, T. M. The receptor for complement component $\mathrm{C} 3 \mathrm{a}$ mediates protection from intestinal ischemia-reperfusion injuries by inhibiting neutrophil mobilization. Proc. Natl. Acad. Sci. U S A, v. 110, n. 23, p. 9439-9444, 2013.

YANG, R. B.; MARK, M. R.; GRAY, A.; HUANG, A.; XIE, M. H.; ZHANG, M.; GODDARD, A.; WOOD, W. I.; GURNEY, A. L.; GODOWSKI, P. J. Toll-like receptor-2 mediates lipopolysaccharide-induced cellular signalling. Nature, v. 395, n. 6699, p. 84-88, 1998.

ZAAL, A.; LISSENBERG-THUNNISSEN, S. N.; van SCHIJNDEL, G.; WOUTERS, D.; van HAM, S. M.; ten BRINKE, A. Crosstalk between Toll like receptors and $\mathrm{C} 5$ a receptor in human monocyte derived DCs suppress inflammatory cytokine production. Immunobiology, v. 218, n. 2, p. 175-180, 2013.

ZHANG, X.; KIMURA, Y.; FANG, C.; ZHOU, L.; SFYROERA, G.; LAMBRIS, J. D.; WETSEL, R. A.; MIWA, T.; SONG, W. C. Regulation of Toll-like receptor-mediated inflammatory response by complement in vivo. Blood, v. 110, n. 1, p. 228-236, 2007. 


\section{APÊNDICES}

APÊNDICE A - Gates utilizados para análise da expressão de moléculas expressas por leucócitos coletados de sangue periférico

A)

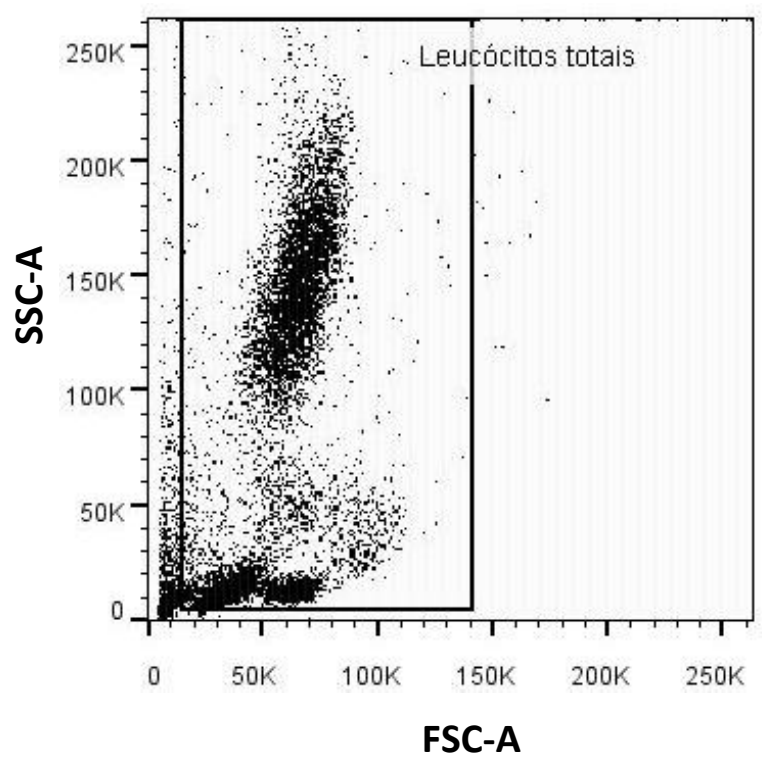

B)

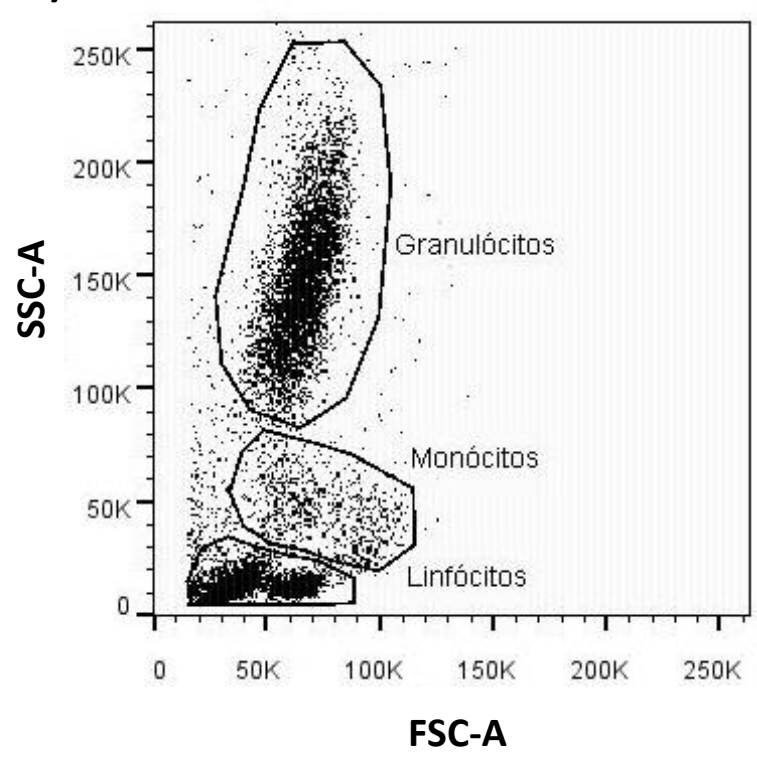

Amostras de sangue humano foram tratadas com PBS por 5 minutos e, em seguida, foi feita uma segunda adição de PBS, com incubação por 30 minutos a $37^{\circ} \mathrm{C}$. Após este período, os eritrócitos foram lisados e os leucócitos coletados para análise das populações celulares por citometria de fluxo. A) P1 - População de leucócitos totais, forward scatter por side scatter - área. B) Subpopulações de leucócitos, gate a partir da P1, forward scatter por side scatter - área. 
APÊNDICE B - Ação do P-MAPA e do LPS na expressão de marcadores celulares em leucócitos: cinética de tempo

A)

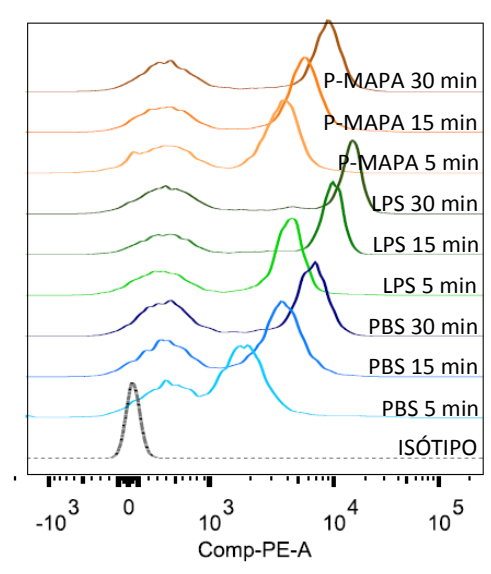

C)

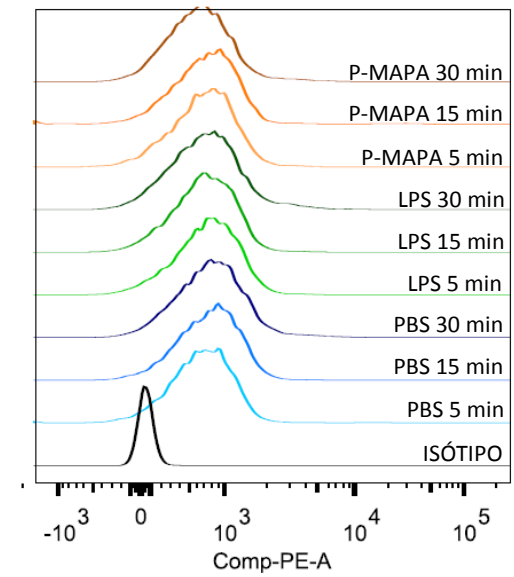

E)

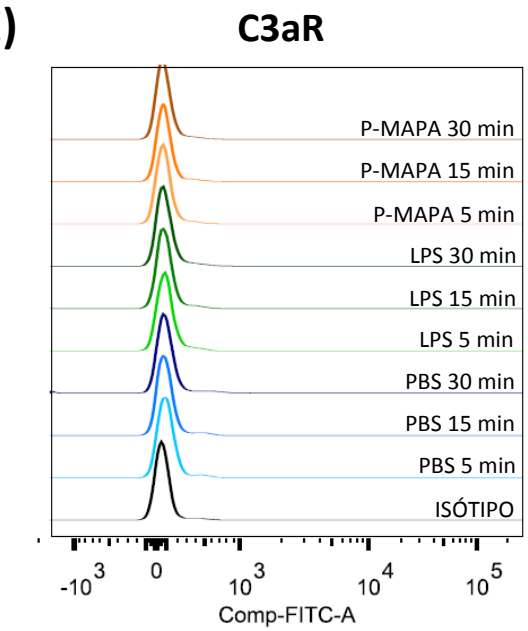

B)

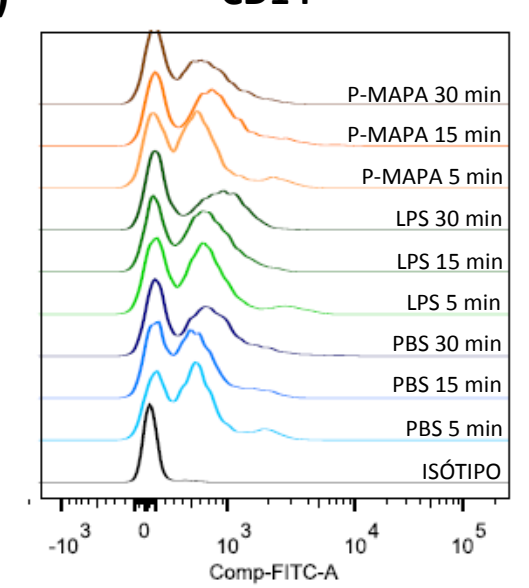

D)

TLR4

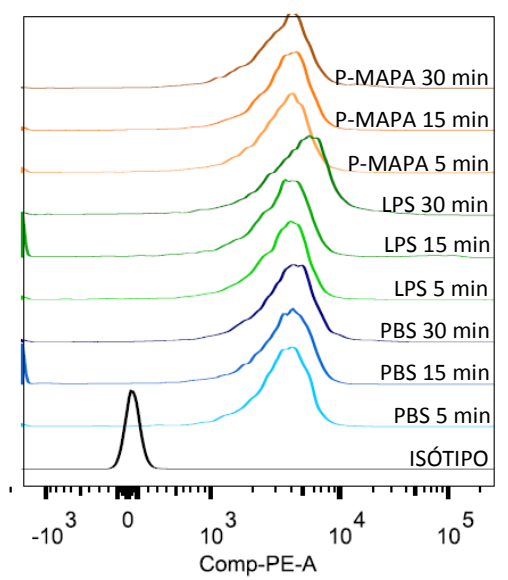

F)

C5aR

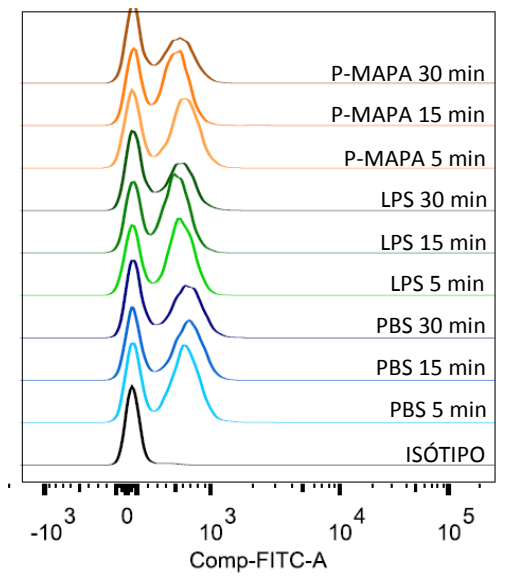

Amostras de sangue humano normal foram tratadas com PBS, P-MAPA $(500 \mu \mathrm{g} / \mathrm{mL})$ ou LPS $(100 \mu \mathrm{g} / \mathrm{mL})$ e incubadas por 5,15 ou 30 minutos a $37^{\circ} \mathrm{C}$. Após a incubação, os leucócitos foram coletados e analisados quanto à expressão de CD11b, CD14, TLR2, TLR4, C3aR e C5aR, nos diferentes tempos. A) Histograma da expressão de CD11b. B) Histograma da expressão de CD14. C) Histograma da expressão de TLR2. D) Histograma da expressão de TLR4. E) Histograma da expressão de C3aR. F) Histograma da expressão de C5aR. 
APÊNDICE C - Ação de tratamentos com PBS ou LPS na expressão de marcadores celulares em leucócitos totais

A)

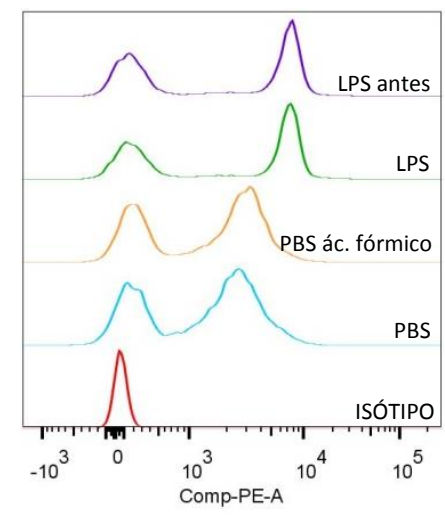

D)

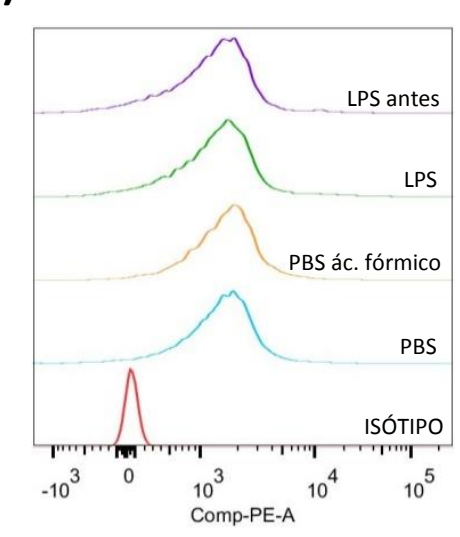

B)

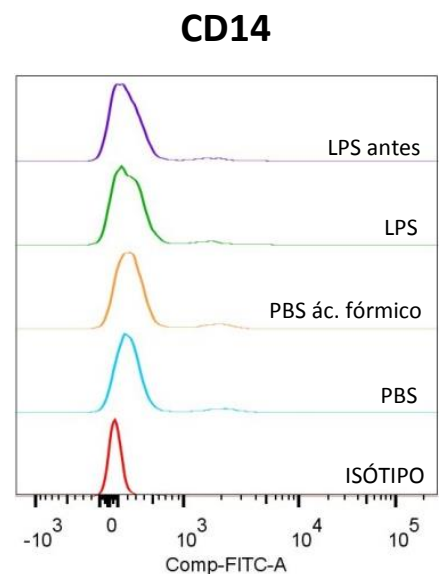

E)

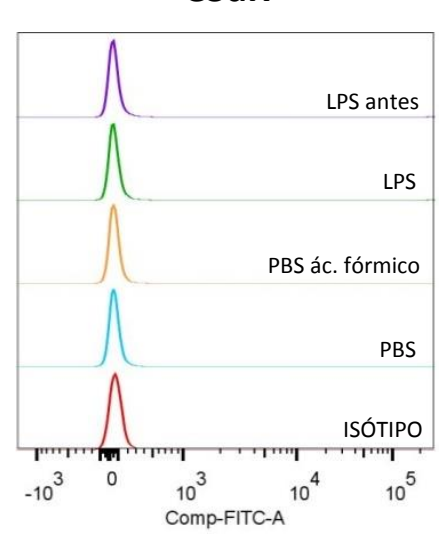

C)

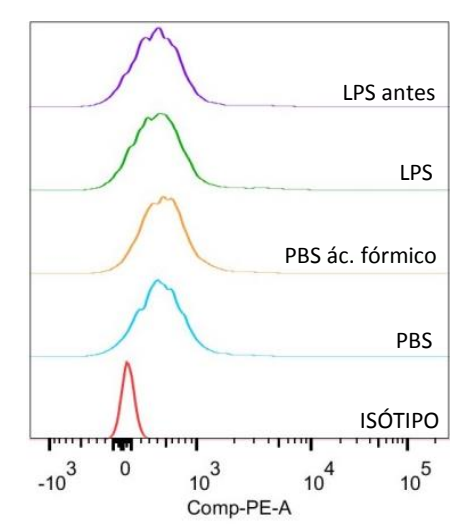

F)

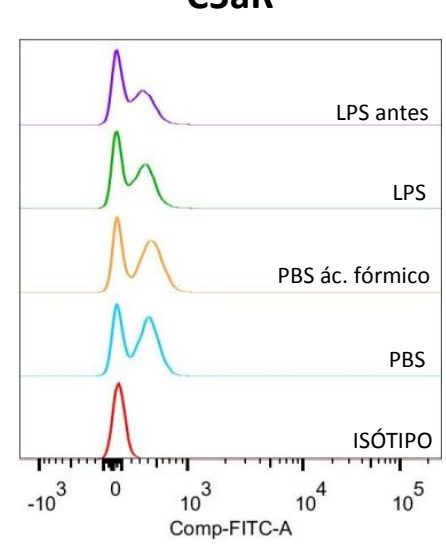

Amostras de sangue humano normal foram tratadas com PBS ou PBS ressuspendido a partir de solução de $1 \mathrm{~mL}$ de água destilada contendo $0,25 \%$ de ácido fórmico ('PBS ác. fórmico") por 5 minutos a temperatura ambiente, seguido de incubação por 30 minutos a $37^{\circ} \mathrm{C}$. Após a incubação, os leucócitos foram coletados e analisados. Os tratamentos com LPS foram feitos incubando amostras de sangue humano normal com PBS ou $100 \mu \mathrm{g} / \mathrm{mL}$ LPS ("LPS antes"), por 5 minutos e, em seguida, foi feita uma segunda adição de LPS (100 $\mu \mathrm{g} / \mathrm{mL}$ ) ou PBS, e incubação por 30 minutos a $37{ }^{\circ} \mathrm{C}$. Após este período, os leucócitos foram coletados e analisados, quanto à expressão de moléculas de superfície. A) Histograma da expressão de CD11b. B) Histograma da expressão de CD14. C) Histograma da expressão de TLR2. D) Histograma da expressão de TLR4. E) Histograma da expressão de C3aR. F) Histograma da expressão de C5aR. Dados de 1 experimento representativo, entre 2 experimentos independentes. 
APÊNDICE D - Ação de duas diferentes partidas de P-MAPA sobre a expressão de receptores celulares em leucócitos totais

A)

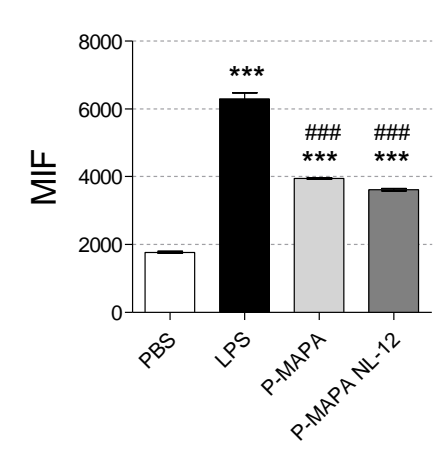

D)

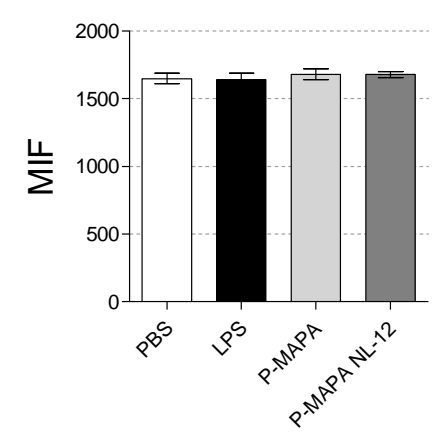

B)

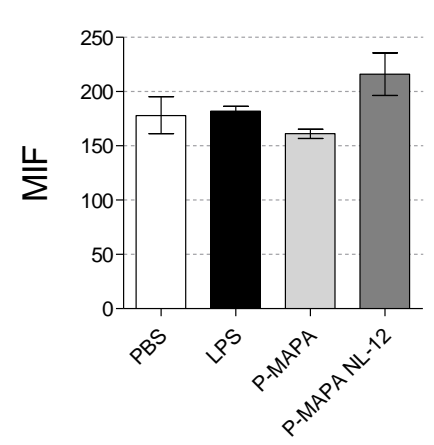

E)

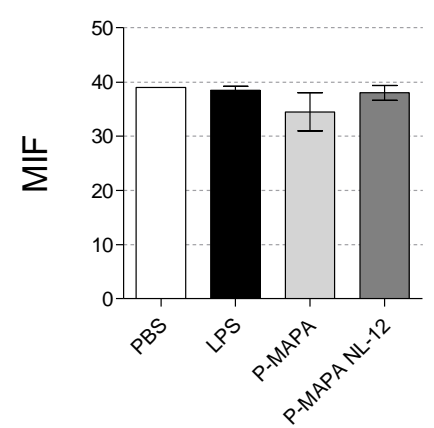

C)

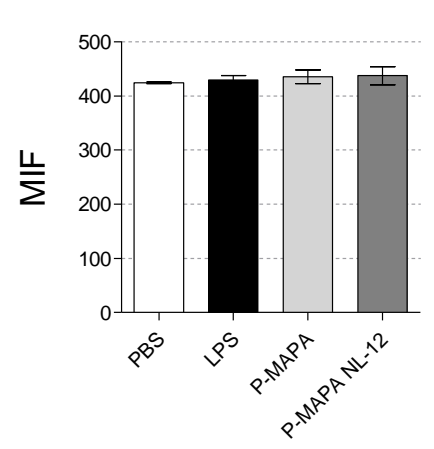

F)

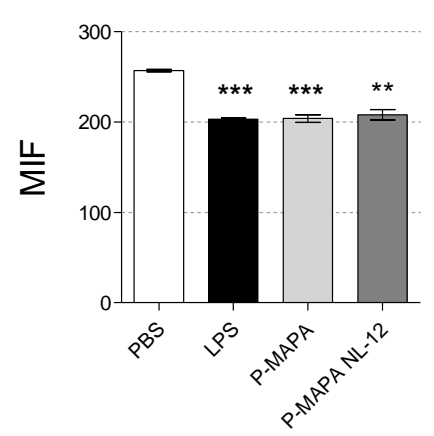

Amostras de sangue humano foram tratadas com PBS, P-MAPA (P-17, $1000 \mu \mathrm{g} / \mathrm{mL}$ ) ou P-MAPA NL-12 (1000 $\mu \mathrm{g} / \mathrm{mL})$, por 5 minutos, a temperatura ambiente, seguido de adição de LPS $(100 \mu \mathrm{g} / \mathrm{mL})$ ou PBS e incubação por 30 minutos a $37^{\circ} \mathrm{C}$. Após a incubação, os leucócitos foram coletados e analisados quanto à expressão de marcadores de superfície. A) Expressão de CD11b. B) Expressão de CD14. C) Expressão de TLR2. D) Expressão de TLR4. E) Expressão de (3aR. F) Expressão de C5aR. Dados expressos como média \pm desvio padrão de duplicatas de 1 experimento representativo, entre 2 experimentos independentes. Análise estatística realizada por ANOVA, complementada com teste de Bonferroni. MIF = mediana de intensidade de fluorescência. $\left({ }^{* *}\right)$ $p<0,01,\left({ }^{* * *}\right) p<0,001$ diferença estatística significativa em relação ao PBS. (\#\#\#) $p<0,001$ diferença estatística em relação ao LPS. 